\title{
Evaluation and Screening of Spherical Pd/C for use as a Catalyst in Pharmaceutical-Scale Continuous Hydrogenations
}

Eneritz Fernandez-Puertas', Andrew J. Robinson ${ }^{\ddagger}$, Hannah Robinson ${ }^{+}$, Shainthavaan

Sathiyalingam + Heather Stubbs ${ }^{+}$Lee J. Edwards*+

† Chemical Development, GlaxoSmithKline, Gunnels Wood Road, Stevenage, SG15NY, UK

¥Chemical Development, GlaxoSmithKline, Park Road, Ware, SG120DP, UK

\section{Supporting information}

\section{Contents}

General information.

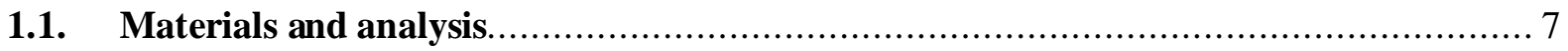

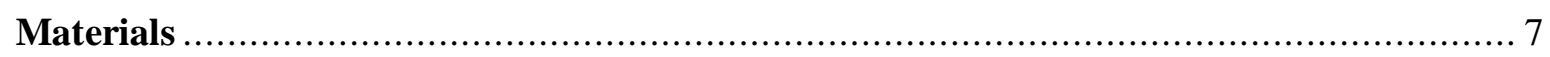

High performance liquid chromatography (HPLC)............................................ 7

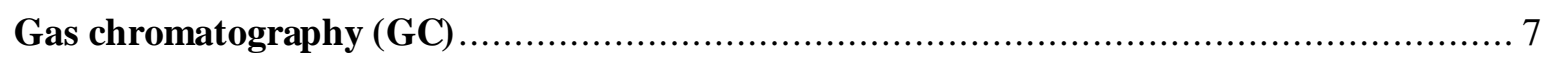

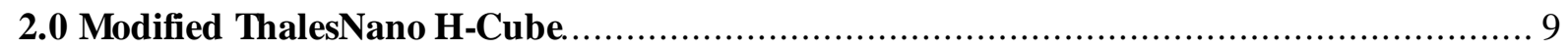

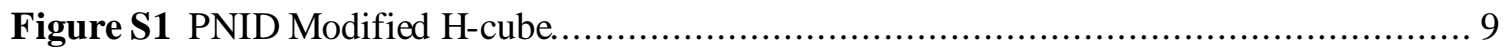

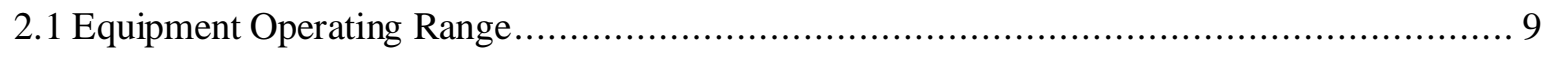

2.2 Design Pressure and Temperature of Equipment, Tubes and Fittings.............................. 9

Table S1 Equipment design pressure and design temperature. ..................................10

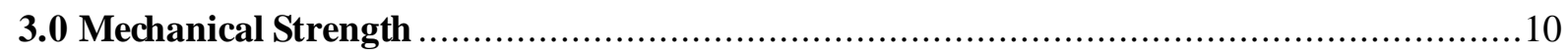

Table S2 Mechanical Strength data for catalysts.................................................. 10

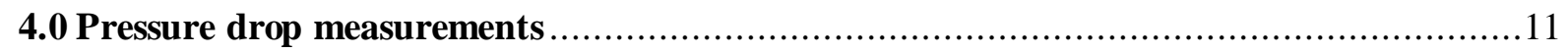

Figure S2. Line diagram of the system used to measure pressure drop through a bed of catalyst

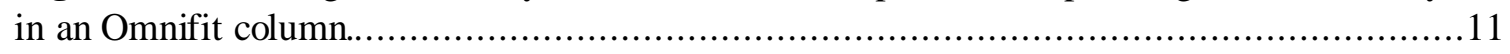

Figure S3 Pressure drop graph of a frit for 100-5PdC at 50, 10, 20, 30, 40 and $50 \mathrm{~mL} / \mathrm{min} . . . . .12$

Figure S4 Pressure drop graph of 100-5PdC (1.43 g, bed height $67 \mathrm{~mm}$ ) before frit pressure drop subtracted at 50,10, 20, 30, 40 and $50 \mathrm{~mL} / \mathrm{min}$.

Figure S5 Pressure drop of 100-5PdC (1.43 g, bed height $67 \mathrm{~mm})$ with frit pressure drop subtracted at 10, 20, 30, 40 and $50 \mathrm{~mL} / \mathrm{min}$..

Figure S6 Pressure drop graph of a frit for 200-5PdC at 50, 10, 20, 30, 40 and $50 \mathrm{~mL} / \mathrm{min} . \ldots . . .13$

Figure S7 Pressure drop graph of 200-5PdC (1.34 g, bed height $67 \mathrm{~mm})$ before frit pressure drop subtracted at 50,10, 20, 30, 40 and $50 \mathrm{~mL} / \mathrm{min}$. 
Figure S8 Pressure drop of 200-5PdC (1.34 g, bed height $67 \mathrm{~mm}$ ) with frit pressure drop subtracted at 10, 20, 30, 40 and $50 \mathrm{~mL} / \mathrm{min}$.

Figure S9 Pressure drop graph of a frit for 200-10PdC at 50, 10, 20, 30, 40 and $50 \mathrm{~mL} / \mathrm{min}$.....15

Figure S10 Pressure drop graph of 200-10PdC (1.28 g, bed height $67 \mathrm{~mm}$ ) before frit pressure



Figure S11 Pressure drop of 200-10PdC (1.28 g, bed height $67 \mathrm{~mm}$ ) with frit pressure drop

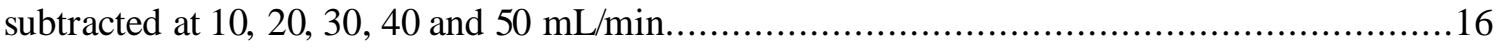

Figure S12 Pressure drop graph of a frit for 100-10PdC at 50, 10, 20, 30, 40 and $50 \mathrm{~mL} / \mathrm{min}$...16

Figure S13 Pressure drop graph of 100-10PdC (1.52 g bed height $67 \mathrm{~mm}$ ) before frit pressure drop subtracted at 50,10, 20, 30, 40 and $50 \mathrm{~mL} / \mathrm{min}$..

Figure S14 Pressure drop of 100-10PdC (1.52 g bed height $67 \mathrm{~mm}$ ) with frit pressure drop subtracted at 10, 20, 30, 40 and $50 \mathrm{~mL} / \mathrm{min}$......

Figure S15 Pressure drop of 100-5PdC at flow rate $50 \mathrm{~mL} / \mathrm{min} 1 \mathrm{hr}, 30 \mathrm{~mL} / \mathrm{min}$ for $23 \mathrm{hr}$, with and without pressure drop $(\Delta \mathrm{P})$ of frit removed.

Figure S16 Pressure drop of 200-5PdC at flow rate $50 \mathrm{~mL} / \mathrm{min} 1 \mathrm{hr}, 30 \mathrm{~mL} / \mathrm{min}$ for $23 \mathrm{hr}$, with and without pressure drop $(\Delta \mathrm{P})$ of frit removed.

Figure S17 Pressure drop of 200-10PdC at flow rate $50 \mathrm{~mL} / \mathrm{min} 1 \mathrm{hr}, 30 \mathrm{~mL} / \mathrm{min}$ for $23 \mathrm{hr}$, with and without pressure drop $(\Delta \mathrm{P})$ of frit removed.

Figure S18 Pressure drop of 100-10PdC at flow rate $50 \mathrm{~mL} / \mathrm{min} 1 \mathrm{hr}, 30 \mathrm{~mL} / \mathrm{min}$ for $23 \mathrm{hr}$, with



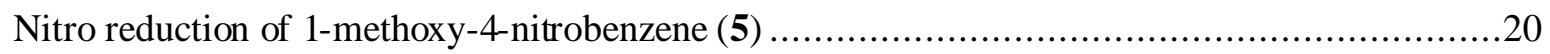

Scheme S1 Nitro reduction of 1-methoxy-4-nitrobenzene (5) ...................................20

Table S3 Catalyst loading screen for 100-5PdC of nitro reduction of 1-methoxy-4-nitrobenzene

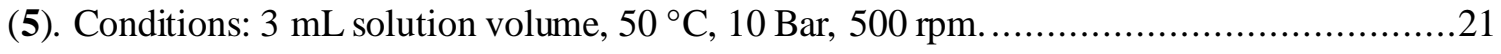

Figure S19 Non-normalised hydrogen uptake curves for Table S3................................21

Table S4 Catalyst loading screen for 200-5PdC of nitro reduction of 1-methoxy-4-nitrobenzene

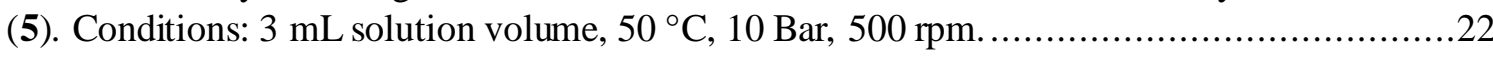

Figure S20 Non-normalised hydrogen uptake curves for Table S4. .................................22

Table S5 Catalyst loading screen for 200-10PdC of nitro reduction of 1-methoxy-4-nitrobenzene

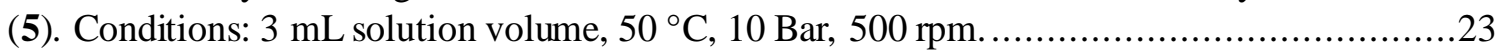

Figure S21 Non-normalised hydrogen uptake curves for Table S5 .............................23

Table S6 Catalyst loading screen for 100-10PdC of nitro reduction of 1-methoxy-4-nitrobenzene

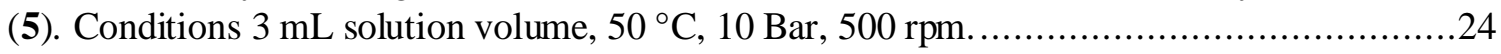

Figure S22 Non-normalised hydrogen uptake curves for Table S6...............................24

Repeatability screen for 200-5PdC of nitro reduction of 1-methoxy-4-nitrobenzene (5).............25

Table S7 Repeatability screen for 200-5PdC of nitro reduction of 1-methoxy-4-nitrobenzene (5).

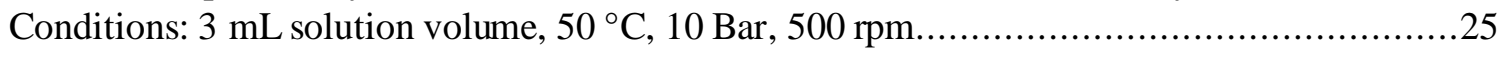

Figure S23 Non-normalised hydrogen uptake curves for Table S7 ..............................25

Solvent screening for 200-5PdC of nitro reduction of 1-methoxy-4-nitrobenzene (5).............26

Table S8 Solvent screen (1) for the nitro reduction of 1-methoxy-4-nitrobenzene (5) with 2005PdC 
Figure S24 Normalised hydrogen uptake curves for Table S8.

Table S9 Solvent screen (2) for the nitro reduction of 1-methoxy-4-nitrobenzene (5) with 2005PdC.

Figure S25 Normalised hydrogen uptake curves for Table S9.................................27

Pressure screening for 200-5PdC of nitro reduction of 1-methoxy-4-nitrobenzene (5)...............28

Table S10 Pressure screening for 200-5PdC of nitro reduction of 1-methoxy-4-nitrobenzene (5).

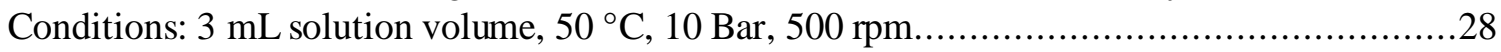

Figure S26 Non-normalised hydrogen uptake curves for Table S10................................28

Table S11 Head to head comparison of Blücher GmbH catalysts for the nitro reduction of 1-

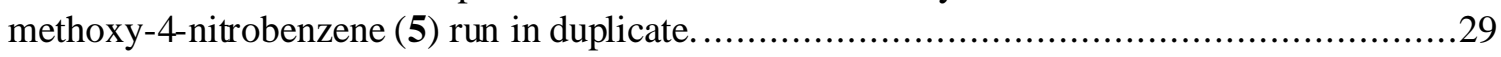

Figure S27 Non-normalised hydrogen uptake curves for Table S11...............................29

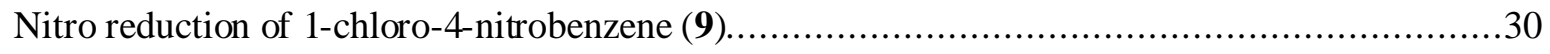

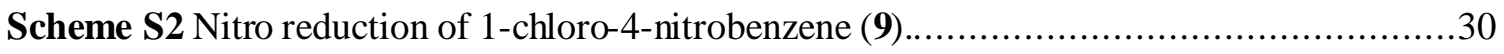

Table S12 Catalyst loading screen for 200-5PdC of nitro reduction 1-chloro-4-nitrobenzene (9). (n)

Figure S28 Normalised hydrogen uptake curves for Table S12 ................................. 30

Solvent screening for 200-5PdC of nitro reduction of 1-chloro-4-nitrobenzene (9) . ................31

Table S13 Solvent screen (1) for the nitro reduction of 1-chloro-4-nitrobenzene (9).with 200-

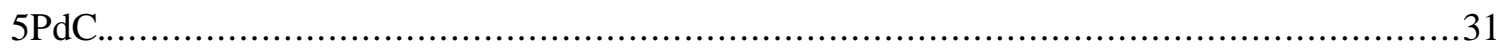

Figure S29 Normalised hydrogen uptake curves for Table S13..................................31

Table S14 Solvent screen (2) for the nitro reduction of 1-chloro-4-nitrobenzene (9) with 200-

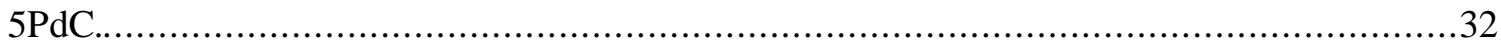

Figure S30 Normalised hydrogen uptake curves for Table S14..................................32

Head to head comparison of Blücher GmbH catalyst for the nitro reduction of 1-chloro-4nitrobenzene (9).

Table S15 Head to head comparison of Blücher GmbH catalysts for the nitro reduction 1-chloro-

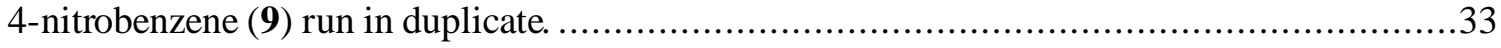

Figure S31 Normalised hydrogen uptake curves for Table S15.....................................33

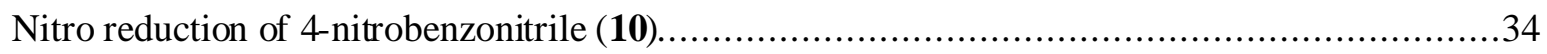

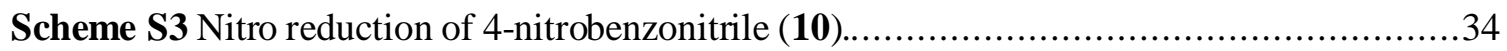

Table S16 Catalyst loading screen for 200-5PdC of nitro reduction 4-nitrobenzonitrile (10)....34

Figure S32 Normalised hydrogen uptake curves for Table S16....................................34

Solvent screening for 200-5PdC of nitro reduction of 4-nitrobenzonitrile (10)......................35

Table S17 Solvent screen (1) for the nitro reduction of 4-nitrobenzonitrile (10) with 200-5PdC.

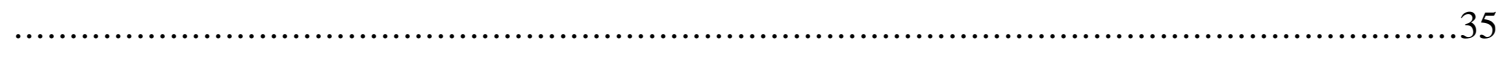

Figure S33 Normalised hydrogen uptake curves for Table S17....................................

Table S18 Solvent screen (2) for the nitro reduction of 4-nitrobenzonitrile (10) with 200-5PdC.

Figure S34 Normalised hydrogen uptake curves for Table S18................................... 
Head to head comparison of Blücher GmbH catalyst for the nitro reduction of 4-nitrobenzonitrile (10).

Table S19 Head to head comparison of Blücher GmbH catalysts for the nitro reduction 4nitrobenzonitrile (10) run in duplicate.

Figure S35 Normalised hydrogen uptake curves for Table S19..................................

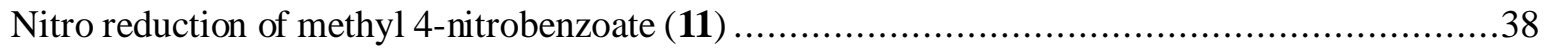

Scheme S4 Nitro reduction of methyl 4-nitrobenzoate (11) .......................................38

Table S20 Catalyst loading screen for 200-5PdC of nitro reduction methyl 4-nitrobenzoate (11).

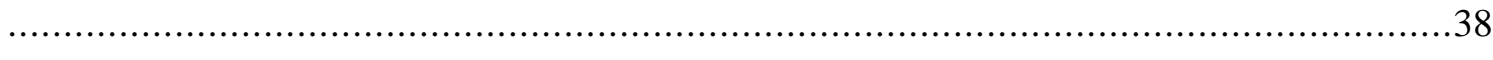

Figure S36 Normalised hydrogen uptake curves for Table S20....................................38

Solvent screening for 200-5PdC of nitro reduction of 4-nitrobenzoate (11) .......................39

Table S21 Solvent screen (1) for the nitro reduction of 4-nitrobenzoate (11) with 200-5PdC....39

Figure S37 Normalised hydrogen uptake curves for Table S21 .................................39

Table S22 Solvent screen (2) for the nitro reduction of 4-nitrobenzoate (11) with 200-5PdC....40

Figure S38 Normalised hydrogen uptake curves for Table S22. ..................................40

Head to head comparison of Blücher GmbH catalyst for the nitro reduction of 4-nitrobenzoate (11).

Table S23 Head to head comparison of Blücher GmbH catalysts for the nitro reduction 4nitrobenzoate (11). Conditions: $4 \mathrm{~mL}$ solution volume, $50^{\circ} \mathrm{C}$, $8 \mathrm{Bar}, 700 \mathrm{rpm}$ run in duplicate. 41

Figure S39 Normalised hydrogen uptake curves for Table S23.....................................41

Deprotection: $N$-debenzylation of $N$-benzyl-4-methoxyaniline (7),...................................42

Table S24 Catalyst loading screen for 200-5PdC for N-debenzylation of N-benzyl-4methoxyaniline (7). Conditions: $4 \mathrm{~mL}$ solution volume, $50^{\circ} \mathrm{C}$, $8 \mathrm{Bar}, 700 \mathrm{rpm} . . \ldots \ldots \ldots \ldots \ldots \ldots . . . . . . . .43$

Figure S40 Non-normalised hydrogen uptake curves for Table S24..............................43

Solvent screening for 200-5PdC for N-debenzylation of N-benzyl-4-methoxyaniline (7).........44

Table S25 Solvent screen for N-debenzylation of N-benzyl-4-methoxyaniline (7) with 200-

5PdC. Conditions: $4 \mathrm{~mL}$ solution volume, $50^{\circ} \mathrm{C}$, 8 Bar, $700 \mathrm{rpm}$....................................44

Figure S41 Normalised hydrogen uptake curves for Table S25......................................4

Head to head comparison of Blücher $\mathrm{GmbH}$ catalyst for $N$-debenzylation of $N$-benzyl-4methoxyaniline (7)

Table S26 Head to head comparison of Blücher GmbH catalysts for N-debenzylation of Nbenzyl-4-methoxyaniline (7). Conditions: $4 \mathrm{~mL}$ solution volume, $50{ }^{\circ} \mathrm{C}$, $8 \mathrm{Bar}, 700 \mathrm{rpm}$ run in duplicate.

Figure S42 Normalised hydrogen uptake curves for Table S23.................................45

Deprotection: $N$-debenzylation of methyl 4-(benzylamino)benzoate (12)...........................46

Scheme S6 $N$-Debenzylation of methyl 4-(benzylamino)benzoate (12)...............................46

Table S27 Catalyst loading screen for 200-5PdC for N-debenzylation of methyl 4(benzylamino)benzoate (12). Conditions: $4 \mathrm{~mL}$ solution volume, $50{ }^{\circ} \mathrm{C}, 8 \mathrm{Bar}, 700 \mathrm{rpm} . . . . . . . .47$

Figure S43 Normalised hydrogen uptake curves for Table S27.....................................47

Solvent screening for 200-5PdC for N-debenzylation of methyl 4-(benzylamino)benzoate (12).48 
Table S28 Solvent screen for N-debenzylation of deprotection of methyl 4(benzylamino)benzoate (12) with 200-5PdC. Conditions: $4 \mathrm{~mL}$ solution volume, $50{ }^{\circ} \mathrm{C}$, $8 \mathrm{Bar}$, $700 \mathrm{rpm}$

Figure S44 Normalised hydrogen uptake curves for Table S28.

Head to head comparison of Blücher GmbH catalyst for $N$-debenzylation of methyl 4(benzylamino)benzoate (12).

Table S29 Head to head comparison of Blücher GmbH catalysts for N-debenzylation of methyl 4-(benzylamino)benzoate (12). Conditions: $4 \mathrm{~mL}$ solution volume, $50^{\circ} \mathrm{C}, 8 \mathrm{Bar}, 700 \mathrm{rpm}$ run in duplicate.

Figure S45 Normalised hydrogen uptake curves for Table S29................................49

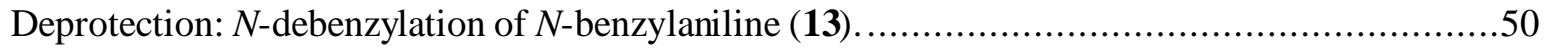

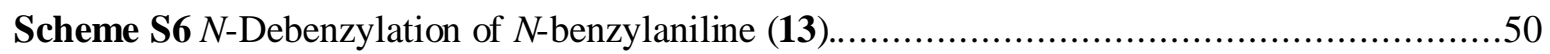

Table S30 Head to head comparison of Blücher GmbH catalyst for N-debenzylation of Nbenzylaniline (13). Conditions: $3 \mathrm{~mL}$ solution volume, $50{ }^{\circ} \mathrm{C}$, $10 \mathrm{Bar}, 500 \mathrm{rpm} . . . \ldots \ldots \ldots \ldots \ldots . . . . . . . .51$

Figure S46 Normalised hydrogen uptake curves for Table S30.....................................51

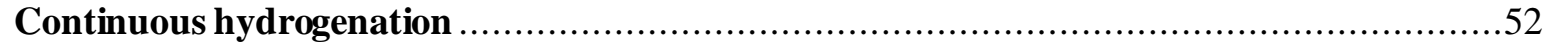

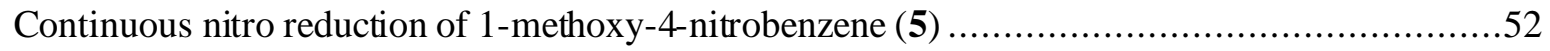

Scheme S8 Continuous nitro reduction of 1-methoxy-4-nitrobenzene (5) ..........................52

Figure S47 HPLC trend of $173 \mathrm{mg}$ 200-5PdC processing 0.169 M 1-methoxy-4-nitrobenzene over $20 \mathrm{~min}$, at $21 \mathrm{Bar}, 21^{\circ} \mathrm{C}$, 3.5 eq $\mathrm{H}_{2}$ and $0.169 \mathrm{M}$ 1-methoxy-4-nitrobenzene $1 \mathrm{~mL} / \mathrm{min} . . .52$

Figure S48 HPLC trend of $173 \mathrm{mg}$ 200-5PdC processing 0.163 M 1-methoxy-4-nitrobenzene over $140 \mathrm{~min}$, at $20 \mathrm{Bar}, 50^{\circ} \mathrm{C}$, 3.5 eq $\mathrm{H}_{2}$ and $0.163 \mathrm{M}$ 1-methoxy-4-nitrobenzene $1 \mathrm{~mL} / \mathrm{min} . .53$

Figure S49 HPLC trend of $178 \mathrm{mg}$ 200-5PdC processing 0.169 M 1-methoxy-4-nitrobenzene over $30 \mathrm{~min}$, at $21 \mathrm{Bar}, 65^{\circ} \mathrm{C}$, 3.5 eq $\mathrm{H}_{2}$ and $0.169 \mathrm{M}$ 1-methoxy-4-nitrobenzene $1 \mathrm{~mL} / \mathrm{min} . . .54$

Scheme S9 Continuous nitro reduction of 4-nitrobenzonitrile (10). .54

Figure S50 HPLC trend of $185 \mathrm{mg}$ 200-5PdC processing 0.169 M 4-nitrobenzonitrile over 30 min, at $10 \mathrm{Bar}, 50^{\circ} \mathrm{C}$, 3.5 eq $\mathrm{H} 2$ and $0.169 \mathrm{M}$ 4-nitrobenzonitrile 1 and $0.5 \mathrm{~mL} / \mathrm{min}$.

Figure S51 HPLC trend of $185 \mathrm{mg} 200-5 \mathrm{PdC}$ processing $0.169 \mathrm{M}$ 4-nitrobenzonitrile at 0.5 $\mathrm{mL} / \mathrm{min}$ over $60 \mathrm{~min}$, at $10.8 \mathrm{Bar}, 50^{\circ} \mathrm{C}$ and 3.5 eq $\mathrm{H}_{2}$

Figure S52 HPLC trend of $185 \mathrm{mg}$ 200-5PdC processing 0.169 M 4-nitrobenzonitrile 0.5

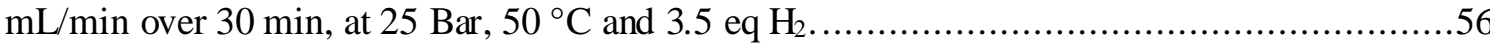

Figure S53 HPLC trend of $182 \mathrm{mg}$ 200-5PdC processing 0.169 M 4-nitrobenzonitrile 0.5

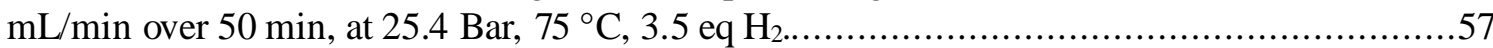

Figure S54 HPLC trend of $182 \mathrm{mg}$ 200-5PdC processing 0.169 M 4-nitrobenzonitrile 0.5 $\mathrm{mL} / \mathrm{min}$ over $20 \mathrm{~min}$, at $25.4 \mathrm{Bar}, 100^{\circ} \mathrm{C}$, 3.5 eq $\mathrm{H}_{2}$.

Figure S55 HPLC trend of $182 \mathrm{mg}$ 200-5PdC processing 0.169 M 4-nitrobenzonitrile 0.25

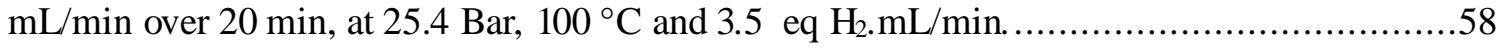

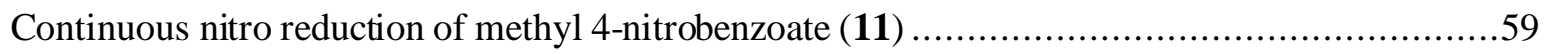

Scheme S10 Continuous nitro reduction of methyl 4-nitrobenzoate (11)............................59

Figure S56 HPLC trend of $170 \mathrm{mg} 200-5 \mathrm{PdC}$ processing 0.138 M 4 Methyl 4(benzylamino)benzoate over $50 \mathrm{~min}$, at $20 \mathrm{Bar}, 50,30$ and $40^{\circ} \mathrm{C}$, 3.5 eq $\mathrm{H} 2$ and $0.169 \mathrm{M}$ Methyl 4-(benzylamino)benzoate $1 \mathrm{~mL} / \mathrm{min}$.............................................................59 
Figure S57 HPLC trend of $172 \mathrm{mg}$ 200-5PdC processing 0.138 M Methyl 4(benzylamino)benzoate over $460 \mathrm{~min}$, at $20 \mathrm{Bar}, 75^{\circ} \mathrm{C}$, 3.5 eq $\mathrm{H}_{2}$ and $0.138 \mathrm{M}$ Methyl 4(benzylamino)benzoate $1 \mathrm{~mL} / \mathrm{min}$. The inconstancy from 350-400 $\mathrm{min}$ is thought to be due to an issue with the furnace on the modified $\mathrm{H}$-Cube.

Figure S58 HPLC trend of $184.4 \mathrm{mg}$ 200-5PdC processing 0.16 M N-benzyl-4-methoxyaniline over $20 \mathrm{~min}$, at $40 \mathrm{Bar}, 50^{\circ} \mathrm{C}$, 2.4 eq $\mathrm{H}_{2}$ and $0.16 \mathrm{M} \mathrm{N}$-benzyl-4-methoxyaniline $1 \mathrm{~mL} / \mathrm{min}$...66

Figure S59 HPLC trend of $188.8 \mathrm{mg}$ 200-5PdC processing 0.16 M N-benzyl-4-methoxyaniline over $55 \mathrm{~min}$, at $10 \mathrm{Bar}, 20,50$ and $75^{\circ} \mathrm{C}, 1.2$ eq $\mathrm{H}_{2}$ and $0.16 \mathrm{M} \mathrm{N}$-benzyl-4-methoxyaniline 1 $\mathrm{mL} / \mathrm{min}$.

Figure S60 HPLC trend of $188.8 \mathrm{mg}$ 200-5PdC processing 0.16 M N-benzyl-4-methoxyaniline over $35 \mathrm{~min}$, at $10 \mathrm{Bar}, 75^{\circ} \mathrm{C}$, 1.2 eq $\mathrm{H}_{2}$ and $0.16 \mathrm{M} \mathrm{N}$-benzyl-4-methoxyaniline $1 \mathrm{~mL} / \mathrm{min}$...62

Figure S61 HPLC trend of $186.5 \mathrm{mg}$ 200-5PdC processing 0.162 M N-benzyl-4-methoxyaniline over $210 \mathrm{~min}$, at $10 \mathrm{Bar}, 75^{\circ} \mathrm{C}, 1.2$ eq $\mathrm{H}_{2}$ and $0.162 \mathrm{M} \mathrm{N}$-benzyl-4-methoxyaniline $1 \mathrm{~mL} / \mathrm{min} .63$

Figure S62 HPLC trend of $170 \mathrm{mg}$ 200-5PdC processing 0.117 M N-benzyl-4-methoxyaniline over 110 min, at 30 and $20 \mathrm{Bar}, 75,50$ and $60^{\circ} \mathrm{C}$, 3.5 eq $\mathrm{H}_{2}$ and $0.117 \mathrm{M} \mathrm{N}$-benzyl-4methoxyaniline $1 \mathrm{~mL} / \mathrm{min}$.

Figure S63 HPLC trend of $170 \mathrm{mg}$ 200-5PdC processing 0.117 M N-benzyl-4-methoxyaniline over $110 \mathrm{~min}$, at $30 \mathrm{Bar}, 60,55$ and $50^{\circ} \mathrm{C}, 1.2$ eq $\mathrm{H}_{2}$ and $0.117 \mathrm{M} \mathrm{N}$-benzyl-4-methoxyaniline 1 $\mathrm{mL} / \mathrm{min}$. 


\section{General information}

\subsection{Materials and analysis}

\section{Materials}

Reagents were obtained commercially, from Sigma-Aldrich, and used as received. Solvents were used wet, and reactions were not performed under an inert atmosphere unless otherwise stated.

\section{High performance liquid chromatography (HPLC)}

These data were recorded on an Agilent HPLC system, equipped with a Waters XBridge C18 (50 mm length $\times 4.6 \mathrm{~mm}$ internal diameter, $3.5 \mu \mathrm{m}$ packing particle size) at $40{ }^{\circ} \mathrm{C}$.

The solvents employed were:

$\mathrm{A}=10 \mathrm{mM}$ NH4HCO3 (adjusted to pH10 with NH3) : Acetonitrile (95:5)

B = Acetonitrile : 10mM NH4HCO3 (adjusted to pH10 with NH3) (95:5)

The gradient employed was as follows:

\begin{tabular}{cccc}
\hline Time (min) & Flow rate (mL/min) & \% A / \% & \% B / \% \\
\hline 0 & 2.25 & 100 & 0 \\
0.5 & 2.25 & 100 & 0 \\
4.00 & 2.25 & 3 & 97 \\
4.01 & 2.25 & 100 & 0 \\
5 & 2.25 & 100 & 0 \\
\hline
\end{tabular}

The UV response was monitored at a wavelength of $220 \mathrm{~nm}$.

\section{Gas chromatography (GC)}

Gas chromatography (GC) analyses were performed on an Agilent 7890 B GC chromatograph equipped with a Gerstel MPS autosampler and FID detector and H2 as carrier gas. Conversion 
for the hydroxylation of ethylbenzene (Section 1.6) was determined using a Hewlett Packard HP-5 column (30 m x $0.32 \mathrm{~mm} \times 0.25 \mu \mathrm{m}, 1$ Bar, $7.557 \mathrm{~mL} \mathrm{~min}^{-1}$ flow). The program is as follows:

\begin{tabular}{cccc}
\hline Rate $\left({ }^{\circ} \mathbf{C} / \mathbf{m i n}\right)$ & $\mathbf{T e m p}\left({ }^{\circ} \mathbf{C}\right)$ & Hold time (min) & Run time (min) \\
\hline 0 & 50 & 0 & 0 \\
10 & 90 & 0 & 4 \\
30 & 160 & 0 & 6.33 \\
\hline
\end{tabular}




\subsection{Modified ThalesNano H-Cube}

The setup (figure S1) involves the use of an H-Cube column (30 x $3 \mathrm{~mm}$ ), which is fed with a gas/liquid mixed feed. The gas feed is controlled using a Bronkhorst Coriflow flow meter and fed from lecture bottles. The liquid feed is fed from a Knauer S100 HPLC pump and mixed with the gas feed using the H-Cube gas-liquid mixer. The system pressure is controlled using an EquiliBar back pressure regulator. The equipment is connected to a Hitec Zang Lab Manager box to enable control of equipment and data logging.



Figure S1 PNID Modified H-cube

\subsection{Equipment Operating Range}

Reactor temperature: $20-100^{\circ} \mathrm{C}$

Pressure: 0-80 Barg

Gas flow rate: 3-200 mL/min

Liquid flow rate: $0-10 \mathrm{~mL} / \mathrm{min}$

\subsection{Design Pressure and Temperature of Equipment, Tubes and Fittings}

The design pressures and temperatures are shown in Table S1. The limiting items of equipment are the H-Cube and the Bronkhorst flow controller which can be operated to a maximum of 100 Bar. Therefore, the pressure relief valve will be set at 91 Bar, with a maximum operating pressure of 80 Bar. 
Table S1 Equipment design pressure and design temperature.

\begin{tabular}{|c|c|c|}
\hline Equipment & $\begin{array}{r}\text { Design } \\
\text { Pressure } \\
\text { (Bar) }\end{array}$ & $\begin{array}{r}\text { Design } \\
\text { Temperature } \\
\left({ }^{\circ} \mathrm{C}\right)\end{array}$ \\
\hline Knauer S100 Pump & 200 & 4 to 40 \\
\hline $\begin{array}{l}\text { Bronkhorst Mini Coriolis Gas Flow } \\
\text { Controller }\end{array}$ & 100 & 0 to 70 \\
\hline H-Cube & $\begin{array}{r}100 \\
\text { (Operating } \\
\text { pressure) }\end{array}$ & $\begin{array}{r}0 \text { to } 100 \\
\text { (Operating } \\
\text { Temperature) }\end{array}$ \\
\hline EquiliBar & 155 & 200 \\
\hline Swagelok $1 / 16^{\text {th }}$ Valve & 172 & 537 \\
\hline Swagelok $1 / 16^{\text {th }} \mathrm{T}$-Piece & 760 & 537 \\
\hline Swagelok $1 / 16^{\text {th }}$ Check Valve & 206 & 537 \\
\hline Swagelok Relief Valve & 338 & 537 \\
\hline
\end{tabular}

\subsection{Mechanical Strength}

Measured using a Stable Micro Systems Texture Analyser.

Table S2 Mechanical Strength data for catalysts.

\begin{tabular}{ccccccc}
\hline Catalyst & $\begin{array}{c}\text { Compact } \\
\text { Mass (g) }\end{array}$ & $\begin{array}{c}\text { Poured Bulk } \\
\text { Density } \\
\text { (g/ml) }\end{array}$ & $\begin{array}{c}\text { "Tapped" } \\
\text { Bulk Density } \\
\text { (g/ml) }\end{array}$ & $\begin{array}{c}\text { Compressibility } \\
\text { (\%) }\end{array}$ & $\begin{array}{c}\text { Max. Density at } \\
\text { 745kgf (g/ml) }\end{array}$ & $\begin{array}{c}\text { Yield Stress } \\
\text { (MPa) }\end{array}$ \\
\hline 100-5PdC & 0.2497 & 0.568 & 0.598 & 5 & 0.94 & 137 \\
$200-5 P d C$ & 0.2418 & 0.55 & 0.557 & 1 & 0.89 & 181.8 \\
$100-10 \mathrm{PdC}$ & 0.2384 & 0.542 & 0.554 & 2 & 0.93 & 169.5 \\
200-10PdC & 0.2573 & 0.585 & 0.608 & 4 & 0.96 & 138.9 \\
\hline
\end{tabular}




\subsection{Pressure drop measurements}

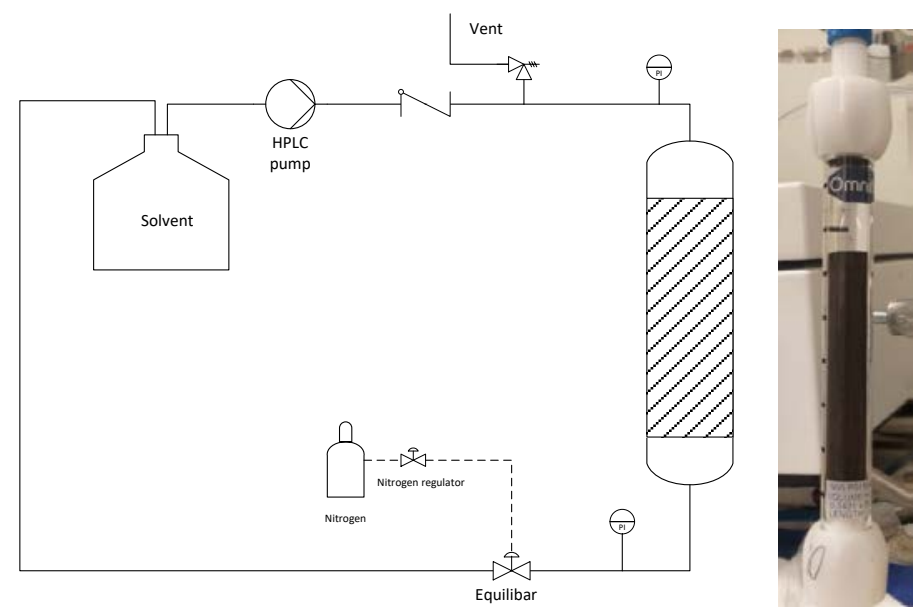

Figure S2. Line diagram of the system used to measure pressure drop through a bed of catalyst in an Omnifit column.

The measurements were obtained by flowing water through the catalyst bed in a glass Omnifit column (6.6 mm inner diameter and $70 \mathrm{~mm}$ height, with a bed height of $65 \mathrm{~mm}$ ) at 50, 10, 20, 30, 40 and $50 \mathrm{~mL} / \mathrm{min}$ and measuring the pressure at the inlet and outlet of the column. Note that the $20 \mu \mathrm{m}$ frit (Omnifit part No. 006FR-06-20) was replaced between catalysts.

Initially the pressure drop of the frit was measured by flowing water through an empty a glass Omnifit column (6.6 mm inner diameter and $70 \mathrm{~mm}$ height) at 50, 10, 20, 30,40 and $50 \mathrm{~mL} / \mathrm{min}$ and measuring the pressure at the inlet and outlet of the column. 


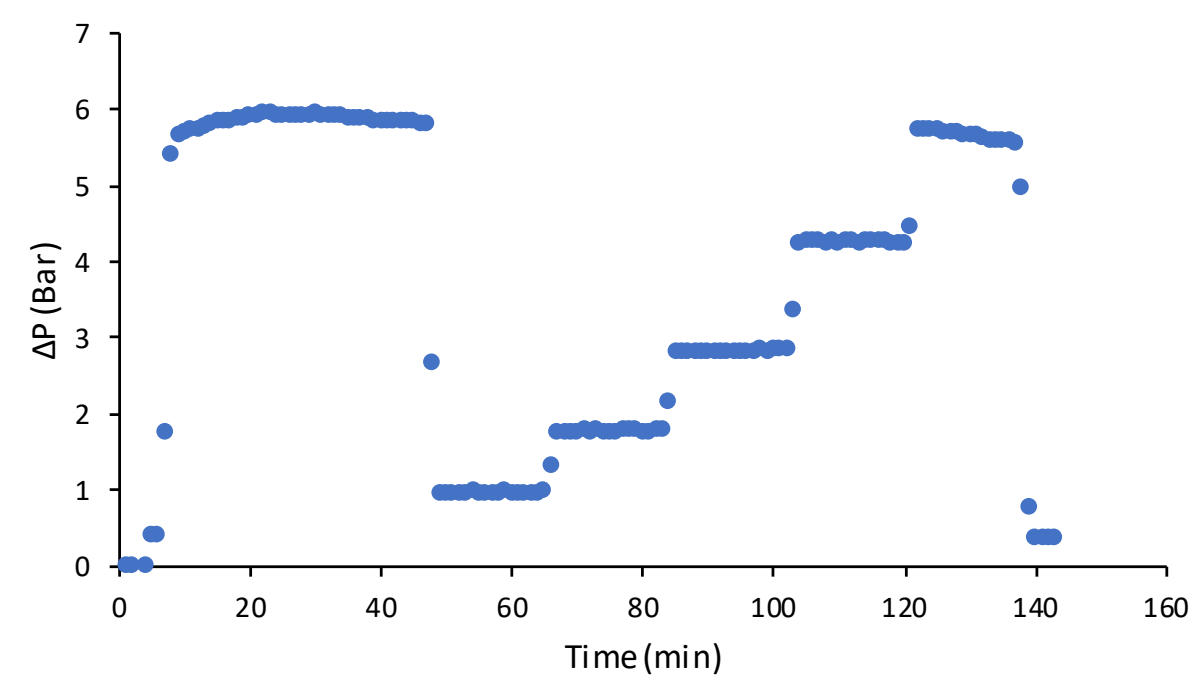

Figure S3 Pressure drop graph of a frit for 100-5PdC at 50, 10, 20, 30, 40 and $50 \mathrm{~mL} / \mathrm{min}$.



Figure S4 Pressure drop graph of 100-5PdC (1.43 g, bed height $67 \mathrm{~mm})$ before frit pressure drop subtracted at 50, 10, 20, 30, 40 and $50 \mathrm{~mL} / \mathrm{min}$. 


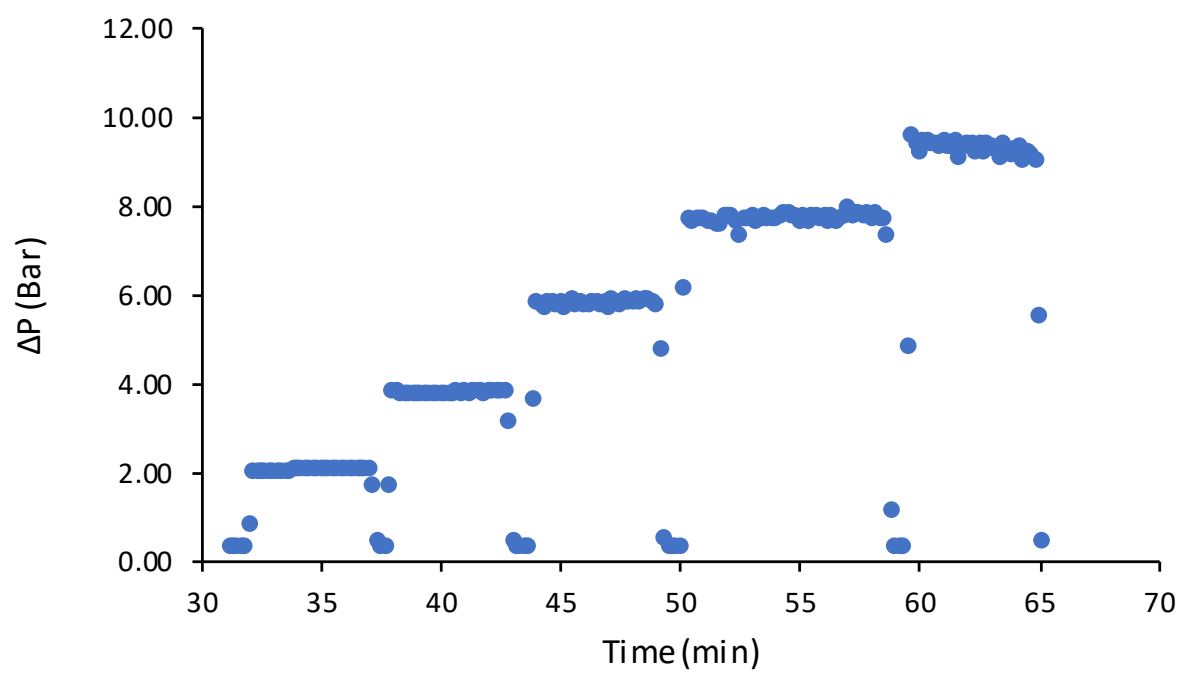

Figure S5 Pressure drop of 100-5PdC (1.43 g, bed height $67 \mathrm{~mm})$ with frit pressure drop subtracted at $10,20,30,40$ and $50 \mathrm{~mL} / \mathrm{min}$.

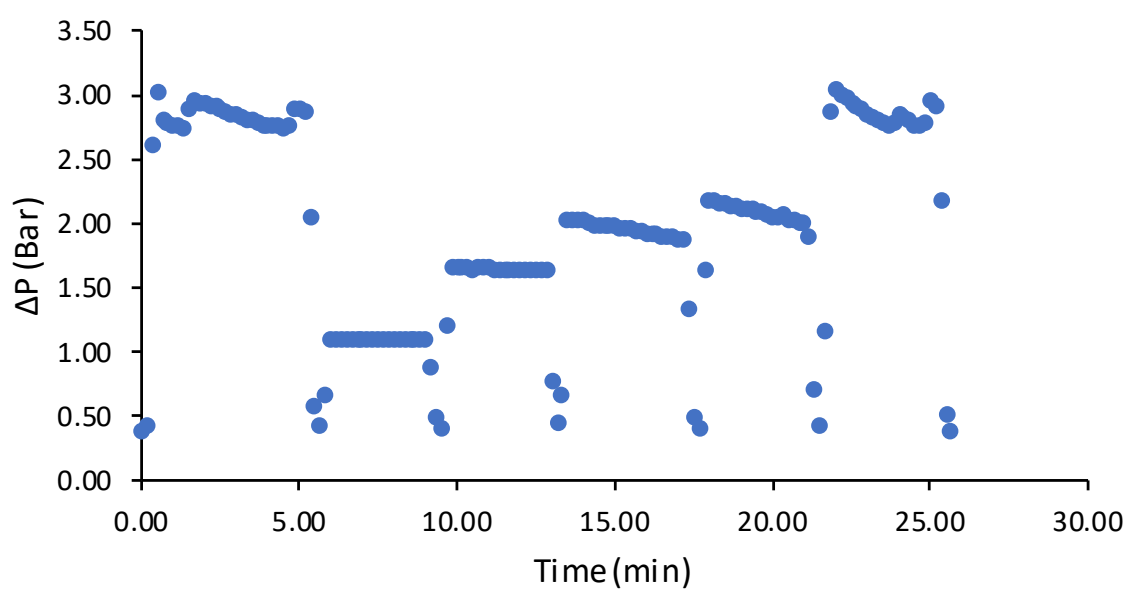

Figure S6 Pressure drop graph of a frit for 200-5PdC at 50, 10, 20, 30, 40 and $50 \mathrm{~mL} / \mathrm{min}$. 


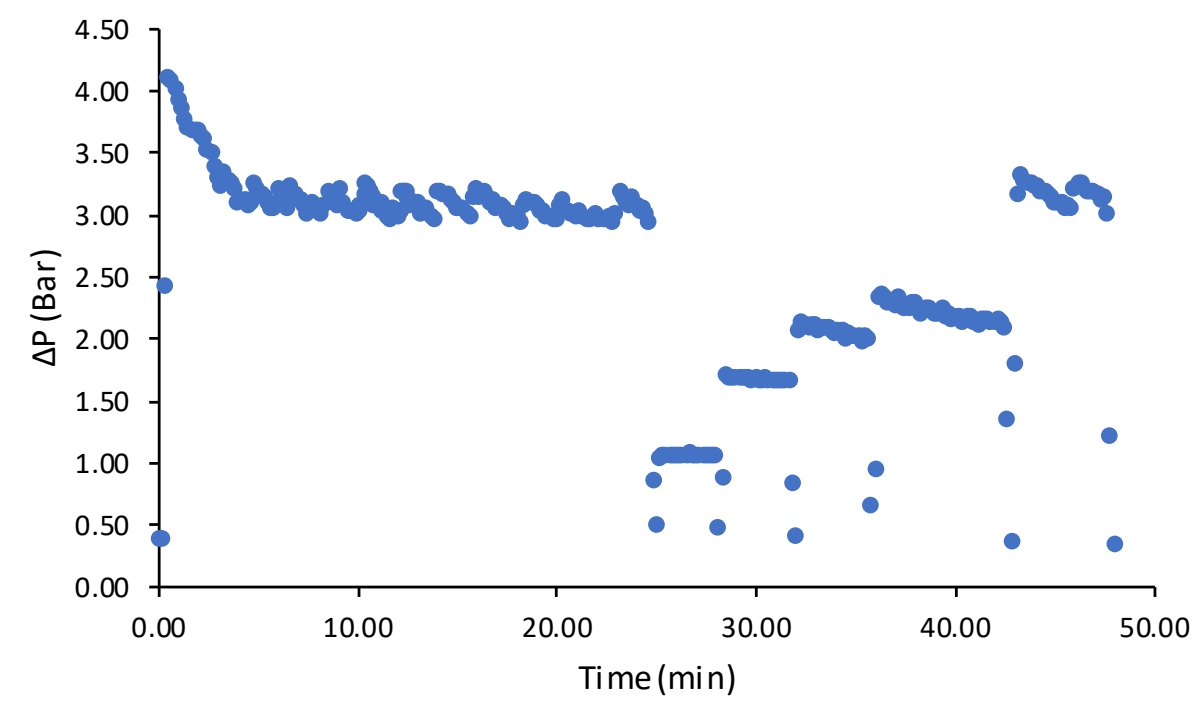

Figure S7 Pressure drop graph of 200-5PdC (1.34 g, bed height $67 \mathrm{~mm})$ before frit pressure drop subtracted at 50, 10, 20, 30, 40 and $50 \mathrm{~mL} / \mathrm{min}$.

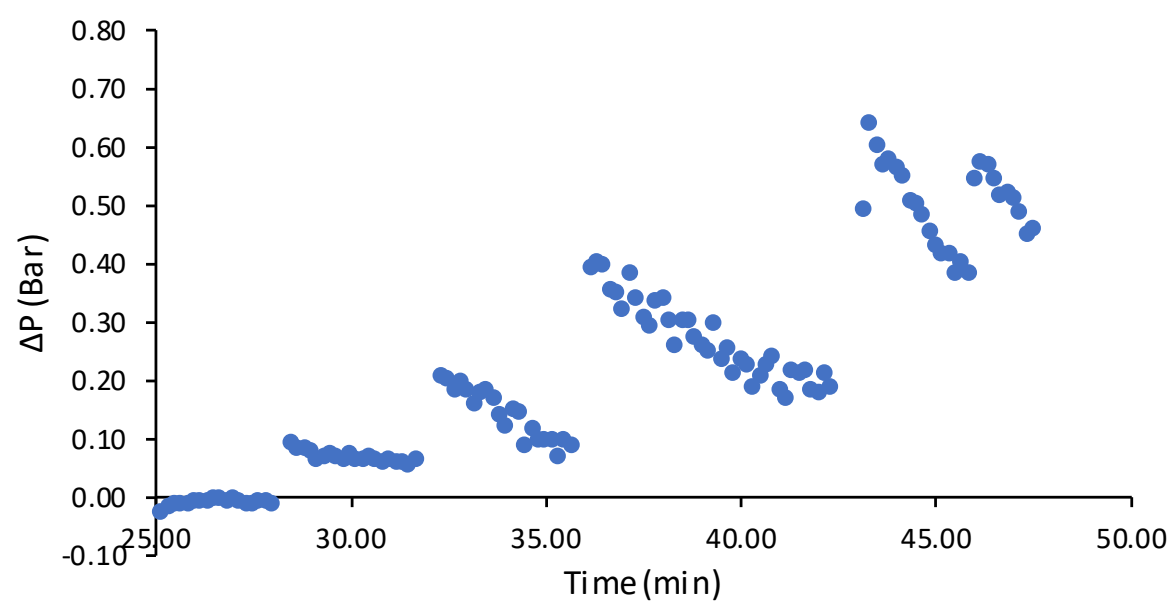

Figure S8 Pressure drop of 200-5PdC (1.34 g, bed height $67 \mathrm{~mm})$ with frit pressure drop subtracted at 10, 20, 30, 40 and $50 \mathrm{~mL} / \mathrm{min}$. 


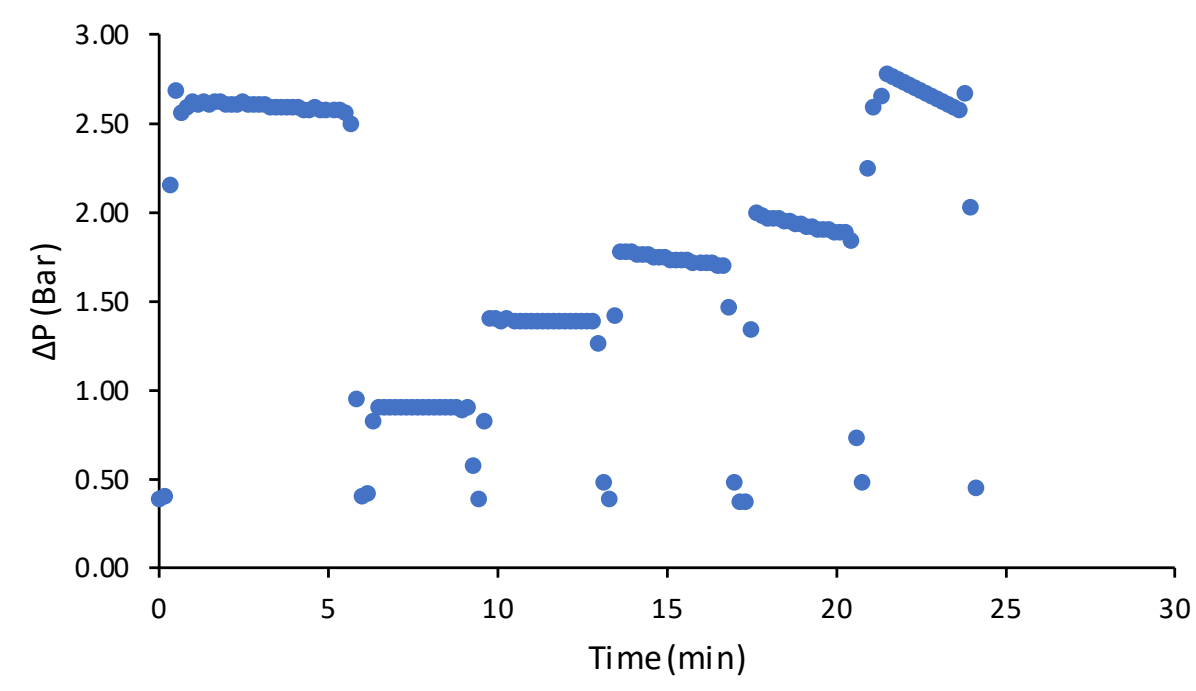

Figure S9 Pressure drop graph of a frit for 200-10PdC at 50, 10, 20, 30, 40 and $50 \mathrm{~mL} / \mathrm{min}$.

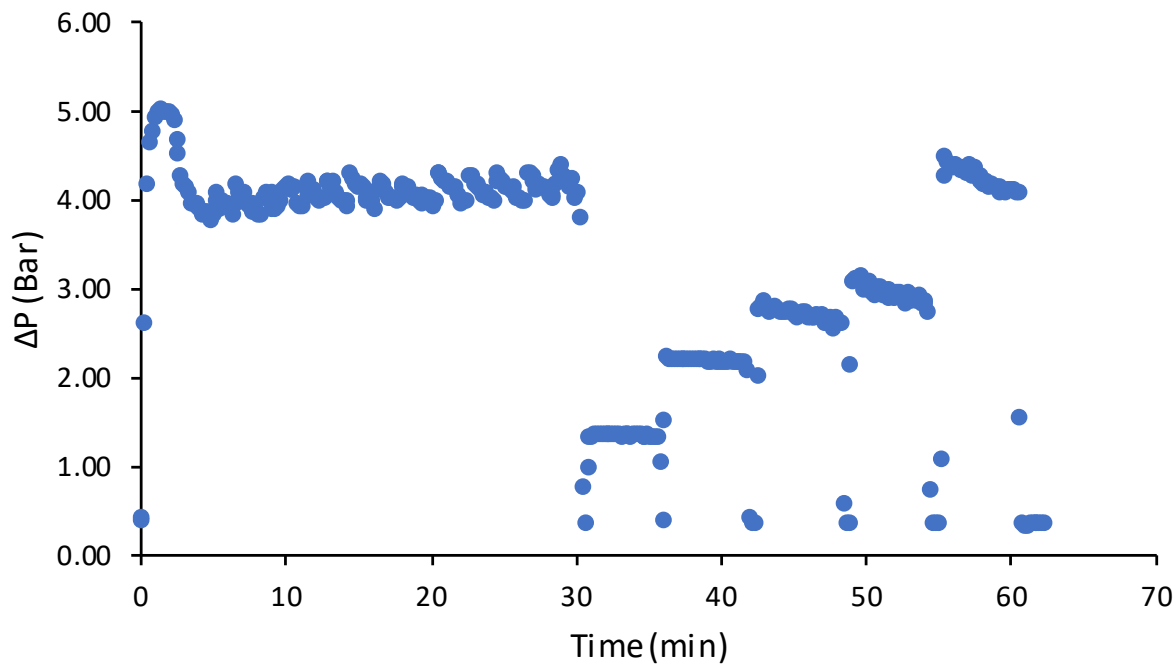

Figure S10 Pressure drop graph of 200-10PdC (1.28 g, bed height $67 \mathrm{~mm}$ ) before frit pressure drop subtracted at 50, 10, 20, 30, 40 and $50 \mathrm{~mL} / \mathrm{min}$. 


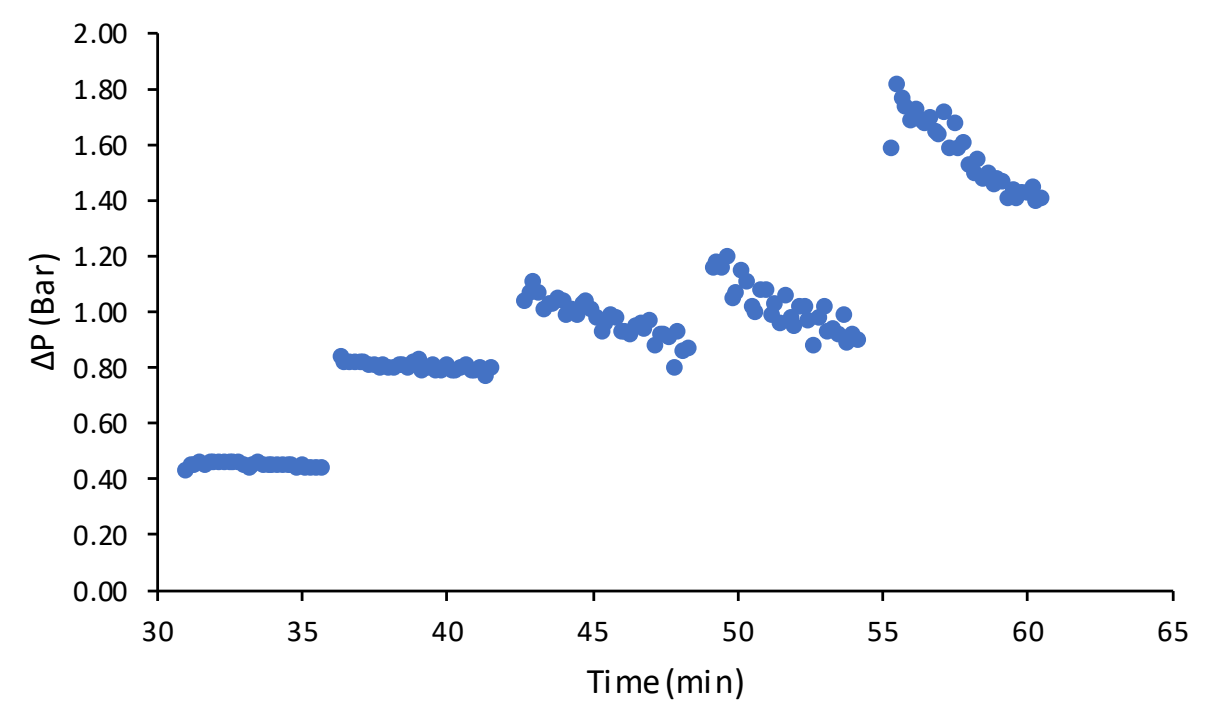

Figure S11 Pressure drop of 200-10PdC (1.28 g, bed height $67 \mathrm{~mm}$ ) with frit pressure drop subtracted at $10,20,30,40$ and $50 \mathrm{~mL} / \mathrm{min}$.

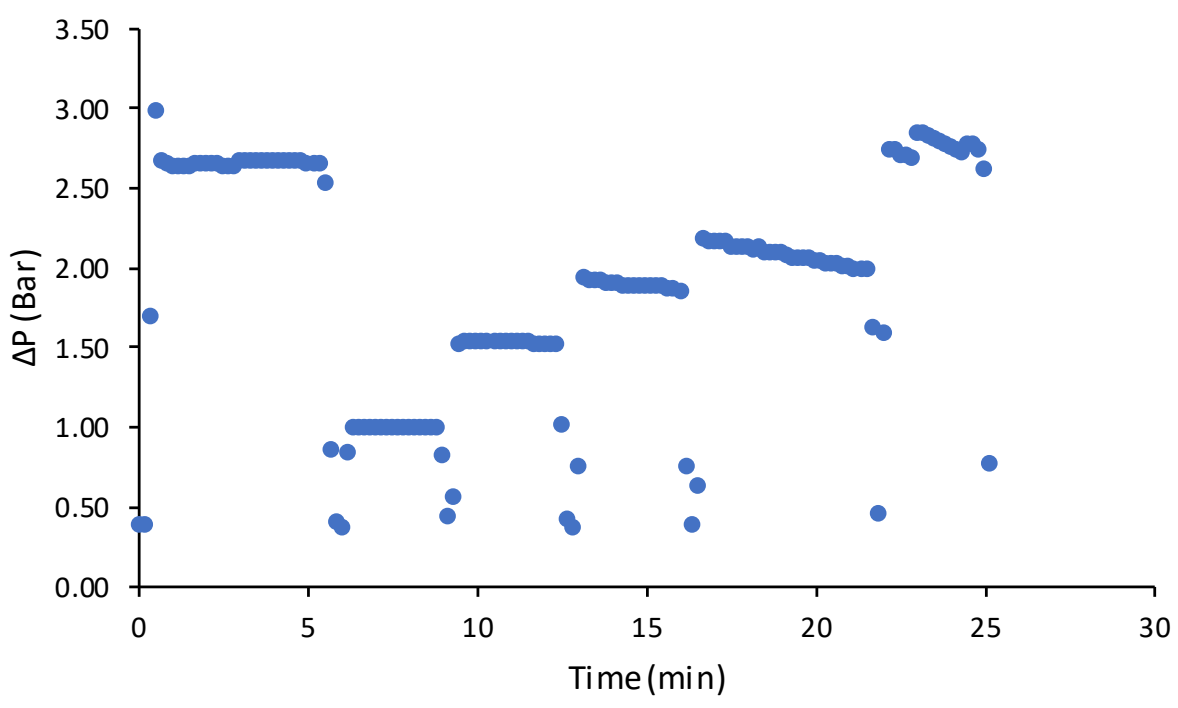

Figure S12 Pressure drop graph of a frit for 100-10PdC at 50, 10, 20, 30, 40 and $50 \mathrm{~mL} / \mathrm{min}$. 


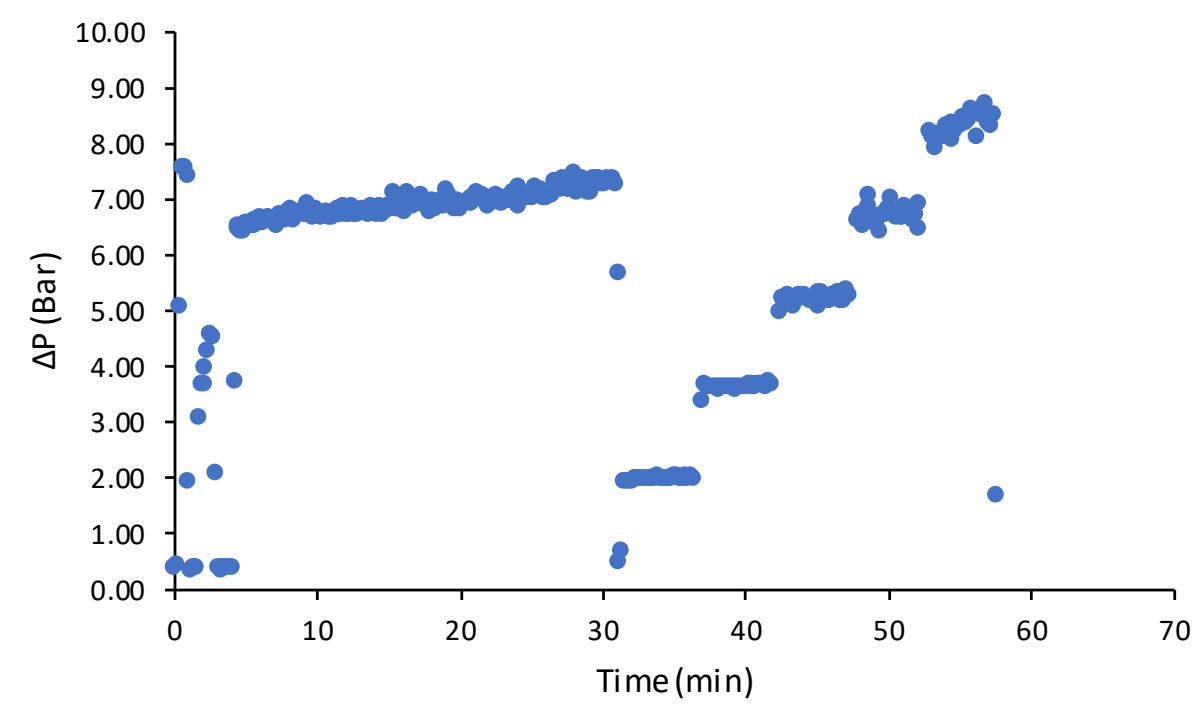

Figure S13 Pressure drop graph of 100-10PdC (1.52 g bed height $67 \mathrm{~mm})$ before frit pressure drop subtracted at 50,10, 20, 30, 40 and $50 \mathrm{~mL} / \mathrm{min}$.

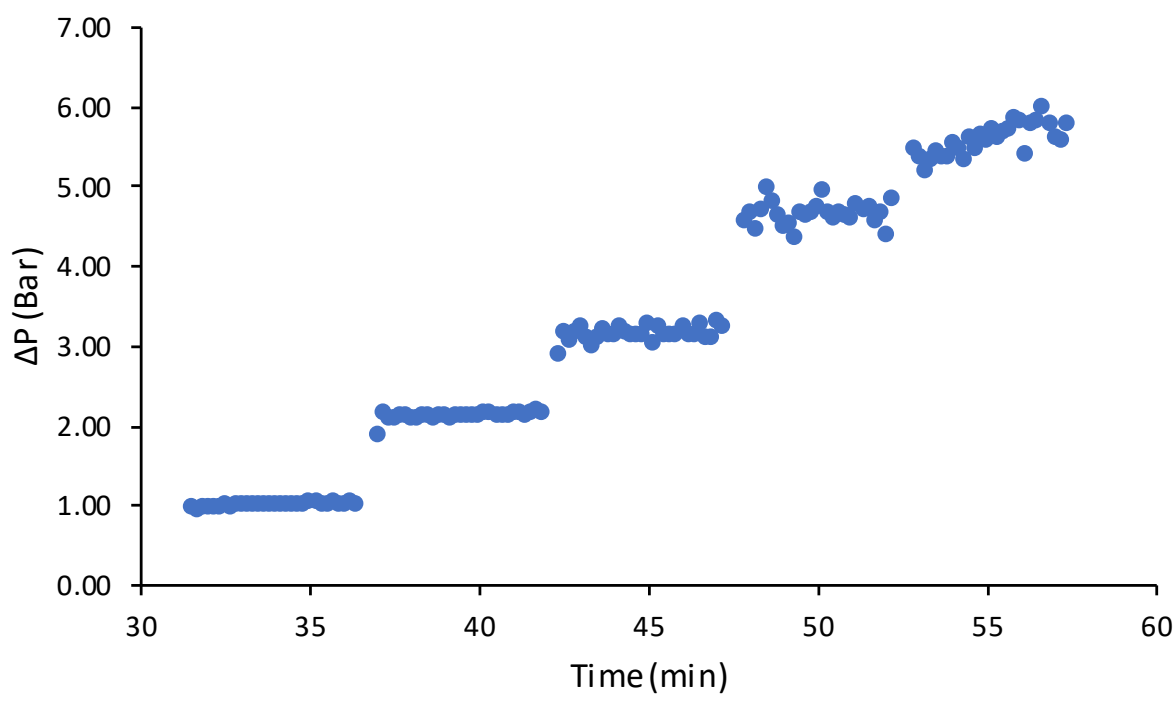

Figure S14 Pressure drop of 100-10PdC (1.52 g bed height $67 \mathrm{~mm}$ ) with frit pressure drop subtracted at $10,20,30,40$ and $50 \mathrm{~mL} / \mathrm{min}$. 


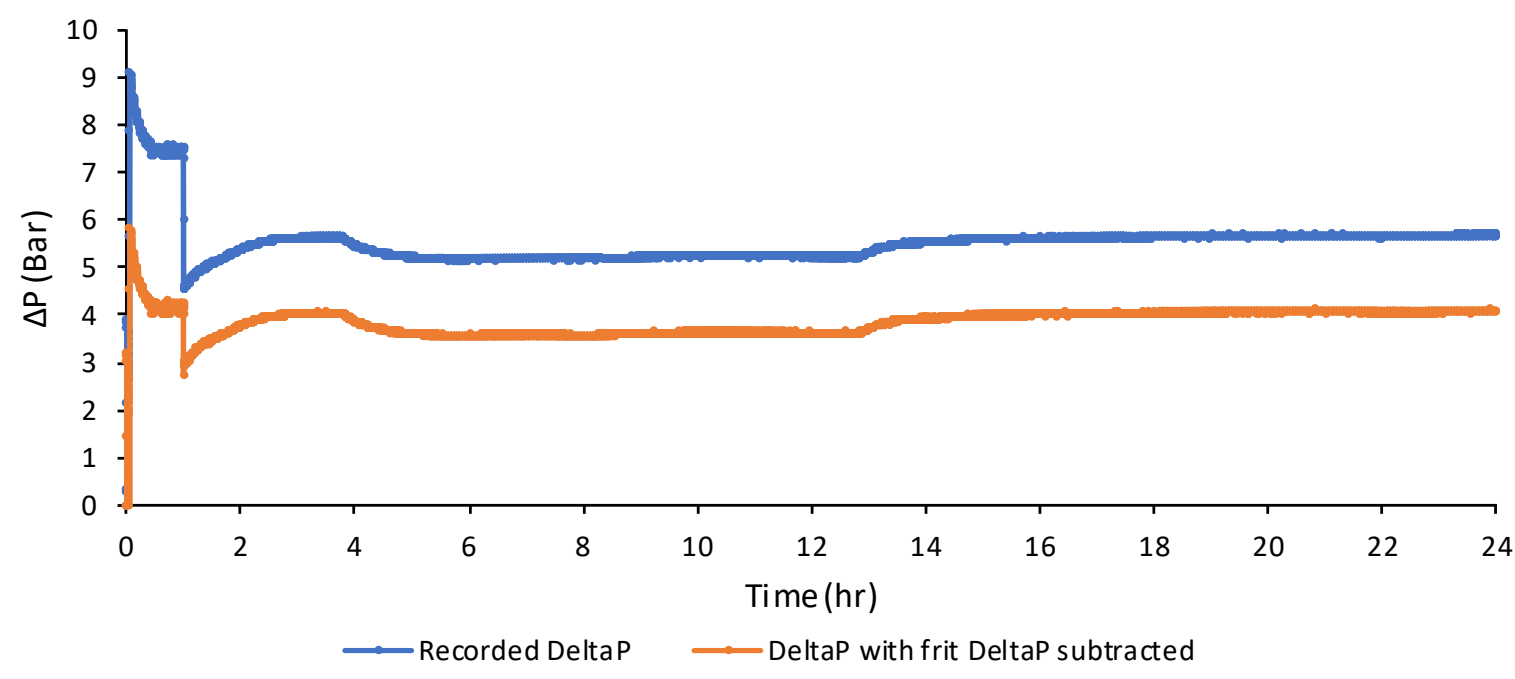

Figure S15 Pressure drop of 100-5PdC at flow rate $50 \mathrm{~mL} / \mathrm{min} 1 \mathrm{hr}, 30 \mathrm{~mL} / \mathrm{min}$ for $23 \mathrm{hr}$, with and without pressure drop $(\Delta \mathrm{P})$ of frit removed.



Figure S16 Pressure drop of 200-5PdC at flow rate $50 \mathrm{~mL} / \mathrm{min} 1 \mathrm{hr}, 30 \mathrm{~mL} / \mathrm{min}$ for $23 \mathrm{hr}$, with and without pressure drop $(\Delta \mathrm{P})$ of frit removed. 


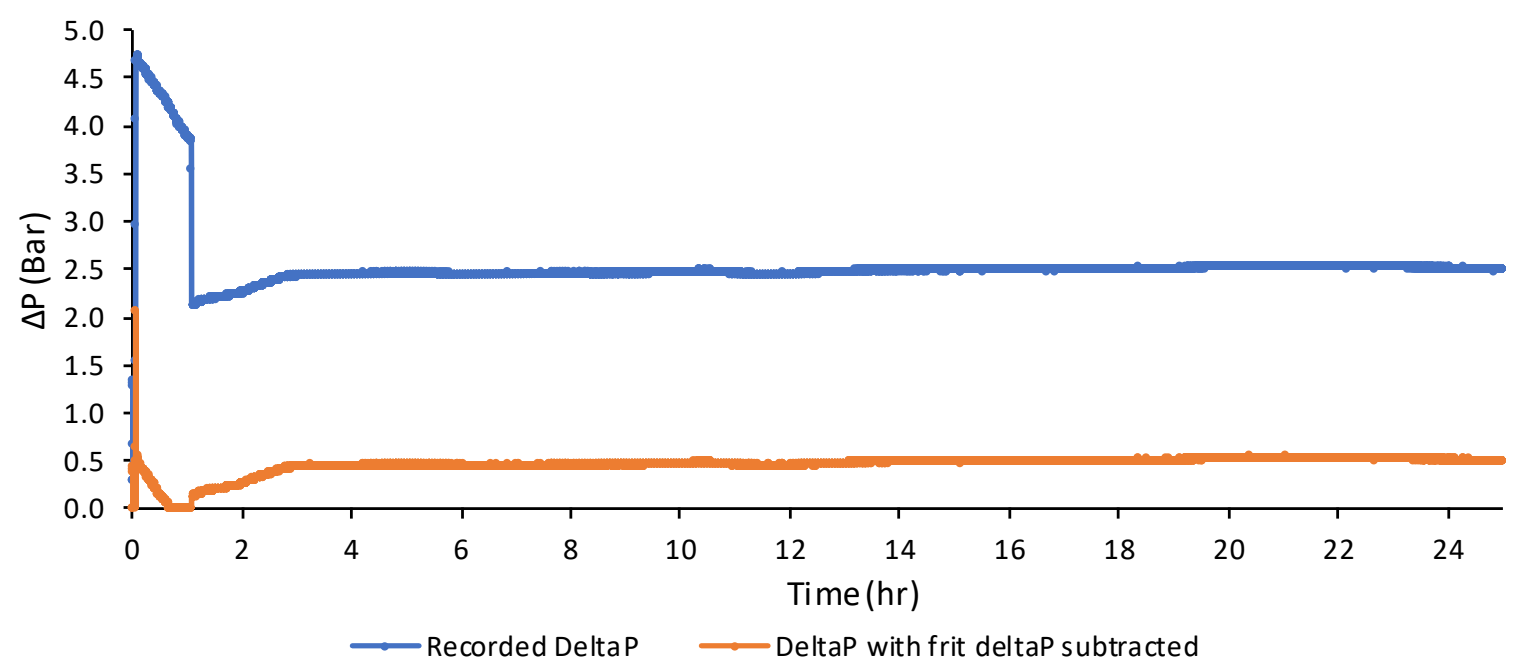

Figure S17 Pressure drop of 200-10PdC at flow rate $50 \mathrm{~mL} / \mathrm{min} 1 \mathrm{hr}, 30 \mathrm{~mL} / \mathrm{min}$ for $23 \mathrm{hr}$, with and without pressure drop $(\Delta \mathrm{P})$ of frit removed.

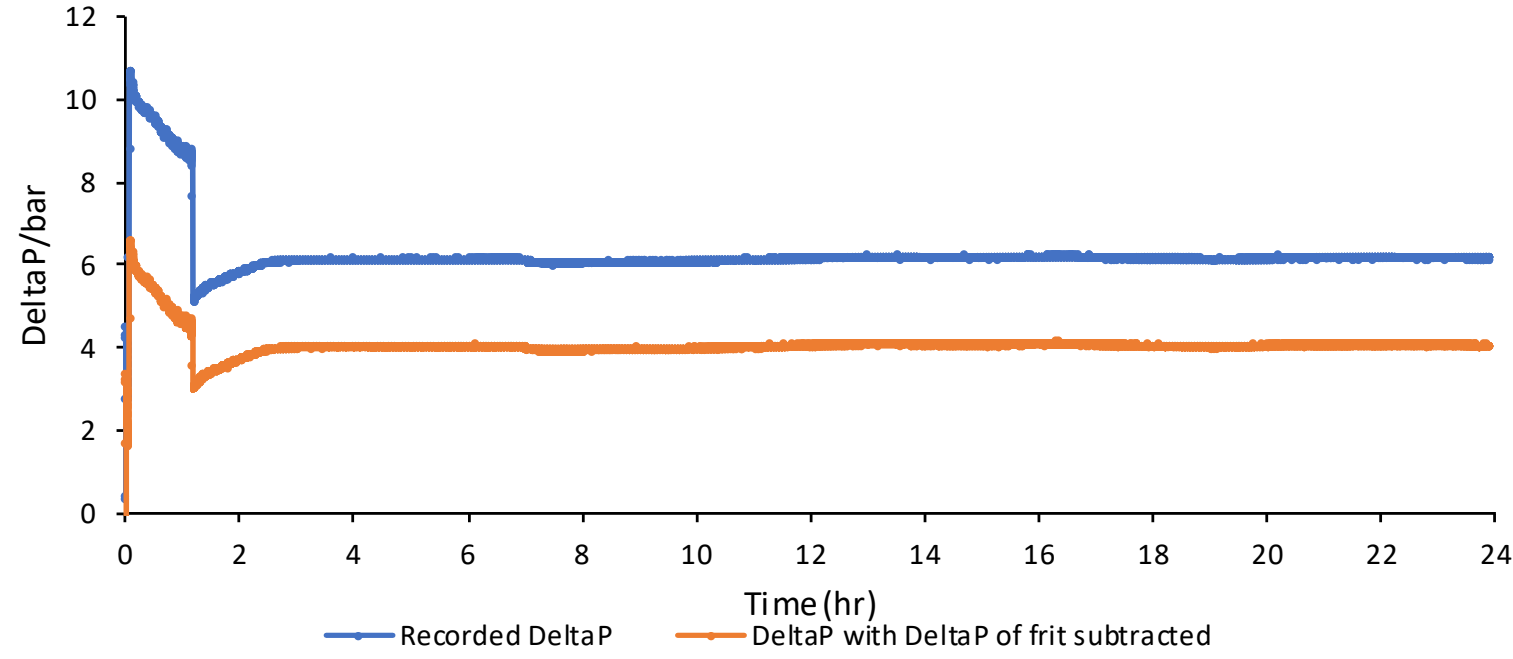

Figure S18 Pressure drop of 100-10PdC at flow rate $50 \mathrm{~mL} / \mathrm{min} 1 \mathrm{hr}, 30 \mathrm{~mL} / \mathrm{min}$ for $23 \mathrm{hr}$, with and without pressure drop $(\Delta \mathrm{P})$ of frit removed. 


\subsection{Chemical selectivity and activity}

Note: Standard practice is not to pre-treatment catalysts with hydrogen in batch experiments, however in flow experiments the catalysts are pre-treated for 10 min with solvent and hydrogen.

Biotage Endeavor at standardized conditions: $40 \mathrm{vol}$ solution ( 1 vol refers to a $1 \mathrm{~g}$ of substrate dissolved in $1 \mathrm{~mL}$ of solvent), $4 \mathrm{~mL}$ solution volume, $50{ }^{\circ} \mathrm{C}$, $10 \mathrm{Bar}, 700 \mathrm{rpm}$, unless otherwise stated.

Note: The hydrogen uptake curves were normalised with respect to the final value of hydrogen consumed. If hydrogen uptake curves are not normalised variance in consumed hydrogen (uptake) is observed.

Nitro reduction of 1-methoxy-4-nitrobenzene (5)

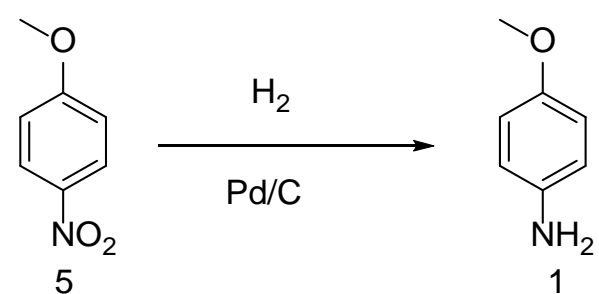

Scheme S1 Nitro reduction of 1-methoxy-4-nitrobenzene (5) 
Catalyst loading studies for nitro reduction of 1-methoxy-4-nitrobenzene (5).

Table S3 Catalyst loading screen for 100-5PdC of nitro reduction of 1-methoxy-4nitrobenzene (5). Conditions: $3 \mathrm{~mL}$ solution volume, $50^{\circ} \mathrm{C}, 10 \mathrm{Bar}, 500 \mathrm{rpm}$.

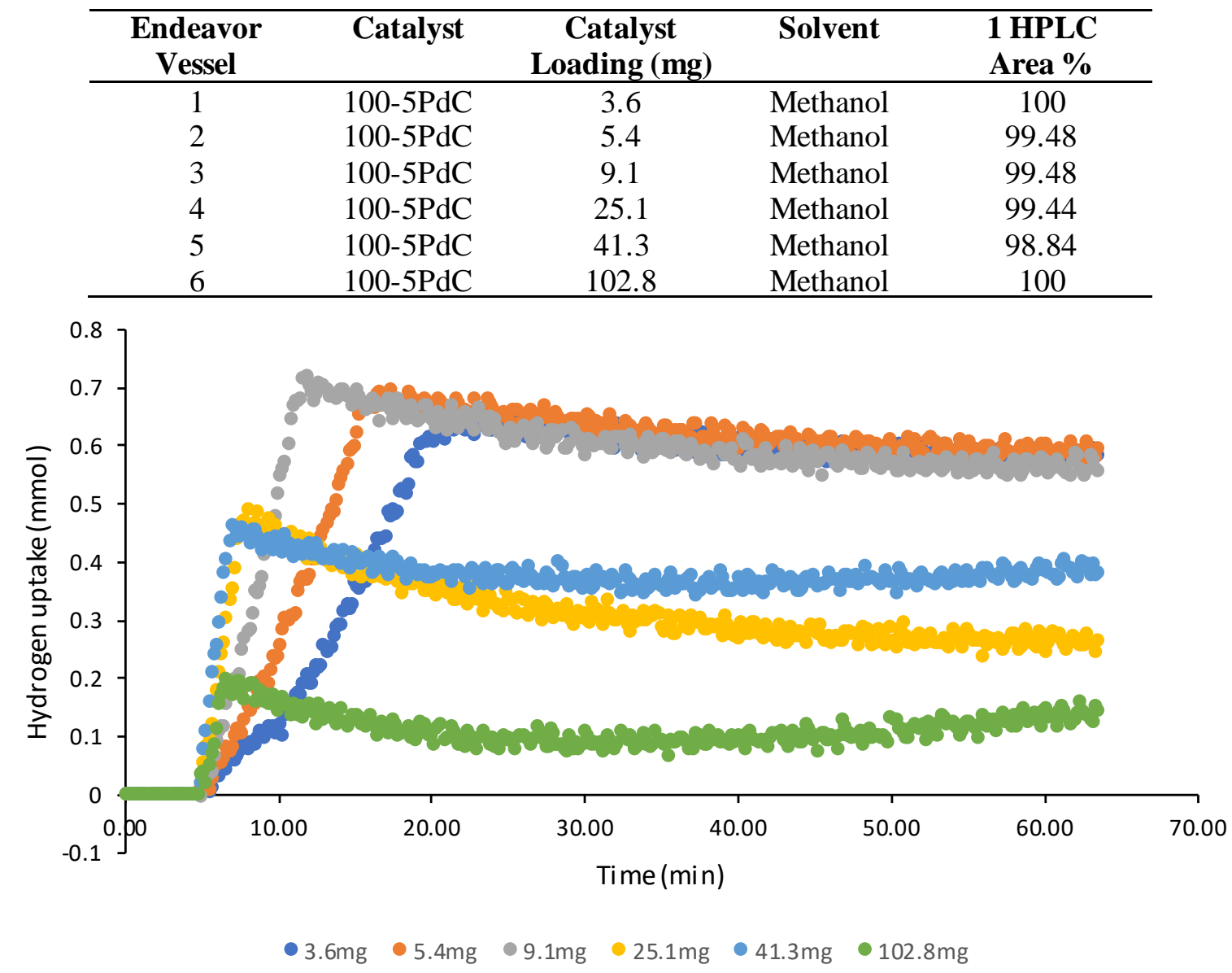

Figure S19 Non-normalised hydrogen uptake curves for Table S3. 
Table S4 Catalyst loading screen for 200-5PdC of nitro reduction of 1-methoxy-4nitrobenzene (5). Conditions: $3 \mathrm{~mL}$ solution volume, $50^{\circ} \mathrm{C}, 10 \mathrm{Bar}, 500 \mathrm{rpm}$.

\begin{tabular}{ccccc}
\hline $\begin{array}{c}\text { Endeavor } \\
\text { Vessel }\end{array}$ & Catalyst & $\begin{array}{c}\text { Catalyst } \\
\text { Loading mg }\end{array}$ & Solvent & $\begin{array}{c}\text { 1 HPLC } \\
\text { Area \% }\end{array}$ \\
\hline 1 & $200-5 P d C$ & 3.1 & Methanol & 99.10 \\
2 & $200-5 P d C$ & 6.2 & Methanol & 98.09 \\
3 & $200-5 P d C$ & 9.1 & Methanol & 98.20 \\
4 & $200-5 P d C$ & 24.3 & Methanol & 100 \\
5 & $200-5 P d C$ & 51.3 & Methanol & 100 \\
6 & $200-5 P d C$ & 104.1 & Methanol & 98.15 \\
\hline
\end{tabular}

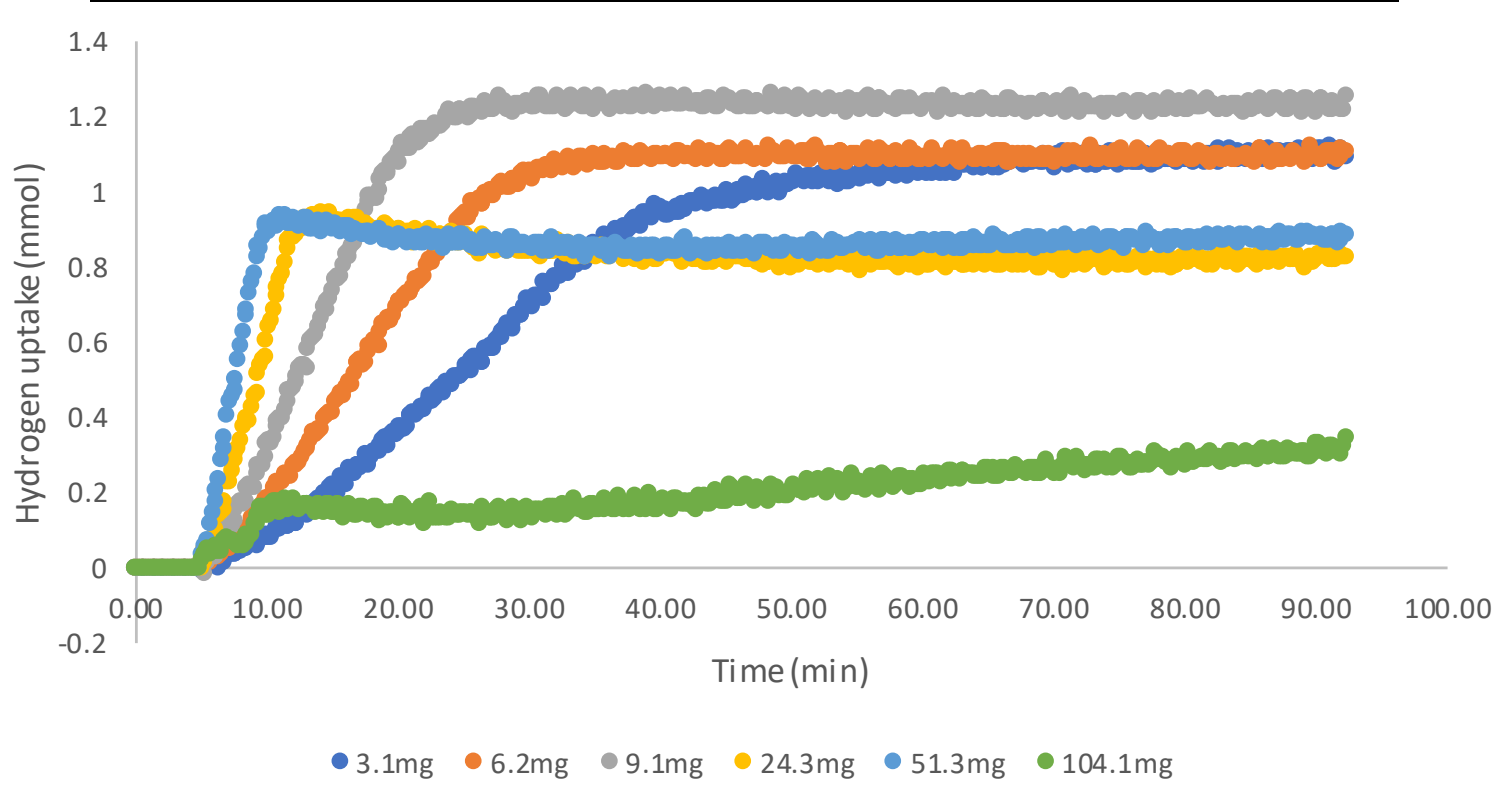

Figure S20 Non-normalised hydrogen uptake curves for Table S4. 
Table S5 Catalyst loading screen for 200-10PdC of nitro reduction of 1-methoxy-4nitrobenzene (5). Conditions: $3 \mathrm{~mL}$ solution volume, $50^{\circ} \mathrm{C}, 10 \mathrm{Bar}, 500 \mathrm{rpm}$.

\begin{tabular}{ccccc}
\hline $\begin{array}{c}\text { Endeavor } \\
\text { Vessel }\end{array}$ & Catalyst & $\begin{array}{c}\text { Catalyst } \\
\text { Loading mg }\end{array}$ & Solvent & $\begin{array}{c}\text { 1 HPLC } \\
\text { Area \% }\end{array}$ \\
\hline 1 & $100-10 \mathrm{PdC}$ & 1.1 & Methanol & 91.9 \\
2 & $100-10 \mathrm{PdC}$ & 2.2 & Methanol & 96.6 \\
3 & $100-10 \mathrm{PdC}$ & 4.5 & Methanol & 96.7 \\
4 & $100-10 \mathrm{PdC}$ & 9.1 & Methanol & 98.8 \\
5 & $100-10 \mathrm{PdC}$ & 21.8 & Methanol & 98.9 \\
6 & $100-10 \mathrm{PdC}$ & 54.3 & Methanol & 98.5 \\
\hline
\end{tabular}

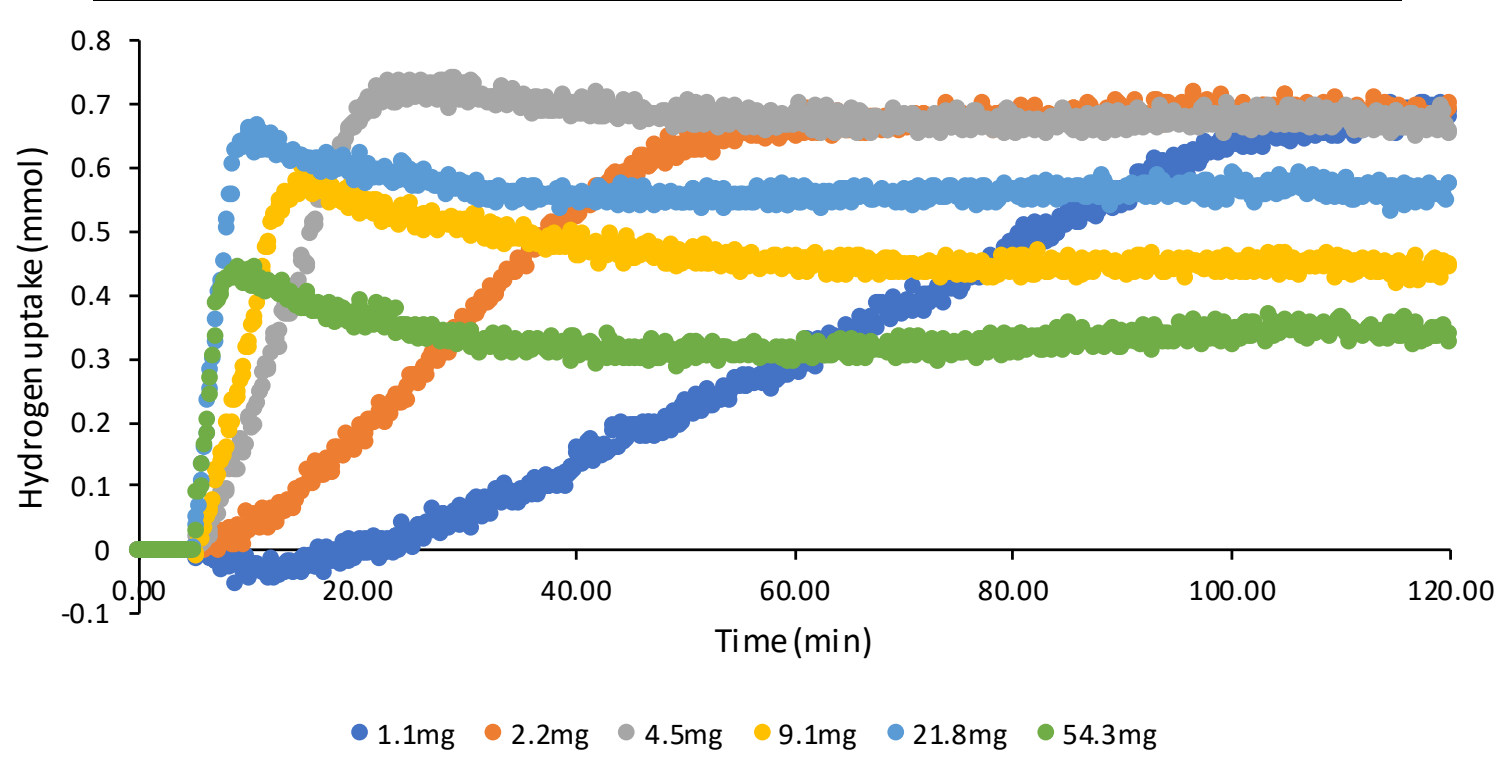

Figure S21 Non-normalised hydrogen uptake curves for Table S5. 
Table S6 Catalyst loading screen for 100-10PdC of nitro reduction of 1-methoxy-4nitrobenzene (5). Conditions $3 \mathrm{~mL}$ solution volume, $50{ }^{\circ} \mathrm{C}, 10 \mathrm{Bar}, 500 \mathrm{rpm}$.

\begin{tabular}{ccccc}
\hline $\begin{array}{c}\text { Endeavor } \\
\text { Vessel }\end{array}$ & Catalyst & $\begin{array}{c}\text { Catalyst } \\
\text { Loading mg }\end{array}$ & Solvent & $\begin{array}{c}\text { 1 HPLC } \\
\text { Area \% }\end{array}$ \\
\hline 1 & $200-10 \mathrm{PdC}$ & 1.1 & Methanol & 100 \\
2 & $200-10 \mathrm{PdC}$ & 2.2 & Methanol & 100 \\
3 & $200-10 \mathrm{PdC}$ & 6.8 & Methanol & 100 \\
4 & $200-10 \mathrm{PdC}$ & 12.3 & Methanol & 100 \\
5 & $200-10 \mathrm{PdC}$ & 21.8 & Methanol & 98.7 \\
6 & $200-10 \mathrm{PdC}$ & 48.5 & Methanol & 98.0 \\
\hline
\end{tabular}

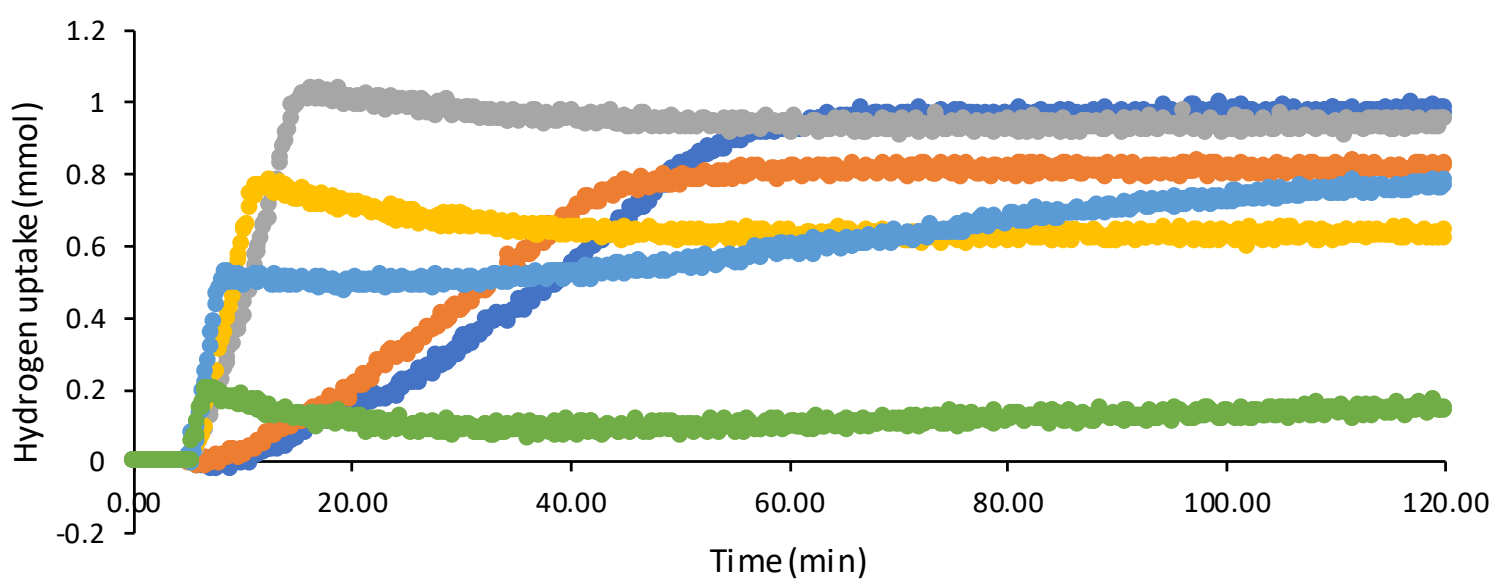

$\bullet 1.1 \mathrm{mg} \bullet 2.2 \mathrm{mg} \bullet 6.8 \mathrm{mg} \bullet 12.3 \mathrm{mg} \bullet 21.8 \mathrm{mg} \bullet 48.5 \mathrm{mg}$

Figure S22 Non-normalised hydrogen uptake curves for Table S6. 
Repeatability screen for 200-5PdC of nitro reduction of 1-methoxy-4-nitrobenzene (5).

Table S7 Repeatability screen for 200-5PdC of nitro reduction of 1-methoxy-4-nitrobenzene (5). Conditions: $3 \mathrm{~mL}$ solution volume, $50{ }^{\circ} \mathrm{C}, 10 \mathrm{Bar}, 500 \mathrm{rpm}$.

\begin{tabular}{ccccc}
\hline $\begin{array}{c}\text { Endeavor } \\
\text { Vessel }\end{array}$ & Catalyst & $\begin{array}{c}\text { Catalyst } \\
\text { Loading mg }\end{array}$ & Solvent & $\begin{array}{c}\text { 1 HPLC } \\
\text { Area \% }\end{array}$ \\
\hline 1 & $200-5 P d C$ & 3.2 & Methanol & 100 \\
2 & $200-5 P d C$ & 3.3 & Methanol & 99.2 \\
3 & $200-5 P d C$ & 3.3 & Methanol & 100 \\
4 & $200-5 P d C$ & 3.2 & Methanol & 100 \\
5 & $200-5 P d C$ & 3.3 & Methanol & 100 \\
6 & $200-5 P d C$ & 3.4 & Methanol & 100 \\
7 & $200-5 P d C$ & 3.3 & Methanol & 99.2 \\
8 & $200-5 P d C$ & 3.3 & Methanol & 100 \\
\hline
\end{tabular}

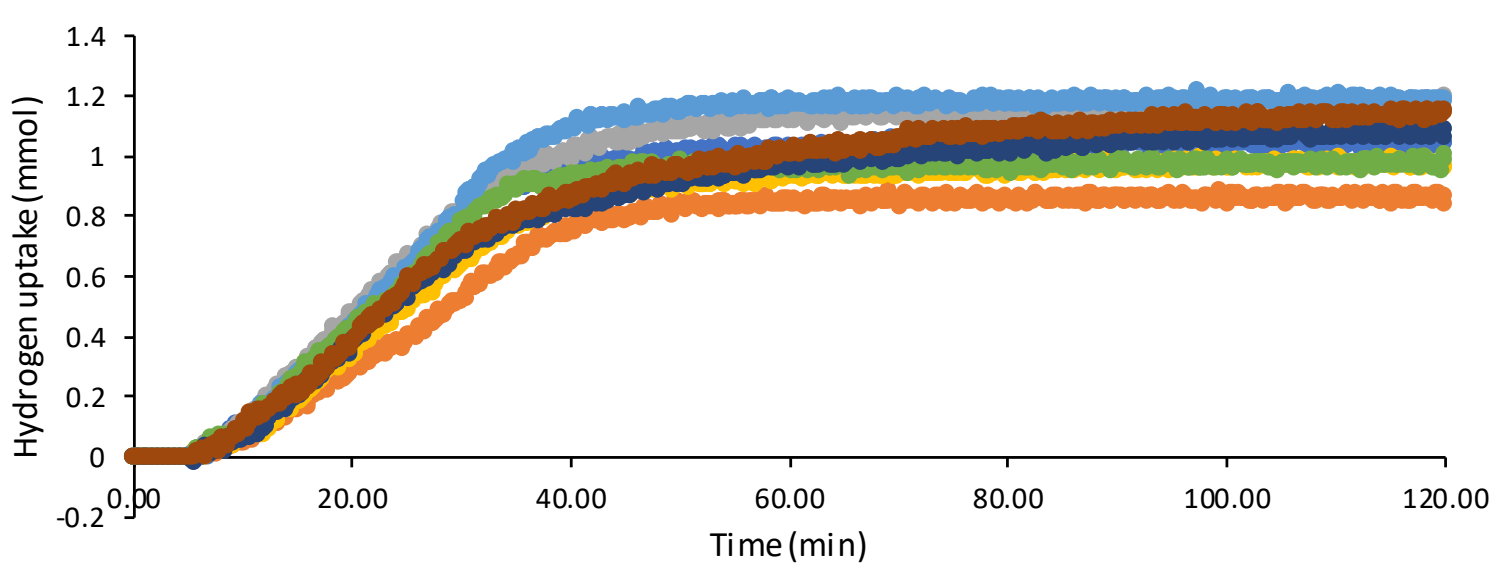

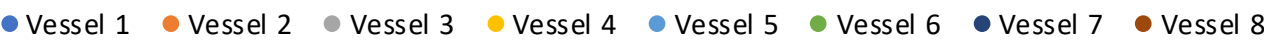

Figure S23 Non-normalised hydrogen uptake curves for Table S7. 
Solvent screening for 200-5PdC of nitro reduction of 1-methoxy-4-nitrobenzene (5).

Table S8 Solvent screen (1) for the nitro reduction of 1-methoxy-4-nitrobenzene (5) with 200-5PdC.

\begin{tabular}{ccccc}
\hline $\begin{array}{c}\text { Endeavor } \\
\text { Vessel }\end{array}$ & Catalyst & $\begin{array}{c}\text { Catalyst } \\
\text { Loading mg }\end{array}$ & Solvent & $\begin{array}{c}\text { 1 GC } \\
\text { Area \% }\end{array}$ \\
\hline 1 & $200-5 P d C$ & 3.0 & Methanol & N/A \\
2 & $200-5 P d C$ & 3.5 & Methanol & 99.1 \\
3 & $200-5 P d C$ & 3.0 & Ethanol & 98.7 \\
4 & $200-5 P d C$ & 3.6 & Ethanol & 98.0 \\
5 & $200-5 P d C$ & 3.1 & Ethyl acetate & 99.0 \\
6 & $200-5 P d C$ & 3.4 & Ethyl acetate & 99.4 \\
7 & $200-5 P d C$ & 3.1 & Tetrahydrofuran & 93.7 \\
8 & $200-5 P d C$ & 3.6 & Tetrahydrofuran & 94.0 \\
\hline
\end{tabular}

a) Sample lost due to vial breaking.

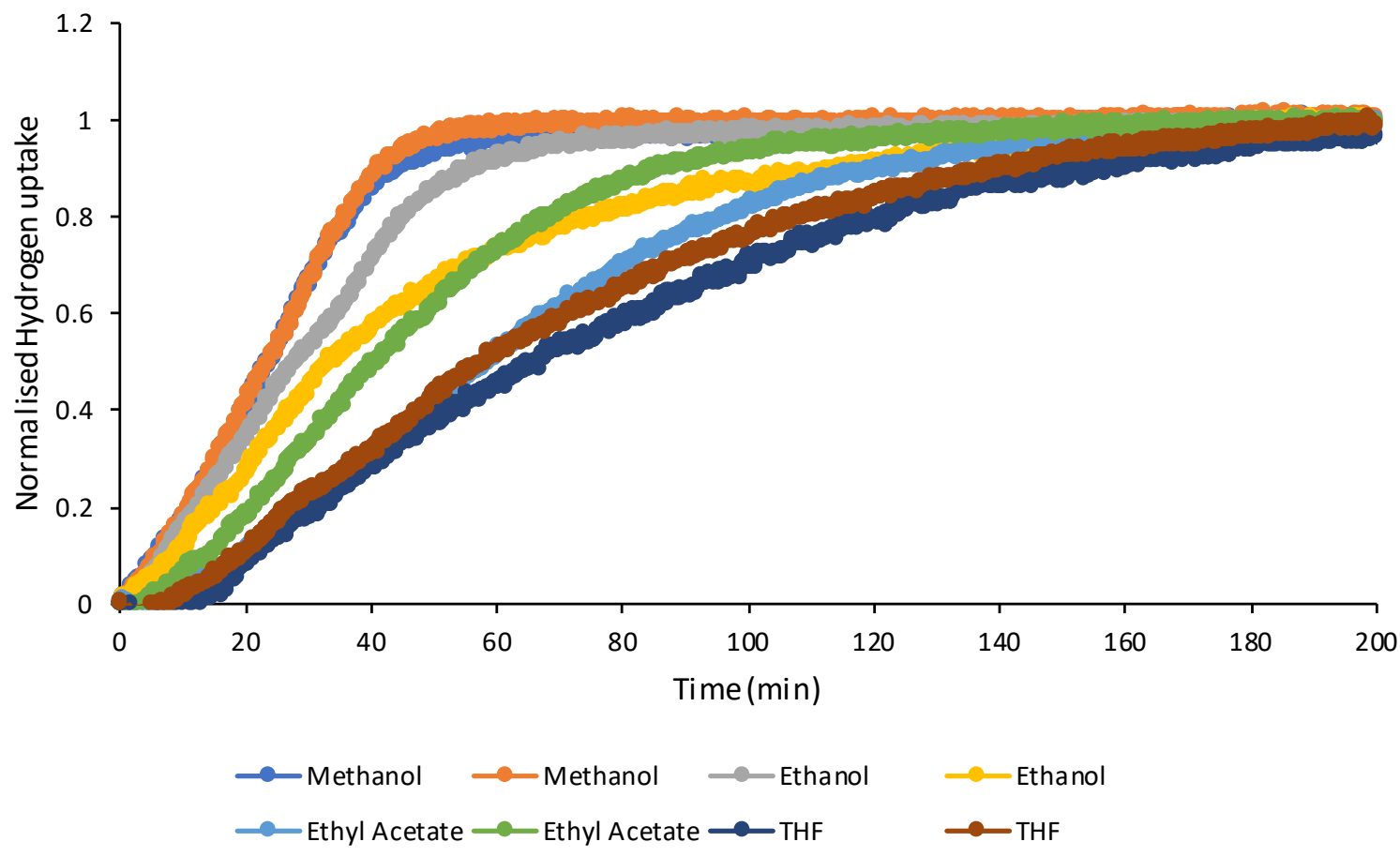

Figure S24 Normalised hydrogen uptake curves for Table S8. 
Table S9 Solvent screen (2) for the nitro reduction of 1-methoxy-4-nitrobenzene (5) with 200-5PdC.

\begin{tabular}{ccccc}
\hline $\begin{array}{c}\text { Endeavor } \\
\text { Vessel }\end{array}$ & Catalyst & $\begin{array}{c}\text { Catalyst } \\
\text { Loading } \mathbf{~ m g}\end{array}$ & Solvent & $\begin{array}{c}\mathbf{1 ~ G C} \\
\text { Area } \\
\mathbf{\%}\end{array}$ \\
\hline 1 & $200-5 \mathrm{PdC}$ & 3.3 & Toluene & 90.0 \\
2 & $200-5 \mathrm{PdC}$ & 3.3 & Toluene & 84.2 \\
3 & $200-5 \mathrm{PdC}$ & 3.6 & 2-Methyl Tetrahydrofuran & 95.7 \\
4 & $200-5 \mathrm{PdC}$ & 3.0 & 2-Methyl Tetrahydrofuran & 86.8 \\
5 & $200-5 \mathrm{PdC}$ & 3.0 & Acetic acid & 93.1 \\
6 & $200-5 \mathrm{PdC}$ & 3.1 & Acetic acid & 94.6 \\
7 & $200-5 \mathrm{PdC}$ & 3.2 & Acetic acid:methanol 1:1 & 90.5 \\
8 & $200-5 \mathrm{PdC}$ & 3.1 & Acetic acid:methanol 1:1 & 93.5 \\
\hline
\end{tabular}



Figure S25 Normalised hydrogen uptake curves for Table S9. 
Pressure screening for 200-5PdC of nitro reduction of 1-methoxy-4-nitrobenzene (5).

Table S10 Pressure screening for 200-5PdC of nitro reduction of 1-methoxy-4-nitrobenzene (5). Conditions: $3 \mathrm{~mL}$ solution volume, $50{ }^{\circ} \mathrm{C}, 10 \mathrm{Bar}, 500 \mathrm{rpm}$.

\begin{tabular}{cccccc}
\hline $\begin{array}{c}\text { Endeavor } \\
\text { Vessel }\end{array}$ & Catalyst & $\begin{array}{c}\text { Catalyst } \\
\text { Loading } \\
\text { mg }\end{array}$ & $\begin{array}{c}\text { Pressure } \\
\text { Bar }\end{array}$ & Solvent & $\begin{array}{c}\mathbf{1} \\
\text { HPLC } \\
\text { Area } \\
\text { \% }\end{array}$ \\
\hline 1 & $200-5$ PdC & 3.1 & 1 & Methanol & 97.9 \\
2 & $200-5$ PdC & 3.3 & 2.5 & Methanol & 98.3 \\
3 & $200-5 P d C$ & 3.0 & 5 & Methanol & 96.6 \\
4 & $200-5 P d C$ & 3.0 & 10 & Methanol & 100 \\
5 & $200-5 P d C$ & 3.0 & 15 & Methanol & 100 \\
\hline
\end{tabular}

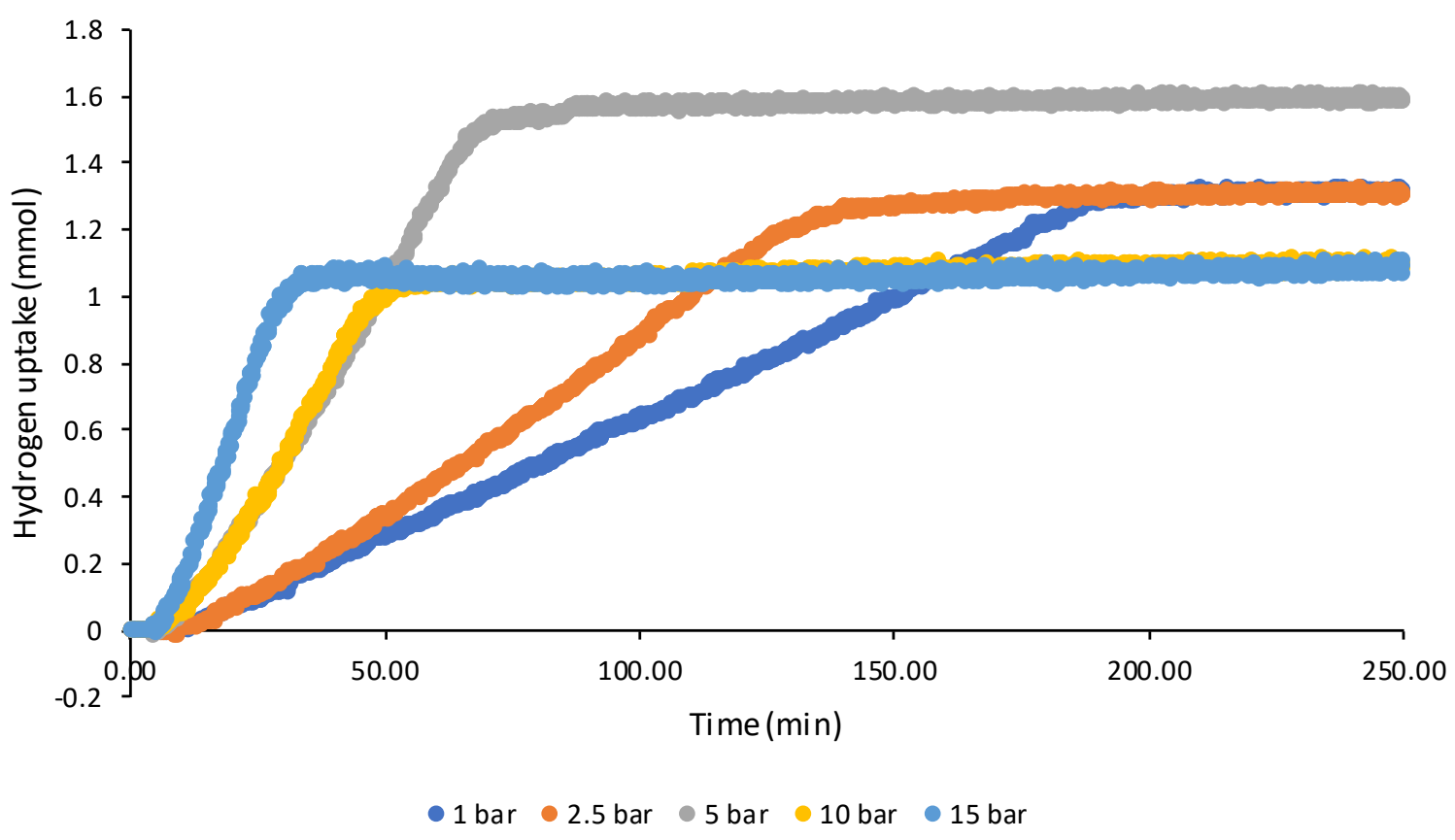

Figure S26 Non-normalised hydrogen uptake curves for Table S10. 
Head to head comparison of Blücher GmbH catalyst for the nitro reduction of 1-methoxy-4nitrobenzene (5).

Table S11 Head to head comparison of Blücher GmbH catalysts for the nitro reduction of 1methoxy-4-nitrobenzene (5) run in duplicate.

\begin{tabular}{ccllc}
\hline $\begin{array}{c}\text { Endeavor } \\
\text { Vessel }\end{array}$ & Catalyst & $\begin{array}{c}\text { Catalyst } \\
\text { Loading } \\
\text { mg }\end{array}$ & Solvent & $\begin{array}{c}\mathbf{1 ~ G C} \\
\text { Area } \\
\text { \% }\end{array}$ \\
\hline 1 & $100-5 \mathrm{PdC}$ & 3.4 & Methanol & 99.6 \\
2 & $100-5 \mathrm{PdC}$ & 3.2 & Methanol & 99.3 \\
3 & $200-5 \mathrm{PdC}$ & 3.5 & Methanol & 98.3 \\
4 & $200-5 \mathrm{PdC}$ & 3.6 & Methanol & 99.2 \\
5 & $100-10 \mathrm{PdC}$ & 3.6 & Methanol & 98.8 \\
6 & $100-10 \mathrm{PdC}$ & 3.0 & Methanol & 97.8 \\
7 & $200-10 \mathrm{PdC}$ & 3.6 & Methanol & 99.1 \\
8 & $200-10 \mathrm{PdC}$ & 3.5 & Methanol & 99.0 \\
\hline
\end{tabular}

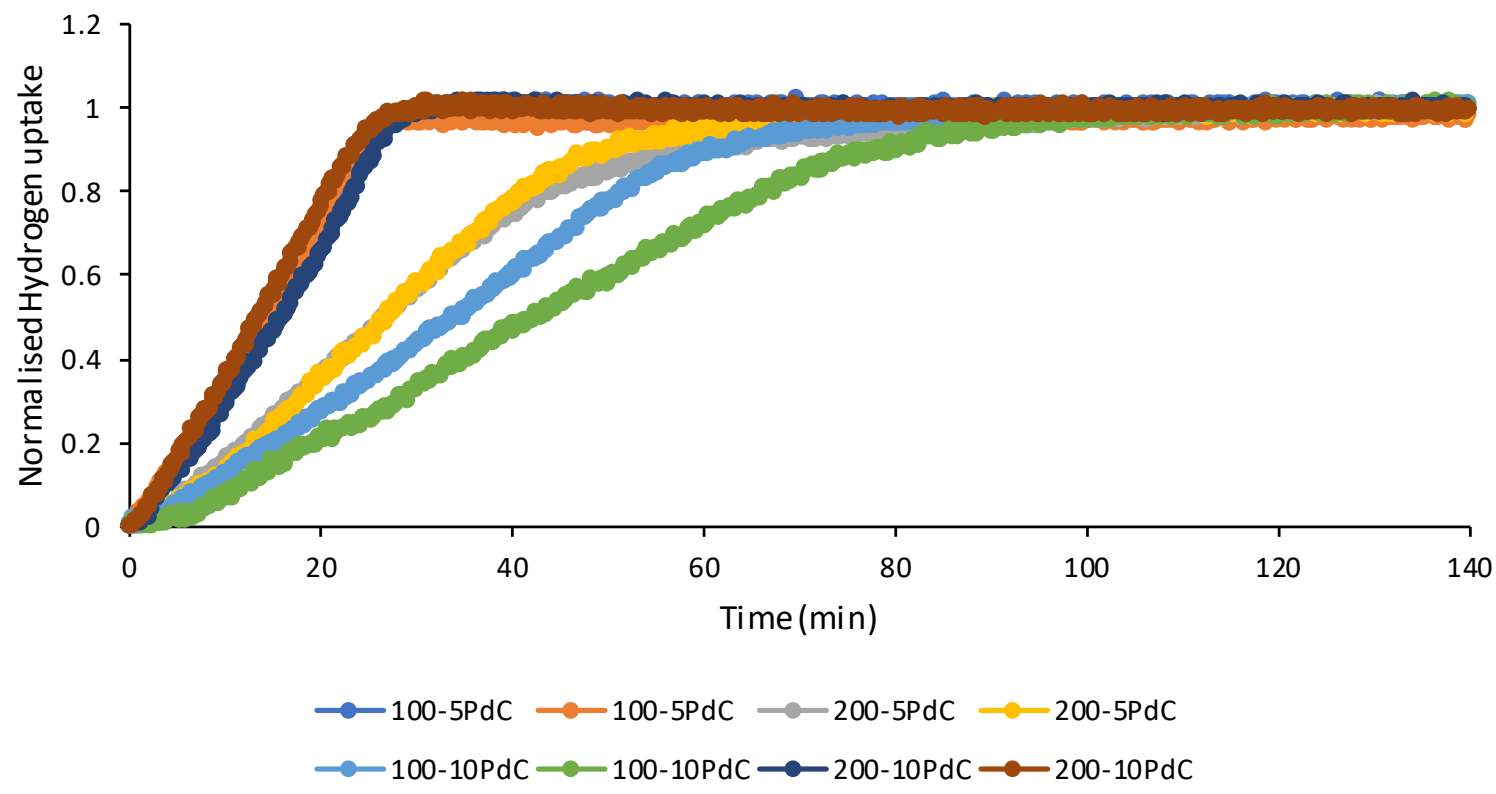

Figure S27 Non-normalised hydrogen uptake curves for Table S11. 
Nitro reduction of 1-chloro-4-nitrobenzene (9)<smiles>[R]Nc1ccc(Cl)cc1</smiles>

Scheme S2 Nitro reduction of 1-chloro-4-nitrobenzene (9).

Catalyst loading studies for nitro reduction of 1-chloro-4-nitrobenzene (9).

Table S12 Catalyst loading screen for 200-5PdC of nitro reduction 1-chloro-4-nitrobenzene (9).

\begin{tabular}{ccccc}
\hline $\begin{array}{c}\text { Endeavor } \\
\text { Vessel }\end{array}$ & Catalyst & $\begin{array}{c}\text { Catalyst } \\
\text { Loading mg }\end{array}$ & Solvent & $\begin{array}{c}\text { 2 GC } \\
\text { Area \% }\end{array}$ \\
\hline 1 & $200-5 P d C$ & 5 & Tetrahydrofuran & 86.7 \\
2 & $200-5 P d C$ & 10 & Tetrahydrofuran & 68.1 \\
3 & $200-5 P d C$ & 15.1 & Tetrahydrofuran & 62.0 \\
4 & $200-5 P d C$ & 20 & Tetrahydrofuran & 56.7 \\
5 & $200-5 P d C$ & 25 & Tetrahydrofuran & 40.0 \\
6 & $200-5 P d C$ & 30 & Tetrahydrofuran & 32.8 \\
7 & $200-5 P d C$ & 40 & Tetrahydrofuran & 83.3 \\
8 & $200-5 P d C$ & 50 & Tetrahydrofuran & 5.5 \\
\hline
\end{tabular}

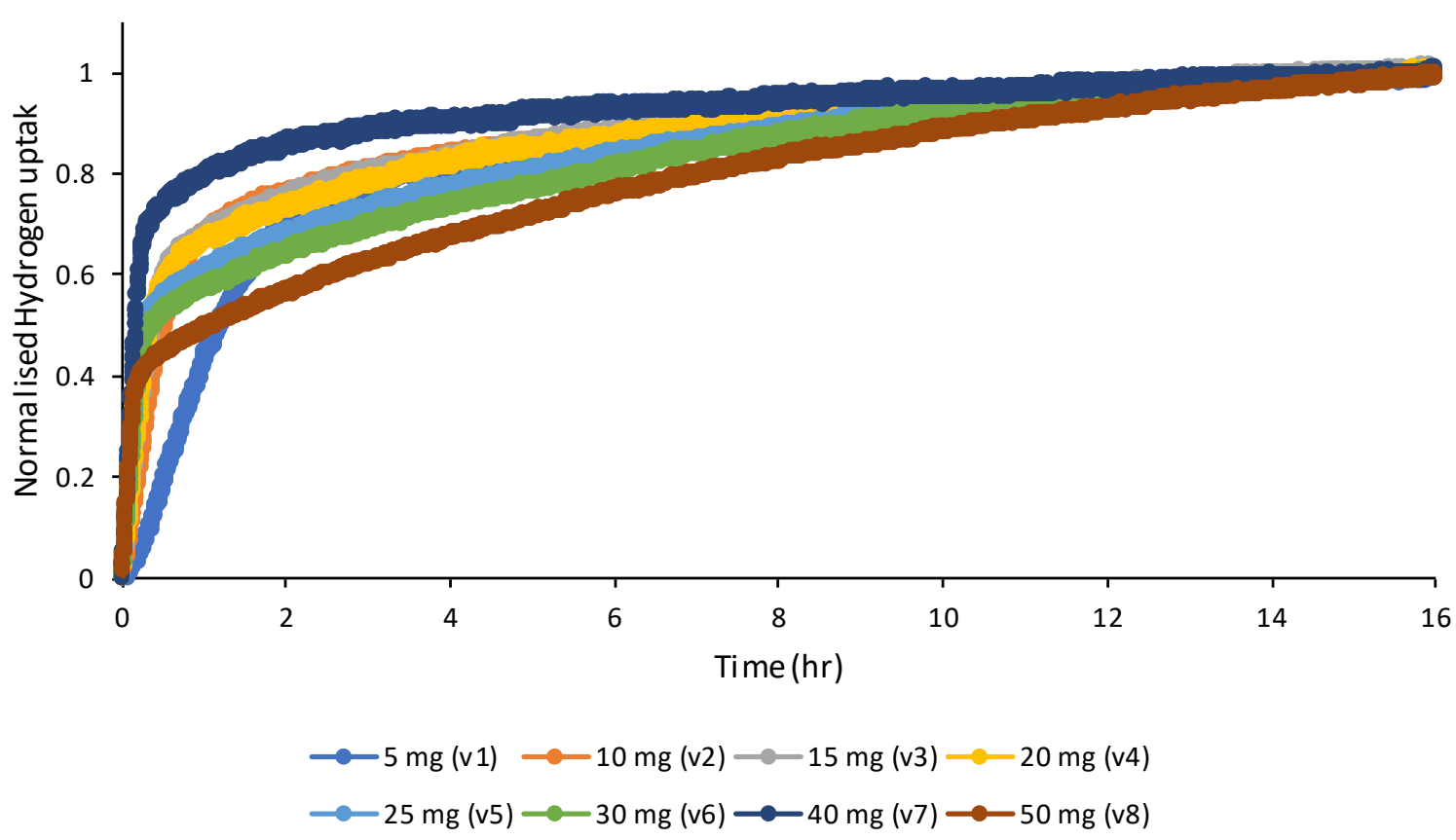

Figure S28 Normalised hydrogen uptake curves for Table S12. 
Solvent screening for 200-5PdC of nitro reduction of 1-chloro-4-nitrobenzene (9).

Table S13 Solvent screen (1) for the nitro reduction of 1-chloro-4-nitrobenzene (9). with 2005PdC.

\begin{tabular}{ccccc}
\hline $\begin{array}{c}\text { Endeavor } \\
\text { Vessel }\end{array}$ & Catalyst & $\begin{array}{c}\text { Catalyst } \\
\text { Loading mg }\end{array}$ & Solvent & $\begin{array}{c}\text { 2 GC } \\
\text { Area \% }\end{array}$ \\
\hline 1 & $200-5 P d C$ & 5.0 & Methanol & 62.7 \\
2 & $200-5 P d C$ & 5.1 & Methanol & 1.5 \\
3 & $200-5 P d C$ & 5.1 & Ethanol & 21.7 \\
4 & $200-5 P d C$ & 5.0 & Ethanol & 61.8 \\
5 & $200-5 P d C$ & 5.0 & Ethyl acetate & 87.7 \\
6 & $200-5 P d C$ & 5.0 & Ethyl acetate & 97.6 \\
7 & $200-5 P d C$ & 5.0 & Tetrahydrofuran & 77.1 \\
8 & $200-5 P d C$ & 5.0 & Tetrahydrofuran & 82.3 \\
\hline
\end{tabular}

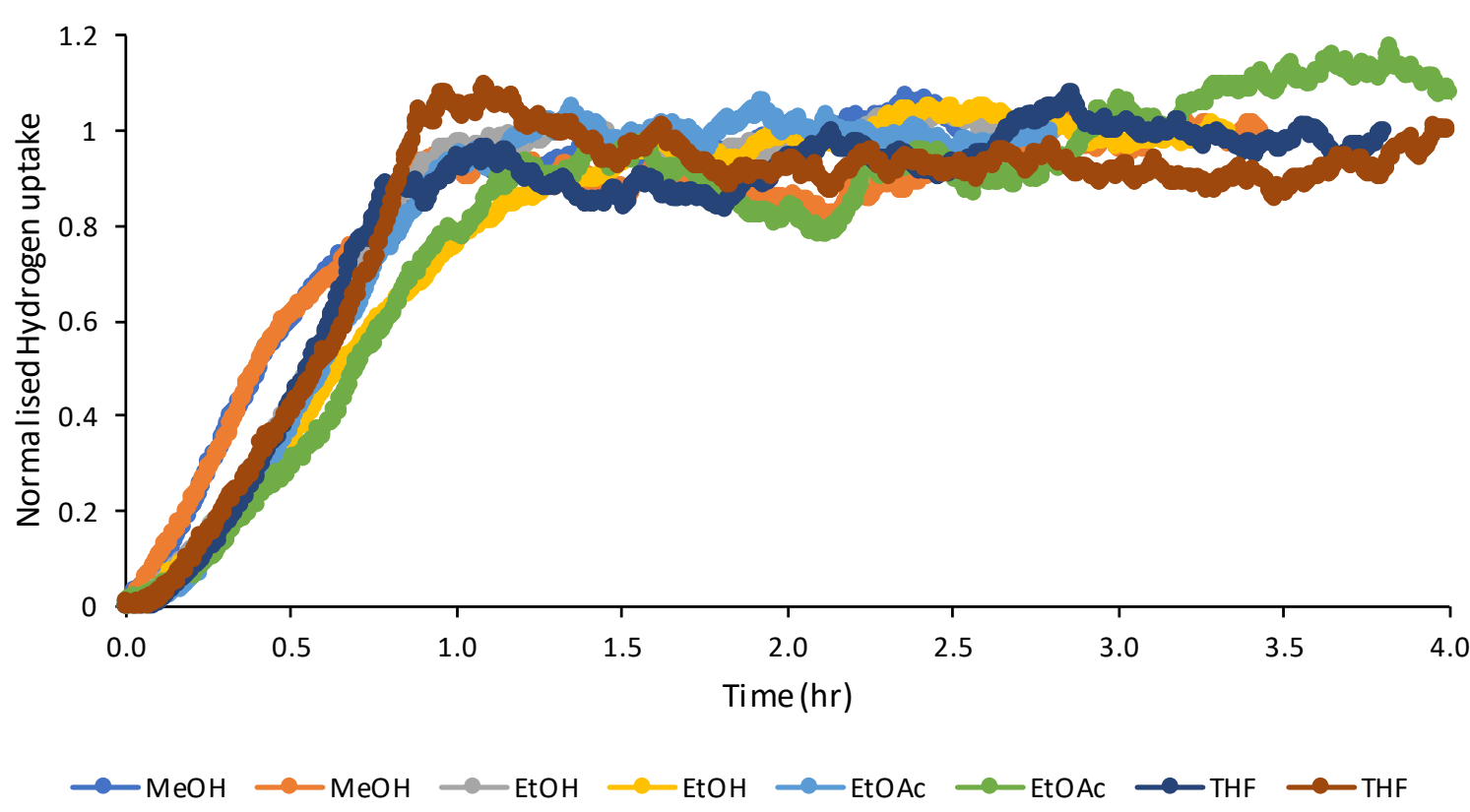

Figure S29 Normalised hydrogen uptake curves for Table S13. 
Table S14 Solvent screen (2) for the nitro reduction of 1-chloro-4-nitrobenzene (9) with 2005PdC.

\begin{tabular}{ccccc}
\hline $\begin{array}{c}\text { Endeavor } \\
\text { Vessel }\end{array}$ & Catalyst & $\begin{array}{c}\text { Catalyst } \\
\text { Loading } \mathbf{~ m g}\end{array}$ & Solvent & $\begin{array}{c}\mathbf{2} \text { GC } \\
\text { Area } \\
\mathbf{\%}\end{array}$ \\
\hline 1 & $200-5 \mathrm{PdC}$ & 5.0 & Toluene & 86.1 \\
2 & $200-5 \mathrm{PdC}$ & 5.0 & Toluene & 77.5 \\
3 & $200-5 \mathrm{PdC}$ & 5.3 & 2-Methyl Tetrahydrofuran & 87.3 \\
4 & $200-5 \mathrm{PdC}$ & 5.0 & 2-Methyl Tetrahydrofuran & 89.9 \\
5 & $200-5 \mathrm{PdC}$ & 5.1 & Acetic acid & 50.7 \\
6 & $200-5 \mathrm{PdC}$ & 5.0 & Acetic acid & 46.5 \\
7 & $200-5 \mathrm{PdC}$ & 5.0 & Acetic acid:methanol 1:1 & 14.2 \\
8 & $200-5 \mathrm{PdC}$ & 5.0 & Acetic acid:methanol 1:1 & 14.6 \\
\hline
\end{tabular}

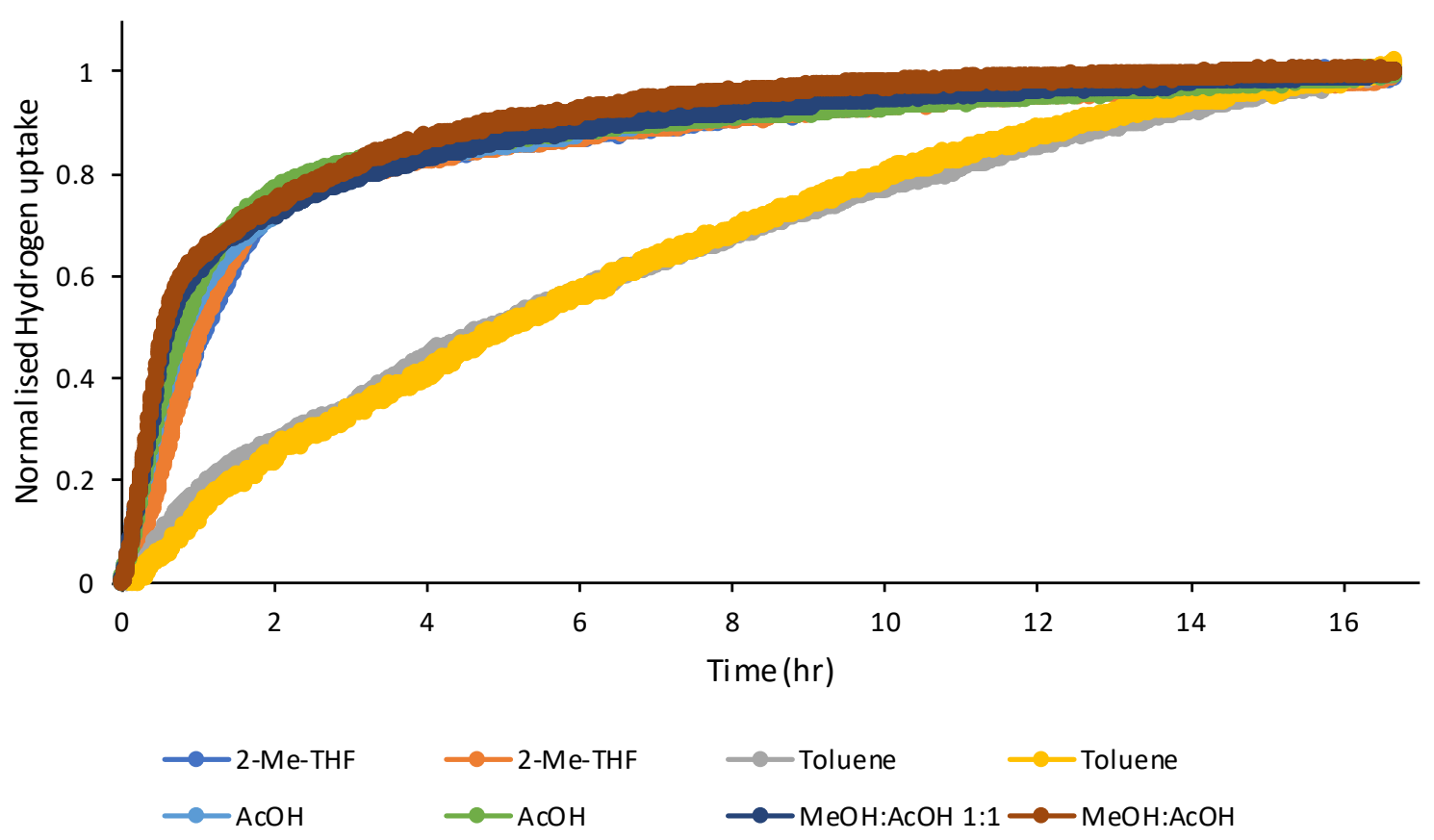

Figure S30 Normalised hydrogen uptake curves for Table S14. 
Head to head comparison of Blücher GmbH catalyst for the nitro reduction of 1-chloro-4nitrobenzene (9).

Table S15 Head to head comparison of Blücher GmbH catalysts for the nitro reduction 1chloro-4-nitrobenzene $\mathbf{( 9 )}$ run in duplicate.

\begin{tabular}{ccccc}
\hline $\begin{array}{c}\text { Endeavor } \\
\text { Vessel }\end{array}$ & Catalyst & $\begin{array}{c}\text { Catalyst } \\
\text { Loading } \\
\text { mg }\end{array}$ & Solvent & $\begin{array}{c}\text { 2 GC } \\
\text { Area } \\
\text { \% }\end{array}$ \\
\hline 1 & $100-5 \mathrm{PdC}$ & 5.2 & Ethyl acetate & 92.5 \\
2 & $100-5 \mathrm{PdC}$ & 5.3 & Ethyl acetate & 96.9 \\
3 & $200-5 \mathrm{PdC}$ & 5.2 & Ethyl acetate & 92.2 \\
4 & $200-5 \mathrm{PdC}$ & 5.1 & Ethyl acetate & 93.1 \\
7 & $100-10 \mathrm{PdC}$ & 5.3 & Ethyl acetate & 92.4 \\
8 & $100-10 \mathrm{PdC}$ & 5.7 & Ethyl acetate & 95.4 \\
5 & $200-10 \mathrm{PdC}$ & 5.2 & Ethyl acetate & 88.9 \\
6 & $200-10 \mathrm{PdC}$ & 5.1 & Ethyl acetate & 94.7 \\
\hline
\end{tabular}

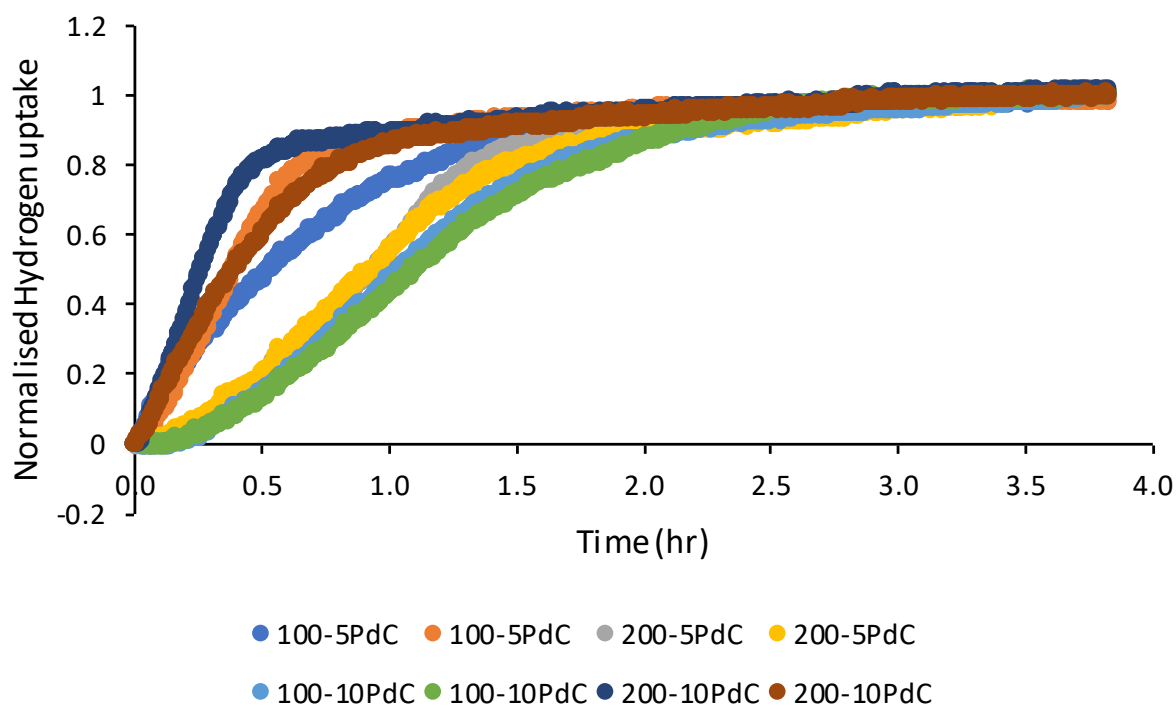

Figure S31 Normalised hydrogen uptake curves for Table S15. 
Nitro reduction of 4-nitrobenzonitrile (10)<smiles>N#Cc1ccc(N)cc1</smiles>

Scheme S3 Nitro reduction of 4-nitrobenzonitrile (10).

Catalyst loading studies for nitro reduction of 4-nitrobenzonitrile (10).

Table S16 Catalyst loading screen for 200-5PdC of nitro reduction 4-nitrobenzonitrile (10).

\begin{tabular}{ccccc}
\hline $\begin{array}{c}\text { Endeavor } \\
\text { Vessel }\end{array}$ & Catalyst & $\begin{array}{c}\text { Catalyst } \\
\text { Loading mg }\end{array}$ & Solvent & $\begin{array}{c}\text { 3 GC } \\
\text { Area \% }\end{array}$ \\
\hline 1 & $200-5 P d C$ & 3.5 & Tetrahydrofuran & 47.1 \\
2 & $200-5 P d C$ & 12 & Tetrahydrofuran & 64.64 \\
3 & $200-5 P d C$ & 21.5 & Tetrahydrofuran & 82.3 \\
4 & $200-5 P d C$ & 24.6 & Tetrahydrofuran & 83.0 \\
5 & $200-5 P d C$ & 29.8 & Tetrahydrofuran & 88.2 \\
6 & $200-5 P d C$ & 35.2 & Tetrahydrofuran & 83.9 \\
7 & $200-5 P d C$ & 43.0 & Tetrahydrofuran & 47.5 \\
8 & $200-5 P d C$ & 50.2 & Tetrahydrofuran & 35.5 \\
\hline
\end{tabular}

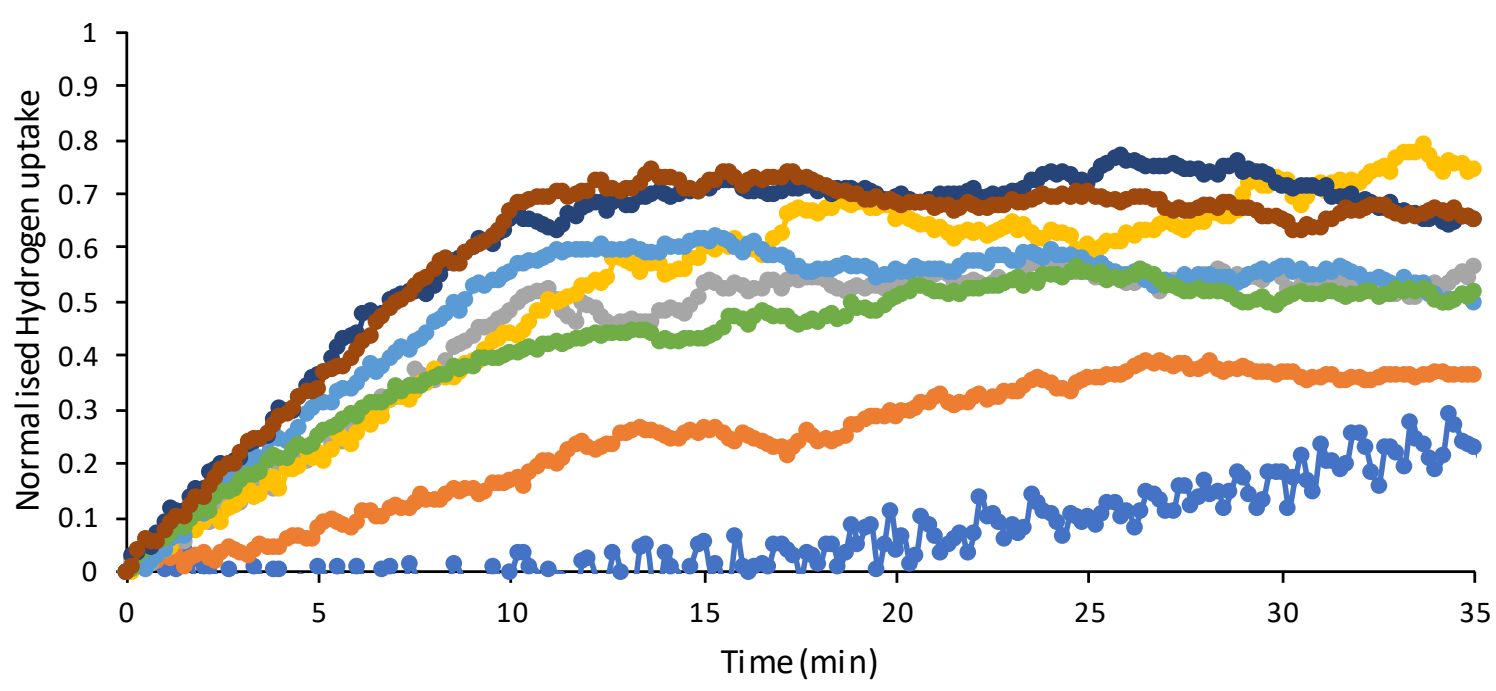

$\longrightarrow-3.5 \mathrm{mg} \longrightarrow-12.0 \mathrm{mg} \longrightarrow-21.5 \mathrm{mg} \longrightarrow-24.6 \mathrm{mg}$
$\longrightarrow-29.8 \mathrm{mg} \longrightarrow-35.2 \mathrm{mg} \longrightarrow-43.0 \mathrm{mg} \longrightarrow-50.2 \mathrm{mg}$

Figure S32 Normalised hydrogen uptake curves for Table S16. 
Solvent screening for 200-5PdC of nitro reduction of 4-nitrobenzonitrile (10).

Table S17 Solvent screen (1) for the nitro reduction of 4-nitrobenzonitrile (10) with 2005PdC.

\begin{tabular}{ccccc}
\hline $\begin{array}{c}\text { Endeavor } \\
\text { Vessel }\end{array}$ & Catalyst & $\begin{array}{c}\text { Catalyst } \\
\text { Loading } \mathbf{~ m g}\end{array}$ & Solvent & $\begin{array}{c}\mathbf{3} \\
\text { GC } \\
\text { Area } \\
\mathbf{\%}\end{array}$ \\
\hline 1 & $200-5 \mathrm{PdC}$ & 30.1 & Tetrahydrofuran & 81.3 \\
2 & $200-5 \mathrm{PdC}$ & 30.0 & Tetrahydrofuran & 70.5 \\
3 & $200-5 \mathrm{PdC}$ & 30.0 & 2-Methyl Tetrahydrofuran & 89.8 \\
4 & $200-5 \mathrm{PdC}$ & 30.0 & 2-Methyl Tetrahydrofuran & 80.9 \\
5 & $200-5 \mathrm{PdC}$ & 30.0 & Toluene & 14.0 \\
6 & $200-5 \mathrm{PdC}$ & 30.1 & Toluene & 26.0 \\
\hline
\end{tabular}

4-nitrobenzonitrile poor solubility in methanol and ethanol.



Figure S33 Normalised hydrogen uptake curves for Table S17. 
Table S18 Solvent screen (2) for the nitro reduction of 4-nitrobenzonitrile (10) with 2005PdC.

\begin{tabular}{ccccc}
\hline $\begin{array}{c}\text { Endeavor } \\
\text { Vessel }\end{array}$ & Catalyst & $\begin{array}{c}\text { Catalyst } \\
\text { Loading } \mathbf{~ m g}\end{array}$ & Solvent & $\begin{array}{l}\text { 3 GC } \\
\text { Area } \\
\mathbf{\%}\end{array}$ \\
\hline 1 & $200-5 \mathrm{PdC}$ & 30.1 & Ethyl acetate & 91.8 \\
2 & $200-5 \mathrm{PdC}$ & 30.0 & Ethyl acetate & 91.5 \\
3 & $200-5 \mathrm{PdC}$ & 30.2 & Acetic acid & 50.1 \\
4 & $200-5 \mathrm{PdC}$ & 30.0 & Acetic acid & 49.4 \\
5 & $200-5 \mathrm{PdC}$ & 30.0 & Acetic acid:methanol 1:1 & 46.7 \\
6 & $200-5 \mathrm{PdC}$ & 30.0 & Acetic acid:methanol 1:1 & 40.9 \\
\hline
\end{tabular}



Figure S34 Normalised hydrogen uptake curves for Table S18. 
Head to head comparison of Blücher GmbH catalyst for the nitro reduction of 4nitrobenzonitrile (10).

Table S19 Head to head comparison of Blücher GmbH catalysts for the nitro reduction 4nitrobenzonitrile (10) run in duplicate.

\begin{tabular}{ccccc}
\hline $\begin{array}{c}\text { Endeavor } \\
\text { Vessel }\end{array}$ & Catalyst & $\begin{array}{c}\text { Catalyst } \\
\text { Loading } \\
\text { mg }\end{array}$ & Solvent & $\begin{array}{c}\text { 3 GC } \\
\text { Area } \\
\text { \% }\end{array}$ \\
\hline 1 & $100-5 \mathrm{PdC}$ & 30.2 & Ethyl acetate & 98.1 \\
2 & $100-5 \mathrm{PdC}$ & 30.1 & Ethyl acetate & 89.5 \\
3 & $200-5 \mathrm{PdC}$ & 30.0 & Ethyl acetate & 99.0 \\
4 & $200-5 \mathrm{PdC}$ & 30.0 & Ethyl acetate & 88.3 \\
7 & $100-10 \mathrm{PdC}$ & 30.0 & Ethyl acetate & 9.5 \\
8 & $100-10 \mathrm{PdC}$ & 30.0 & Ethyl acetate & 11.2 \\
5 & $200-10 \mathrm{PdC}$ & 30.1 & Ethyl acetate & 100 \\
6 & $200-10 \mathrm{PdC}$ & 30.0 & Ethyl acetate & 100 \\
\hline
\end{tabular}

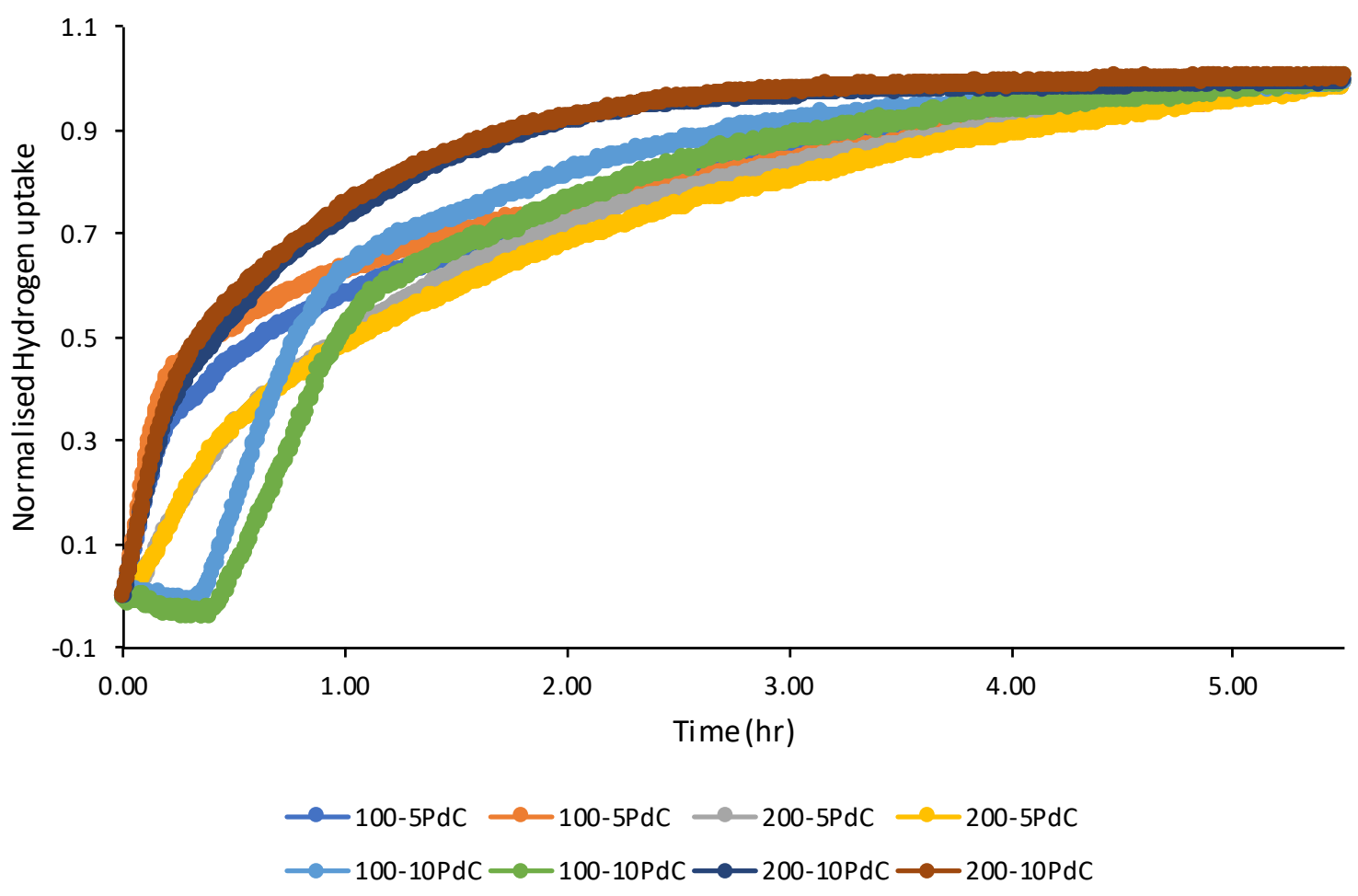

Figure S35 Normalised hydrogen uptake curves for Table S19. 
Nitro reduction of methyl 4-nitrobenzoate (11)

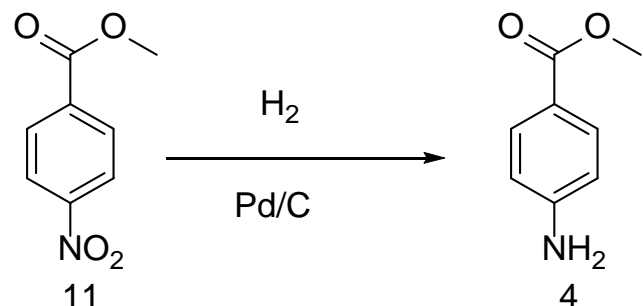

Scheme S4 Nitro reduction of methyl 4-nitrobenzoate (11).

Catalyst loading studies for nitro reduction of methyl 4-nitrobenzoate (11).

Table S20 Catalyst loading screen for 200-5PdC of nitro reduction methyl 4-nitrobenzoate (11).

\begin{tabular}{ccccc}
\hline $\begin{array}{c}\text { Endeavor } \\
\text { Vessel }\end{array}$ & Catalyst & $\begin{array}{c}\text { Catalyst } \\
\text { Loading mg }\end{array}$ & Solvent & $\begin{array}{c}\text { 4 GC } \\
\text { Area \% }\end{array}$ \\
\hline 1 & $200-5 P d C$ & 5.0 & Tetrahydrofuran & 86.9 \\
2 & $200-5 P d C$ & 10.0 & Tetrahydrofuran & 96.3 \\
3 & $200-5 P d C$ & 15.0 & Tetrahydrofuran & 91.5 \\
4 & $200-5 P d C$ & 20.0 & Tetrahydrofuran & 97.4 \\
5 & $200-5 P d C$ & 25.0 & Tetrahydrofuran & 98.3 \\
6 & $200-5 P d C$ & 30.0 & Tetrahydrofuran & 98.6 \\
7 & $200-5 P d C$ & 40.0 & Tetrahydrofuran & 98.5 \\
8 & $200-5 P d C$ & 50.0 & Tetrahydrofuran & 99.7 \\
\hline
\end{tabular}

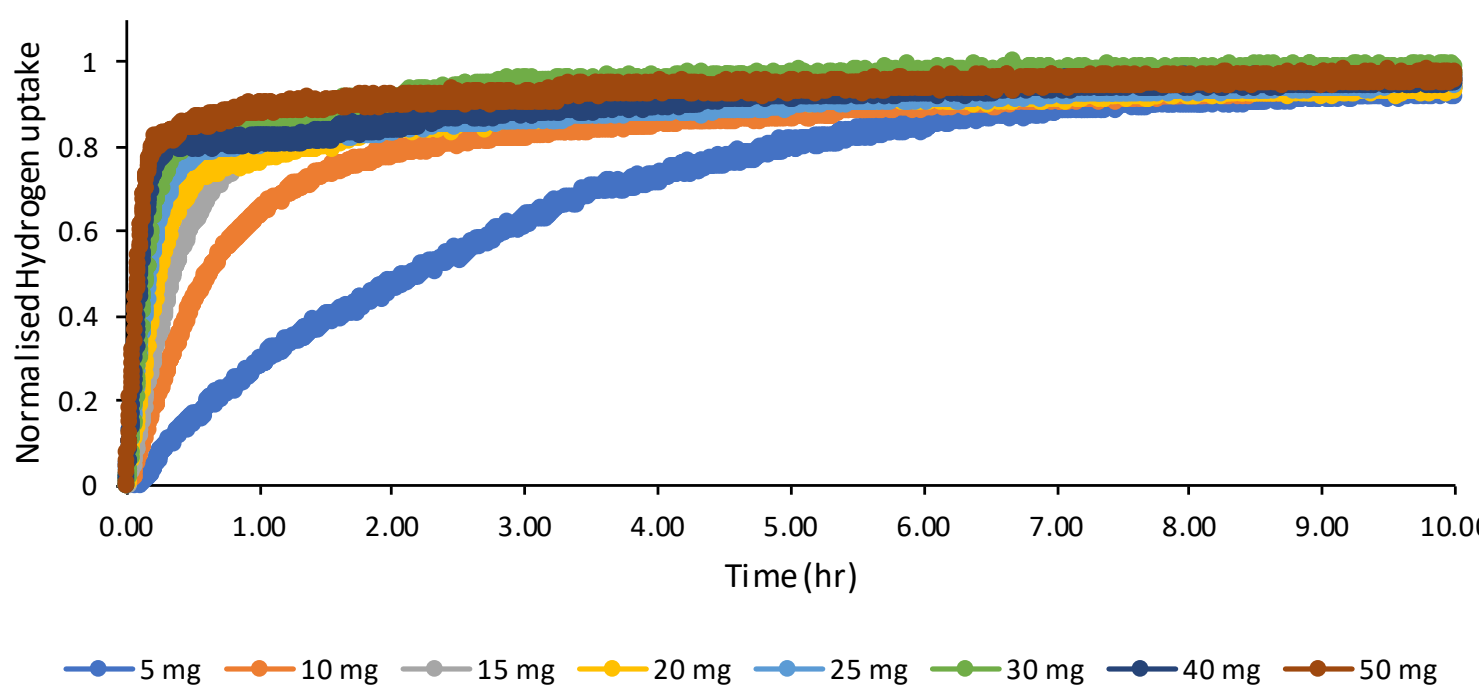

Figure S36 Normalised hydrogen uptake curves for Table S20. 
Solvent screening for 200-5PdC of nitro reduction of 4-nitrobenzoate (11).

Table S21 Solvent screen (1) for the nitro reduction of 4-nitrobenzoate (11) with 200-5PdC.

\begin{tabular}{ccccc}
\hline $\begin{array}{c}\text { Endeavor } \\
\text { Vessel }\end{array}$ & Catalyst & $\begin{array}{c}\text { Catalyst } \\
\text { Loading } \mathbf{~ m g}\end{array}$ & Solvent & $\begin{array}{c}\text { 4 GC } \\
\text { Area \% }\end{array}$ \\
\hline 1 & $200-5 P d C$ & 25.0 & Methanol & 100 \\
2 & $200-5 P d C$ & 25.4 & Methanol & 96.8 \\
3 & $200-5 P d C$ & N/A & Ethanol & N/A \\
4 & $200-5 P d C$ & N/A & Ethanol & N/A \\
5 & $200-5 P d C$ & 25.5 & Ethyl acetate & 99.8 \\
6 & $200-5 P d C$ & 25.6 & Ethyl acetate & 99.3 \\
7 & $200-5 P d C$ & 25.1 & Tetrahydrofuran & 98.8 \\
8 & $200-5 P d C$ & 25.1 & Tetrahydrofuran & 99.2 \\
\hline
\end{tabular}

4-Nitrobenzoate ( $\mathbf{9}$ ) poor solublty in ethanol



Figure S37 Normalised hydrogen uptake curves for Table S21. 
Table S22 Solvent screen (2) for the nitro reduction of 4-nitrobenzoate (11) with 200-5PdC.

\begin{tabular}{ccccc}
\hline $\begin{array}{c}\text { Endeavor } \\
\text { Vessel }\end{array}$ & Catalyst & $\begin{array}{c}\text { Catalyst } \\
\text { Loading mg }\end{array}$ & Solvent & $\begin{array}{l}\text { 4 GC } \\
\text { Area } \\
\mathbf{\%}\end{array}$ \\
\hline 5 & $200-5 \mathrm{PdC}$ & 25.9 & Toluene & 98.3 \\
6 & $200-5 \mathrm{PdC}$ & 25.5 & Toluene & 98.2 \\
1 & $200-5 \mathrm{PdC}$ & 25.2 & 2-Methyl Tetrahydrofuran & 97.8 \\
2 & $200-5 \mathrm{PdC}$ & 25.4 & 2-Methyl Tetrahydrofuran & 98.0 \\
3 & $200-5 \mathrm{PdC}$ & 25.2 & Acetic acid & 99.7 \\
4 & $200-5 \mathrm{PdC}$ & 25.1 & Acetic acid & 99.7 \\
7 & $200-5 \mathrm{PdC}$ & 25.0 & Acetic acid:methanol 1:1 & 96.8 \\
8 & $200-5 \mathrm{PdC}$ & 25.6 & Acetic acid:methanol 1:1 & 95.9 \\
\hline
\end{tabular}

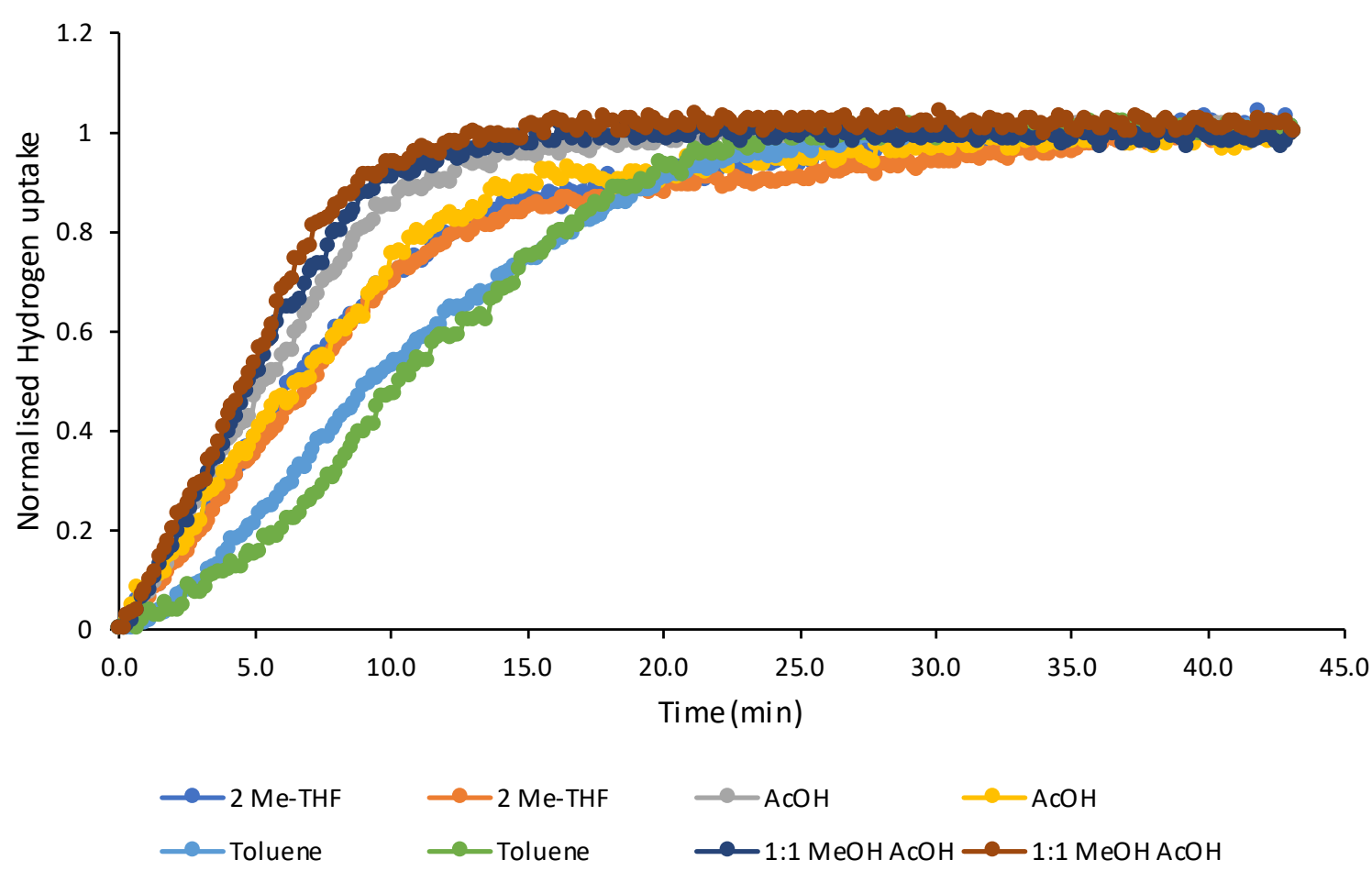

Figure S38 Normalised hydrogen uptake curves for Table S22. 
Head to head comparison of Blücher GmbH catalyst for the nitro reduction of 4nitrobenzoate (11).

Table S23 Head to head comparison of Blücher GmbH catalysts for the nitro reduction 4nitrobenzoate (11). Conditions: $4 \mathrm{~mL}$ solution volume, $50^{\circ} \mathrm{C}$, $8 \mathrm{Bar}, 700 \mathrm{rpm}$ run in duplicate.

\begin{tabular}{ccclc}
\hline $\begin{array}{c}\text { Endeavor } \\
\text { Vessel }\end{array}$ & Catalyst & $\begin{array}{c}\text { Catalyst } \\
\text { Loading } \\
\text { mg }\end{array}$ & Solvent & $\begin{array}{c}\text { 4 HPLC } \\
\text { Area \% }\end{array}$ \\
\hline 3 & $100-5 \mathrm{PdC}$ & 5.1 & Methanol & 89.8 \\
4 & $100-5 \mathrm{PdC}$ & 4.9 & Methanol & 82.5 \\
1 & $200-5 \mathrm{PdC}$ & 4.9 & Methanol & 95.1 \\
2 & $200-5 \mathrm{PdC}$ & 5.2 & Methanol & 93.9 \\
7 & $100-10 \mathrm{PdC}$ & 5.1 & Methanol & 96.6 \\
8 & $100-10 \mathrm{PdC}$ & 4.8 & Methanol & 89.7 \\
5 & $200-10 \mathrm{PdC}$ & 5.1 & Methanol & 80.8 \\
6 & $200-10 \mathrm{PdC}$ & 4.8 & Methanol & 87.3 \\
\hline
\end{tabular}

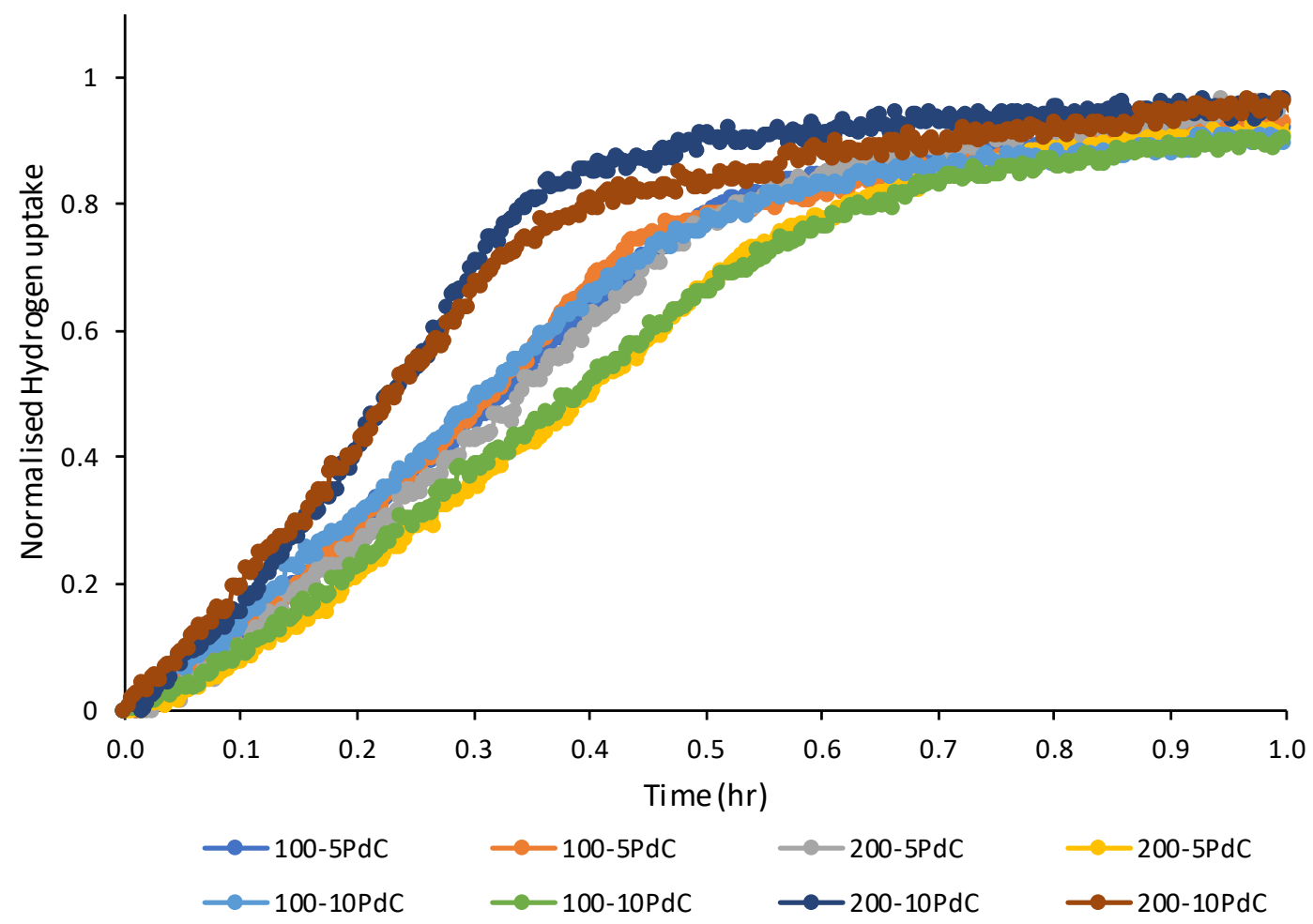

Figure S39 Normalised hydrogen uptake curves for Table S23. 
Deprotection: $N$-debenzylation of $N$-benzyl-4-methoxyaniline (7)

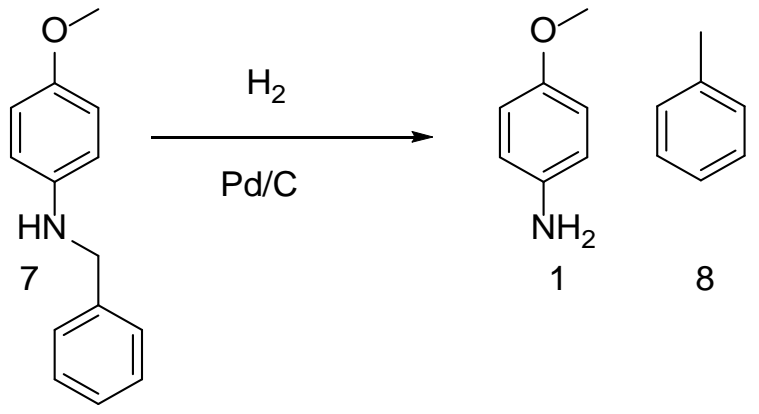

Scheme S5 $N$-Debenzylation of $N$-benzyl-4-methoxyaniline (7). 
Catalyst loading studies for $N$-debenzylation of $N$-benzyl-4-methoxyaniline (7).

Table S24 Catalyst loading screen for 200-5PdC for $N$-debenzylation of $N$-benzyl-4methoxyaniline (7). Conditions: $4 \mathrm{~mL}$ solution volume, $50{ }^{\circ} \mathrm{C}$, $8 \mathrm{Bar}, 700 \mathrm{rpm}$.

\begin{tabular}{ccccccc}
\hline $\begin{array}{c}\text { Endeavor } \\
\text { Vessel }\end{array}$ & Catalyst & $\begin{array}{c}\text { Catalyst } \\
\text { Loading } \\
\text { mg }\end{array}$ & Solvent & $\begin{array}{c}\mathbf{7} \\
\text { HPLC } \\
\text { Area } \\
\text { \% }\end{array}$ & $\begin{array}{c}\text { 1 HPLC } \\
\text { Area \% }\end{array}$ & $\begin{array}{c}\mathbf{8} \\
\text { HPLC } \\
\text { Area } \\
\text { \% }\end{array}$ \\
\hline 3 & $200-5 P d C$ & 0.8 & Ethyl acetate & 47.1 & 40.1 & 12.8 \\
4 & $200-5 P d C$ & 2.8 & Ethyl acetate & 17.3 & 66.6 & 16.1 \\
1 & $200-5 P d C$ & 5.0 & Ethyl acetate & 0.0 & 81.1 & 18.9 \\
2 & $200-5 P d C$ & 10.5 & Ethyl acetate & 0.0 & 79.9 & 20.1 \\
5 & $200-5 P d C$ & 14.8 & Ethyl acetate & 0.0 & 80.4 & 19.6 \\
6 & $200-5 P d C$ & 19.7 & Ethyl acetate & 0.0 & 77.5 & 20.6 \\
7 & $200-5 P d C$ & 24.8 & Ethyl acetate & 47.1 & 77.6 & 12.8 \\
8 & $200-5 P d C$ & 30.1 & Ethyl acetate & 17.3 & 77.7 & 16.1 \\
\hline
\end{tabular}

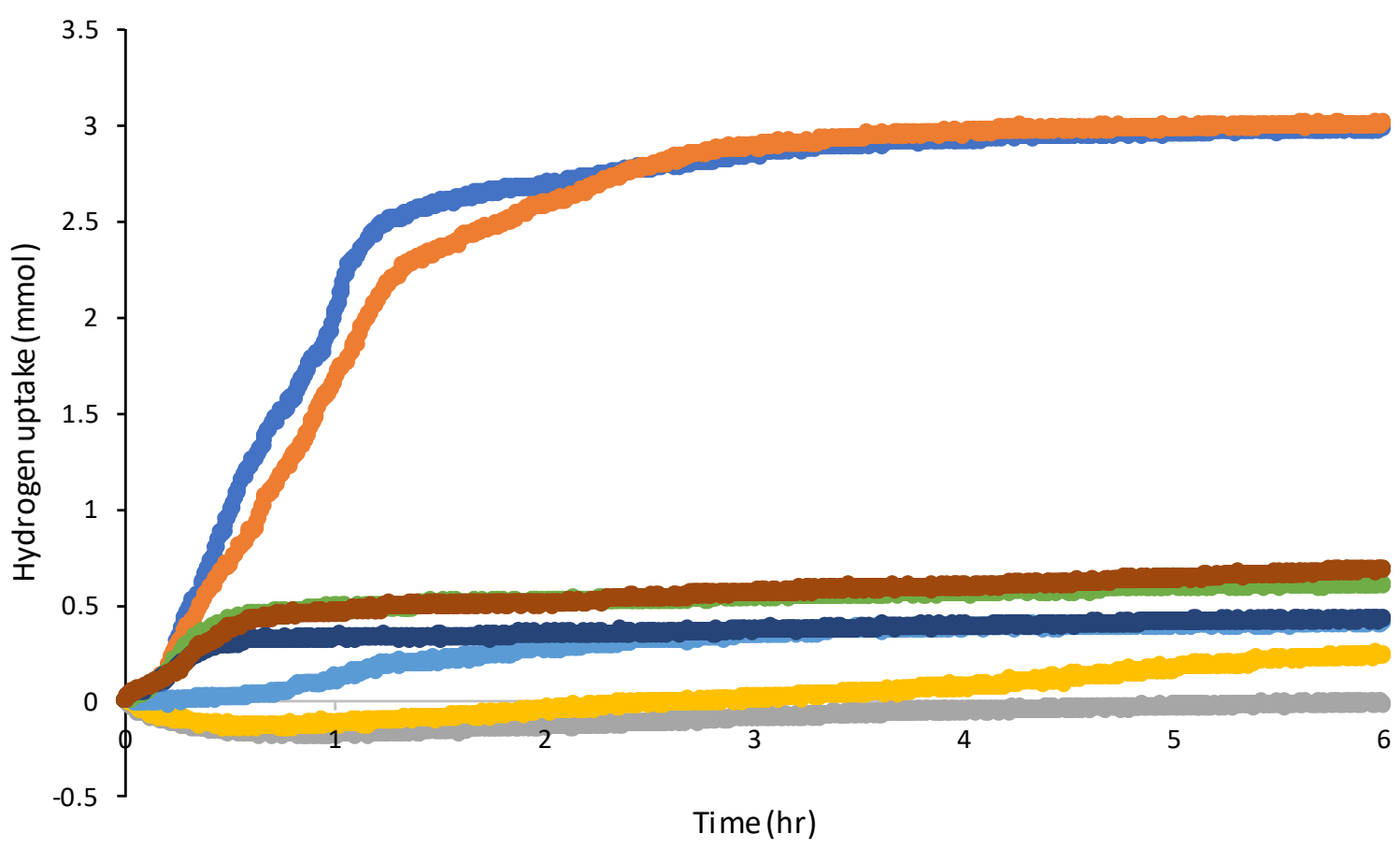

$$
\begin{aligned}
& \longrightarrow 5 \mathrm{mg}(\mathrm{v} 1) \longrightarrow 10 \mathrm{mg}(\mathrm{v} 2) \longrightarrow 1 \mathrm{mg}(\mathrm{v} 3) \longrightarrow 3 \mathrm{mg}(\mathrm{v} 4) \\
& -15 \mathrm{mg}(\mathrm{v} 5) \longrightarrow-20 \mathrm{mg}(\mathrm{v} 6) \longrightarrow 25 \mathrm{mg}(\mathrm{v} 7) \longrightarrow-30 \mathrm{mg}(\mathrm{v} 8)
\end{aligned}
$$

Figure S40 Non-normalised hydrogen uptake curves for Table S24. 
Solvent screening for 200-5PdC for $N$-debenzylation of $N$-benzyl-4-methoxyaniline (7).

Table S25 Solvent screen for $N$-debenzylation of $N$-benzyl-4-methoxyaniline (7) with 2005PdC. Conditions: $4 \mathrm{~mL}$ solution volume, $50^{\circ} \mathrm{C}$, $8 \mathrm{Bar}, 700 \mathrm{rpm}$.

\begin{tabular}{ccccccc}
\hline $\begin{array}{c}\text { Endeavor } \\
\text { Vessel }\end{array}$ & Catalyst & $\begin{array}{c}\text { Catalyst } \\
\text { Loading } \\
\mathbf{m g}\end{array}$ & Solvent & $\begin{array}{c}\mathbf{7} \\
\text { HPLC } \\
\text { Area } \\
\mathbf{\%}\end{array}$ & $\begin{array}{c}\mathbf{1} \\
\text { HPLC } \\
\text { Area } \\
\mathbf{\%}\end{array}$ & $\begin{array}{c}\mathbf{8} \\
\text { HPLC } \\
\text { Area } \\
\mathbf{\%}\end{array}$ \\
\hline 1 & $200-5 \mathrm{PdC}$ & 5.2 & Methanol & 0.0 & 82.8 & 17.2 \\
2 & $200-5 \mathrm{PdC}$ & 4.7 & $\begin{array}{c}\text { Ethanol } \\
0.0\end{array}$ & 80.3 & 19.0 \\
3 & $200-5 \mathrm{PdC}$ & 5.0 & Tetrahydrofuran & 2.1 & 77.5 & 19.5 \\
4 & $200-5 \mathrm{PdC}$ & 5.0 & $\begin{array}{c}\text { 2-Methyl } \\
\text { tetrahydrofuran }\end{array}$ & 4.1 & 74.5 & 20.4 \\
& & & Ethyl acetate & 0.0 & 80.3 & 19.7 \\
5 & $200-5 \mathrm{PdC}$ & 5.1 & Toluene & 0.5 & 9.8 & 89.5 \\
7 & $200-5 \mathrm{PdC}$ & 5.1 & Acetic Acid & 5.9 & 72.0 & 19.5 \\
8 & $200-5 \mathrm{PdC}$ & 4.9 & MeOH:AcOH 1:1 & 0.0 & 73.0 & 20.2 \\
\hline
\end{tabular}

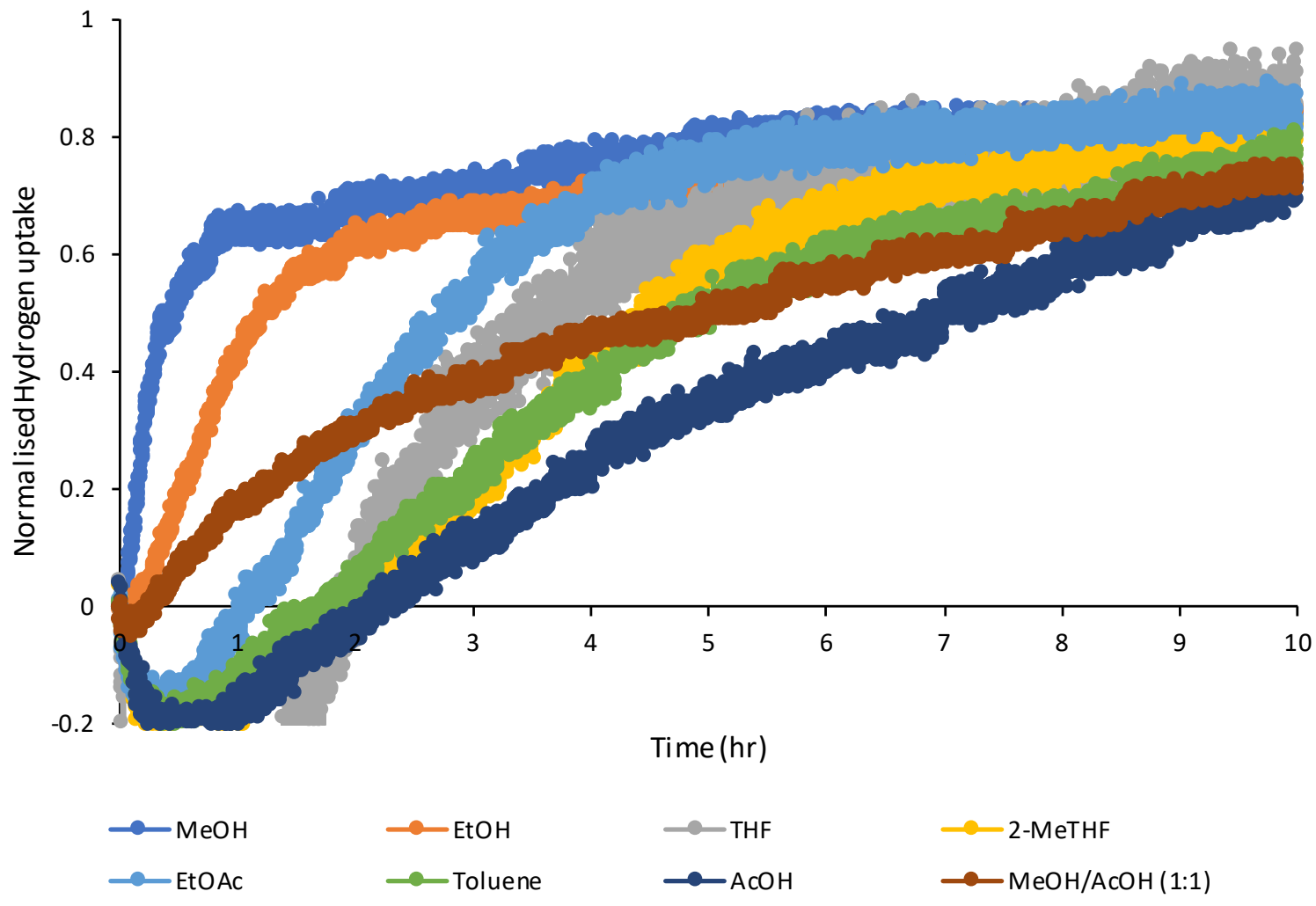

Figure S41 Normalised hydrogen uptake curves for Table S25. 
Head to head comparison of Blücher GmbH catalyst for $N$-debenzylation of $N$-benzyl-4methoxyaniline (7)

Table S26 Head to head comparison of Blücher GmbH catalysts for $N$-debenzylation of $N$ benzyl-4-methoxyaniline (7). Conditions: $4 \mathrm{~mL}$ solution volume, $50{ }^{\circ} \mathrm{C}$, $8 \mathrm{Bar}, 700 \mathrm{rpm}$ run in duplicate.

\begin{tabular}{|c|c|c|c|c|c|c|}
\hline $\begin{array}{c}\text { Endeavor } \\
\text { Vessel }\end{array}$ & Catalyst & $\begin{array}{c}\text { Catalyst } \\
\text { Loading } \\
\text { mg }\end{array}$ & Solvent & $\begin{array}{c}7 \\
\text { HPLC } \\
\text { Area } \\
\%\end{array}$ & $\begin{array}{c}4 \\
\text { HPLC } \\
\text { Area } \\
\%\end{array}$ & $\begin{array}{c}8 \\
\text { HPLC } \\
\text { Area } \\
\%\end{array}$ \\
\hline 1 & $100-5 \mathrm{PdC}$ & 4.9 & Methanol & 18.4 & 81.6 & 0 \\
\hline 2 & $100-5 \mathrm{PdC}$ & 5.0 & Methanol & 19.1 & 80.9 & 0 \\
\hline 3 & 200-5PdC & 5.2 & Methanol & 19.2 & 80.8 & 0 \\
\hline 4 & 200-5PdC & 4.9 & Methanol & 19.9 & 80.1 & 0 \\
\hline 5 & $\begin{array}{c}\text { 100- } \\
\text { 10PdC }\end{array}$ & 5.1 & Methanol & 18.4 & 80.5 & 0 \\
\hline 6 & $\begin{array}{c}100- \\
10 \mathrm{PdC}\end{array}$ & 4.8 & Methanol & 32.1 & 67.0 & 0 \\
\hline 7 & $\begin{array}{c}200- \\
10 P d C\end{array}$ & 4.9 & Methanol & 18.7 & 80.1 & 0 \\
\hline 8 & $\begin{array}{l}200- \\
10 \mathrm{PdC}\end{array}$ & 5.0 & Methanol & 18.4 & 79.7 & 0 \\
\hline
\end{tabular}

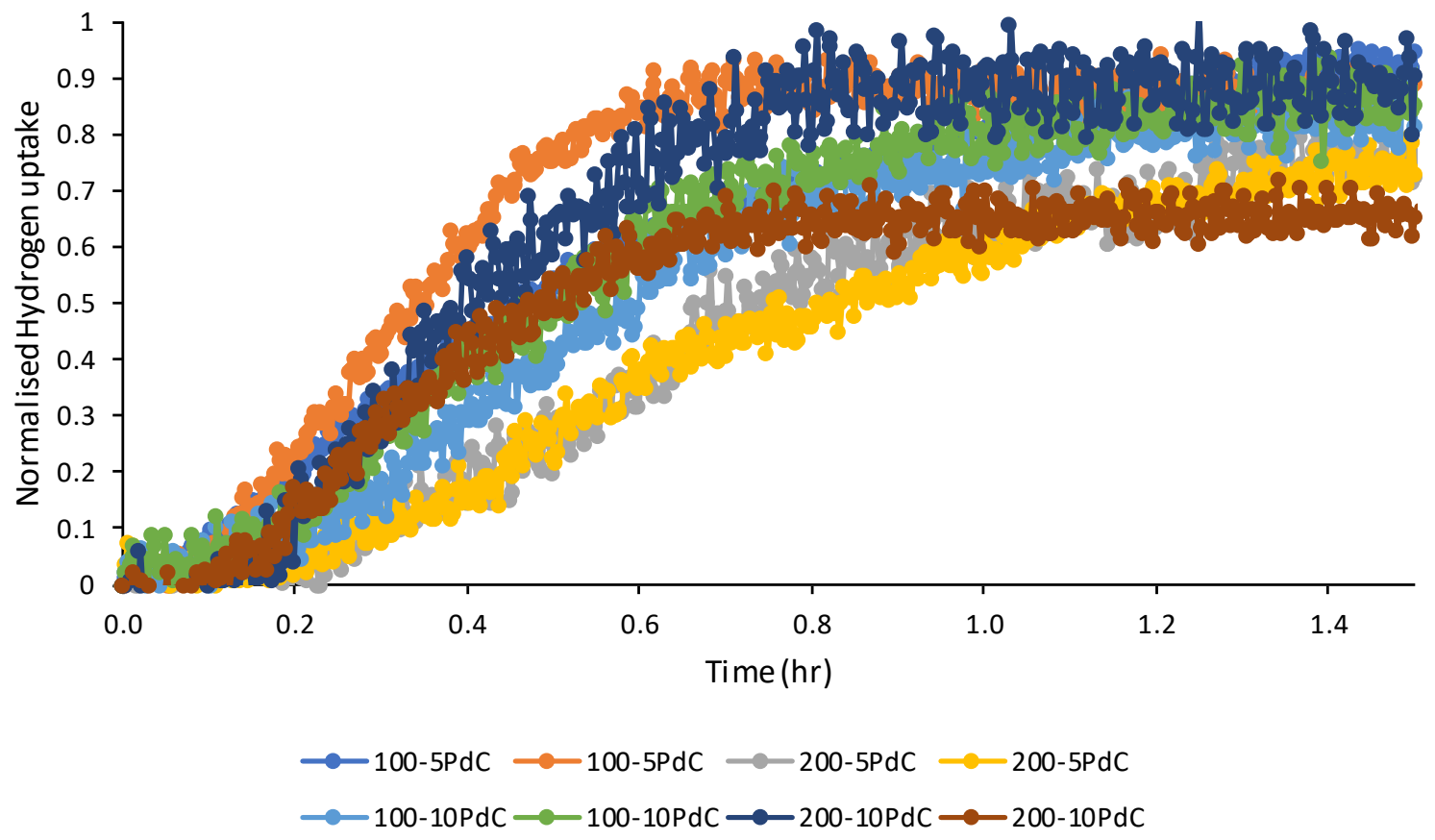

Figure S42 Normalised hydrogen uptake curves for Table S23. 
Deprotection: $N$-debenzylation of methyl 4-(benzylamino)benzoate (12).

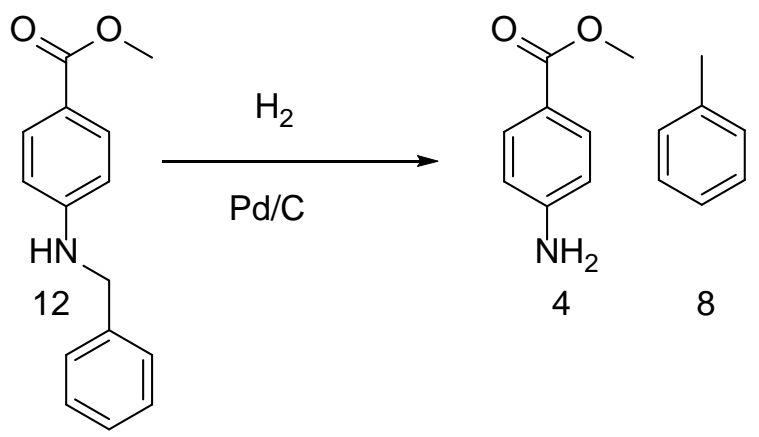

Scheme S6 $N$-Debenzylation of methyl 4-(benzylamino)benzoate (12). 
Catalyst loading studies for $N$-debenzylation of methyl 4-(benzylamino)benzoate (12).

Table S27 Catalyst loading screen for 200-5PdC for $N$-debenzylation of methyl 4(benzylamino)benzoate (12). Conditions: $4 \mathrm{~mL}$ solution volume, $50{ }^{\circ} \mathrm{C}$, 8 Bar, $700 \mathrm{rpm}$.

\begin{tabular}{ccccccc}
\hline $\begin{array}{c}\text { Endeavor } \\
\text { Vessel }\end{array}$ & Catalyst & $\begin{array}{c}\text { Catalyst } \\
\text { Loading } \\
\text { mg }\end{array}$ & Solvent & $\begin{array}{c}\mathbf{1 2} \\
\text { HPLC } \\
\text { Area } \\
\text { \% }\end{array}$ & $\begin{array}{c}\text { 4 HPLC } \\
\text { Area \% }\end{array}$ & $\begin{array}{c}\mathbf{8} \\
\text { HPLC } \\
\text { Area } \\
\text { \% }\end{array}$ \\
\hline 1 & $200-5 P d C$ & 2.7 & Ethyl acetate & 53.4 & 40.5 & 5.6 \\
2 & $200-5 P d C$ & 5.2 & Ethyl acetate & 63.2 & 31.2 & 4.8 \\
3 & $200-5 P d C$ & 10.1 & Ethyl acetate & 0.0 & 87.2 & 12.2 \\
4 & $200-5 P d C$ & 15.3 & Ethyl acetate & 0.0 & 83.4 & 12.7 \\
5 & $200-5 P d C$ & 19.7 & Ethyl acetate & 0.0 & 81.4 & 12.1 \\
6 & $200-5 P d C$ & 25.1 & Ethyl acetate & 0.0 & 80.3 & 12.4 \\
7 & $200-5 P d C$ & 29.8 & Ethyl acetate & 0.0 & 78.1 & 12.6 \\
8 & $200-5 P d C$ & 39.9 & Ethyl acetate & 0.6 & 81.1 & 11.8 \\
\hline
\end{tabular}

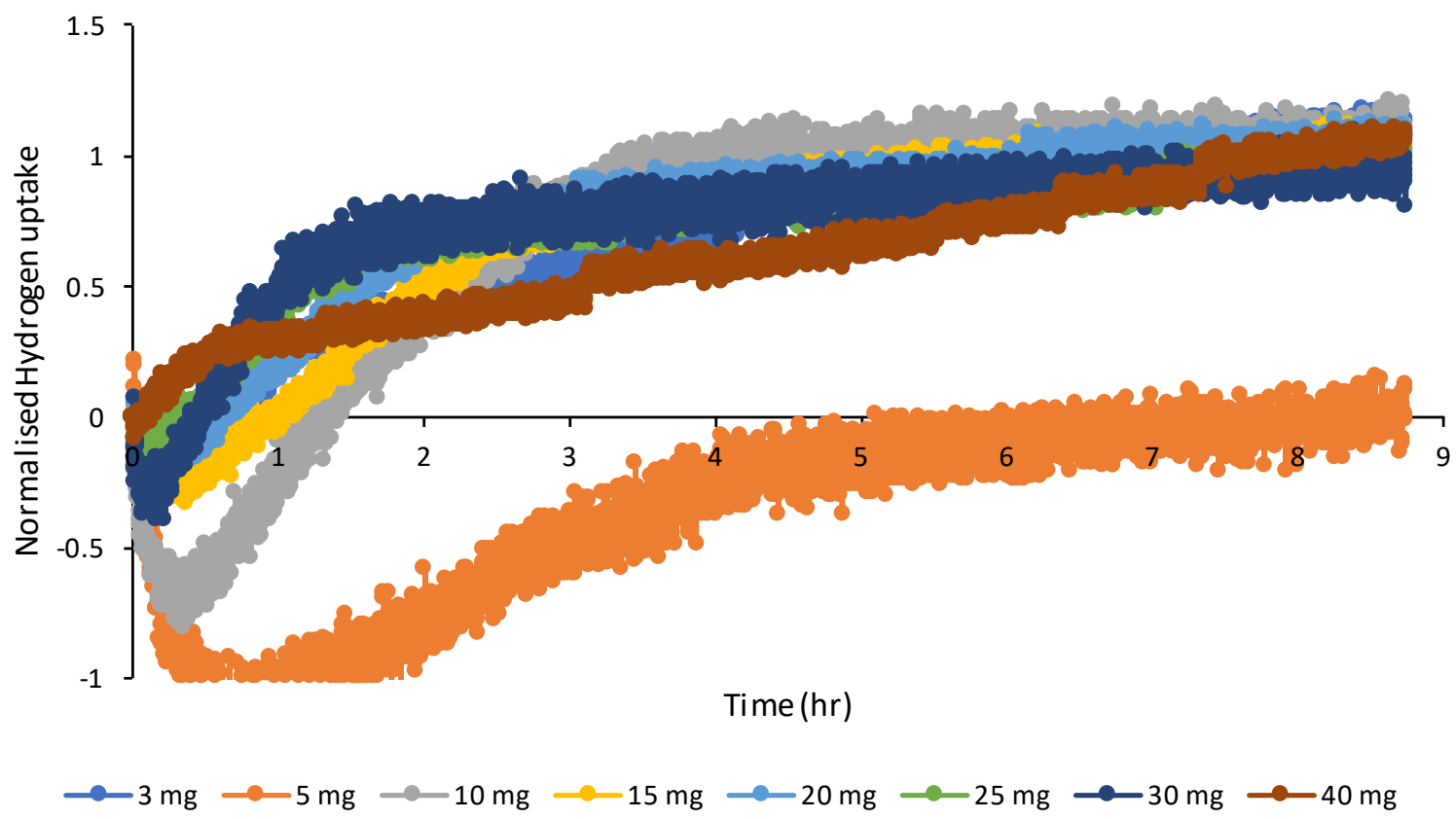

Figure S43 Normalised hydrogen uptake curves for Table S27. 
Solvent screening for 200-5PdC for $N$-debenzylation of methyl 4-(benzylamino)benzoate (12).

Table S28 Solvent screen for $N$-debenzylation of deprotection of methyl 4(benzylamino)benzoate (12) with 200-5PdC. Conditions: $4 \mathrm{~mL}$ solution volume, $50{ }^{\circ} \mathrm{C}, 8$ Bar, 700 rpm.

\begin{tabular}{|c|c|c|c|c|c|c|}
\hline $\begin{array}{c}\text { Endeavor } \\
\text { Vessel }\end{array}$ & Catalyst & $\begin{array}{c}\text { Catalyst } \\
\text { Loading } \\
\text { mg }\end{array}$ & Solvent & $\begin{array}{c}12 \\
\text { HPLC } \\
\text { Area } \\
\%\end{array}$ & $\begin{array}{c}4 \\
\text { HPLC } \\
\text { Area } \\
\%\end{array}$ & $\begin{array}{c}8 \\
\text { HPLC } \\
\text { Area } \\
\%\end{array}$ \\
\hline 1 & 200-5PdC & 15.2 & Ethyl acetate & 0.0 & 88.3 & 11.7 \\
\hline 2 & 200-5PdC & 15.0 & Ethyl acetate & 0.0 & 87.0 & 13.0 \\
\hline 3 & 200-5PdC & 15.0 & Tetrahydrofuran & 0.0 & 87.4 & 11.9 \\
\hline 4 & 200-5PdC & 14.7 & Tetrahydrofuran & 0.0 & 86.6 & 12.7 \\
\hline 5 & 200-5PdC & 14.9 & $\begin{array}{l}\text { 2-Methyl } \\
\text { tetrahydrofuran }\end{array}$ & 0.0 & 86.7 & 12.8 \\
\hline 6 & 200-5PdC & 15.1 & $\begin{array}{l}\text { 2-Methyl } \\
\text { tetrahydrofuran }\end{array}$ & 0.0 & 87.2 & 12.2 \\
\hline
\end{tabular}

Methyl 4-(benzylamino)benzoate (12) poor solubility in methanol, ethanol, acetic acid and toluene.



Figure S44 Normalised hydrogen uptake curves for Table S28. 
Head to head comparison of Blücher GmbH catalyst for $N$-debenzylation of methyl 4(benzylamino)benzoate (12).

Table S29 Head to head comparison of Blücher GmbH catalysts for $N$-debenzylation of methyl 4-(benzylamino)benzoate (12). Conditions: $4 \mathrm{~mL}$ solution volume, $50{ }^{\circ} \mathrm{C}$, 8 Bar, 700 rpm run in duplicate.

\begin{tabular}{|c|c|c|c|c|c|c|}
\hline $\begin{array}{c}\text { Endeavor } \\
\text { Vessel }\end{array}$ & Catalyst & $\begin{array}{c}\text { Catalyst } \\
\text { Loading } \\
\text { mg }\end{array}$ & Solvent & $\begin{array}{c}12 \\
\text { HPLC } \\
\text { Area } \\
\%\end{array}$ & $\begin{array}{c}4 \\
\text { HPLC } \\
\text { Area } \\
\%\end{array}$ & $\begin{array}{c}8 \\
\text { HPLC } \\
\text { Area } \\
\%\end{array}$ \\
\hline 1 & 100-5PdC & 14.7 & Ethyl acetate & 12.0 & 88.0 & 0 \\
\hline 2 & 100-5PdC & 15.0 & Ethyl acetate & 12.6 & 87.4 & 0 \\
\hline 3 & 200-5PdC & 15.1 & Ethyl acetate & 12.4 & 87.6 & 0 \\
\hline 4 & 200-5PdC & 14.7 & Ethyl acetate & 12.7 & 87.3 & 0 \\
\hline 7 & $\begin{array}{l}\text { 100- } \\
\text { 10PdC }\end{array}$ & 15.0 & Ethyl acetate & 13.2 & 86.8 & 0 \\
\hline 8 & $\begin{array}{c}100- \\
10 \mathrm{PdC}\end{array}$ & 14.8 & Ethyl acetate & 12.7 & 87.3 & 0 \\
\hline 5 & $\begin{array}{l}200- \\
10 \mathrm{PdC}\end{array}$ & 15.0 & Ethyl acetate & 12.0 & 88.0 & 0 \\
\hline 6 & $\begin{array}{c}200- \\
10 \mathrm{PdC}\end{array}$ & 14.7 & Ethyl acetate & 11.7 & 88.3 & 0 \\
\hline
\end{tabular}

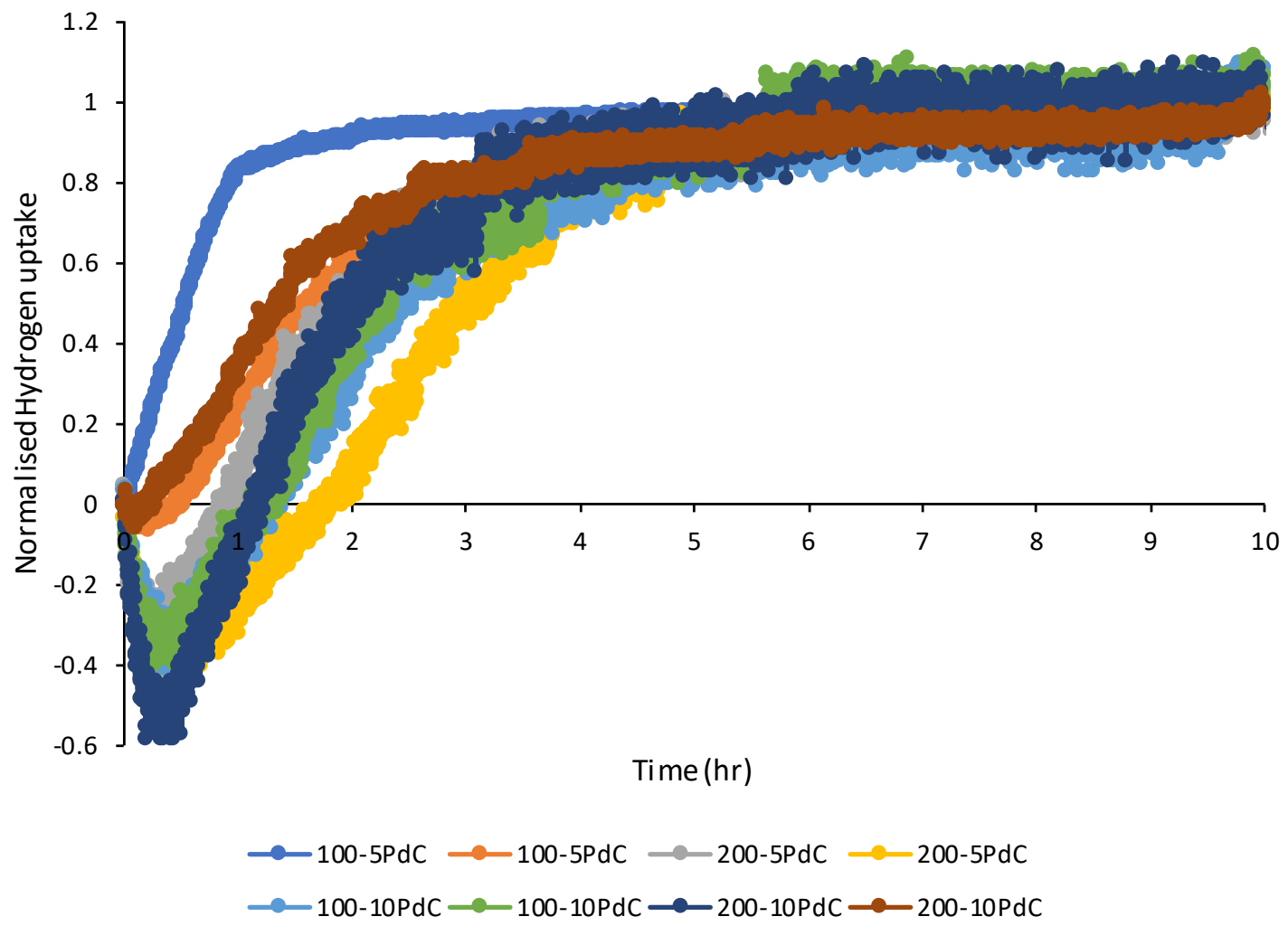

Figure S45 Normalised hydrogen uptake curves for Table S29. 
Deprotection: $N$-debenzylation of $N$-benzylaniline (13).

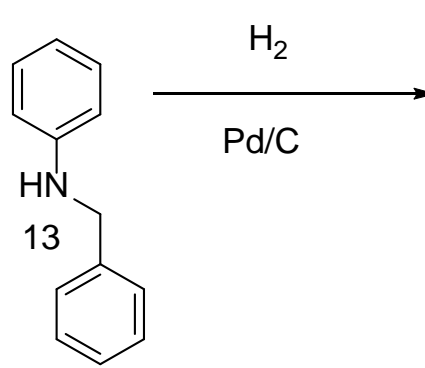<smiles>Cc1ccccc1</smiles>

Scheme S7 $N$-Debenzylation of $N$-benzylaniline (13). 
Head to head comparison of Blücher GmbH catalyst for $N$-debenzylation of $N$-benzylaniline (13).

Table S30 Head to head comparison of Blücher GmbH catalyst for N-debenzylation of $\mathrm{N}$ benzylaniline (13). Conditions: $3 \mathrm{~mL}$ solution volume, $50^{\circ} \mathrm{C}$, $10 \mathrm{Bar}, 500 \mathrm{rpm}$.

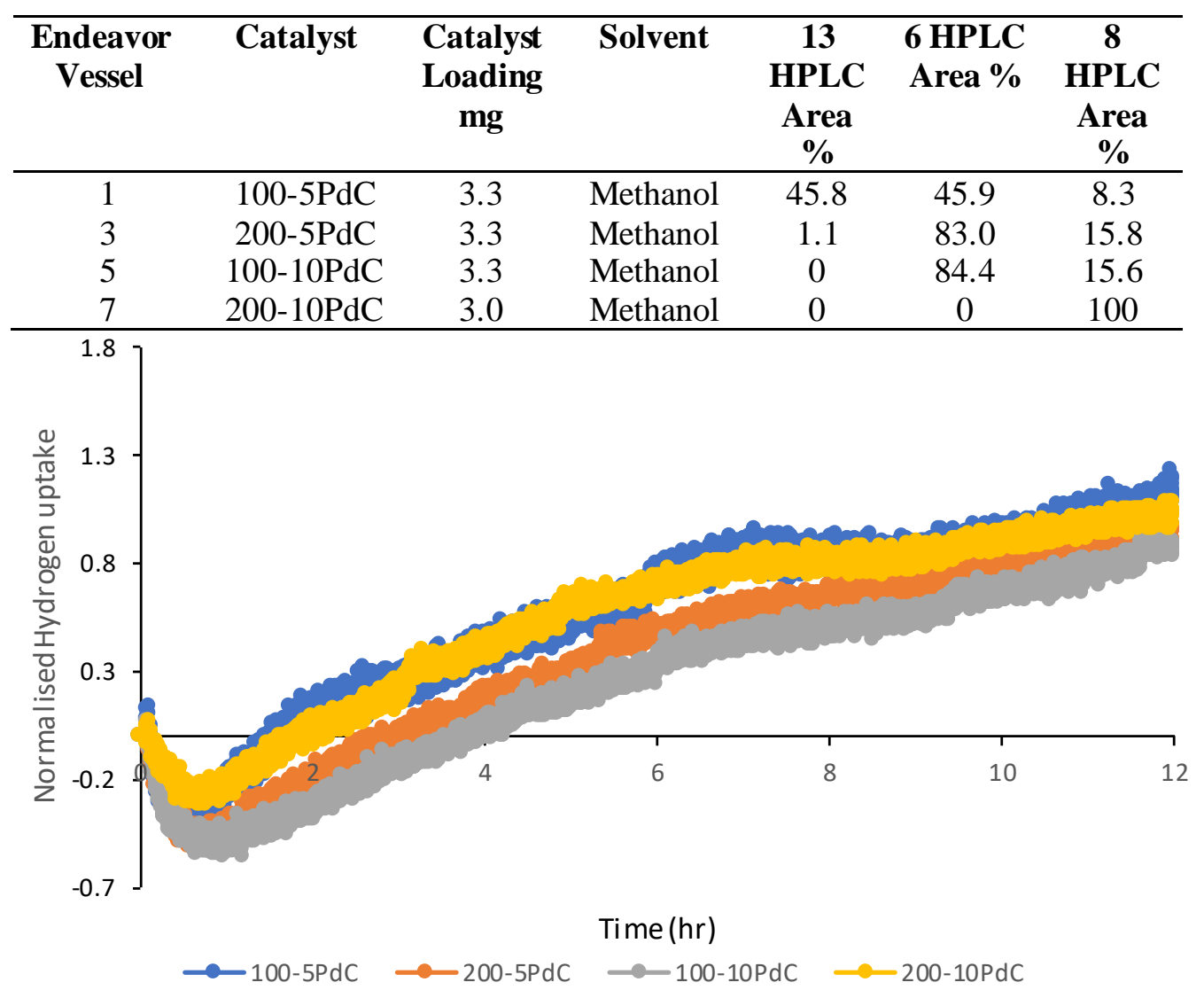

Figure S46 Normalised hydrogen uptake curves for Table S30. 


\section{Continuous hydrogenation}

H-Cube column (30 x 3 mm CatCart) was packed with catalyst, then the CatCart was loaded into Modified ThalesNano H-Cube.

The columns were preconditioned $1 \mathrm{mg} / \mathrm{min}$ hydrogen and $1 \mathrm{~mL} / \mathrm{min}$ solvent at the reaction pressure and room temperature for 10 minutes, unless otherwise stated.

Continuous nitro reduction of 1-methoxy-4-nitrobenzene (5)

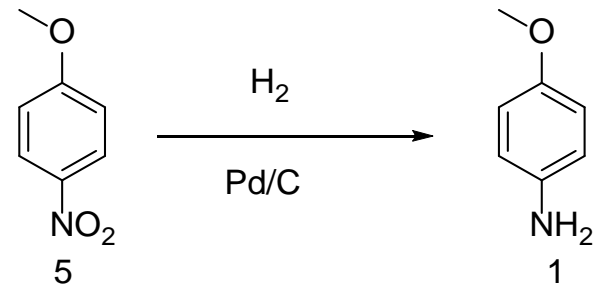

Scheme S8 Continuous nitro reduction of 1-methoxy-4-nitrobenzene (5)

$173 \mathrm{mg}$ 200-5PdC, CatCart was washed with methanol $1 \mathrm{~mL} / \mathrm{min}$, at 21 Bar (hydrogen, 1 $\mathrm{mg} / \mathrm{ml}), 21{ }^{\circ} \mathrm{C}$ for 10 minutes. 1-Methoxy-4-nitrobenzene $(5,15.46 \mathrm{~g})$ in methanol (597 ml) to give a solution $(0.169 \mathrm{M})$. The mixture was pumped through the CatCart at $1 \mathrm{~mL} / \mathrm{min}$, at 21 Bar (3.5 eq hydrogen, $1.18 \mathrm{mg} / \mathrm{ml}), 21^{\circ} \mathrm{C}$, sampled every 10 minutes for HPLC (20 $\mu \mathrm{l}$ in $1 \mathrm{ml}$ methanol).



Figure S47 HPLC trend of $173 \mathrm{mg}$ 200-5PdC processing 0.169 M 1-methoxy-4-nitrobenzene over $20 \mathrm{~min}$, at $21 \mathrm{Bar}, 21^{\circ} \mathrm{C}, 3.5$ eq $\mathrm{H}_{2}$ and $0.169 \mathrm{M} 1$-methoxy-4-nitrobenzene $1 \mathrm{~mL} / \mathrm{min}$. 
$173 \mathrm{mg}$ 200-5PdC, CatCart was washed with methanol $1 \mathrm{~mL} / \mathrm{min}$, at 20 Bar (hydrogen, 1 $\mathrm{mg} / \mathrm{mL}), 50{ }^{\circ} \mathrm{C}$ for 10 minutes. 1-Methoxy-4-nitrobenzene $(5,19.99 \mathrm{~g})$ in methanol $(800 \mathrm{~mL})$ to give a solution $(0.163 \mathrm{M})$. The mixture was pumped through the CatCart at $1 \mathrm{~mL} / \mathrm{min}$, at 20 Bar (3.5 eq hydrogen, $1.18 \mathrm{mg} / \mathrm{ml}$ ), $50^{\circ} \mathrm{C}$, sampled every 10 minutes for HPLC (20 $\mu \mathrm{l}$ in $1 \mathrm{ml}$ methanol).

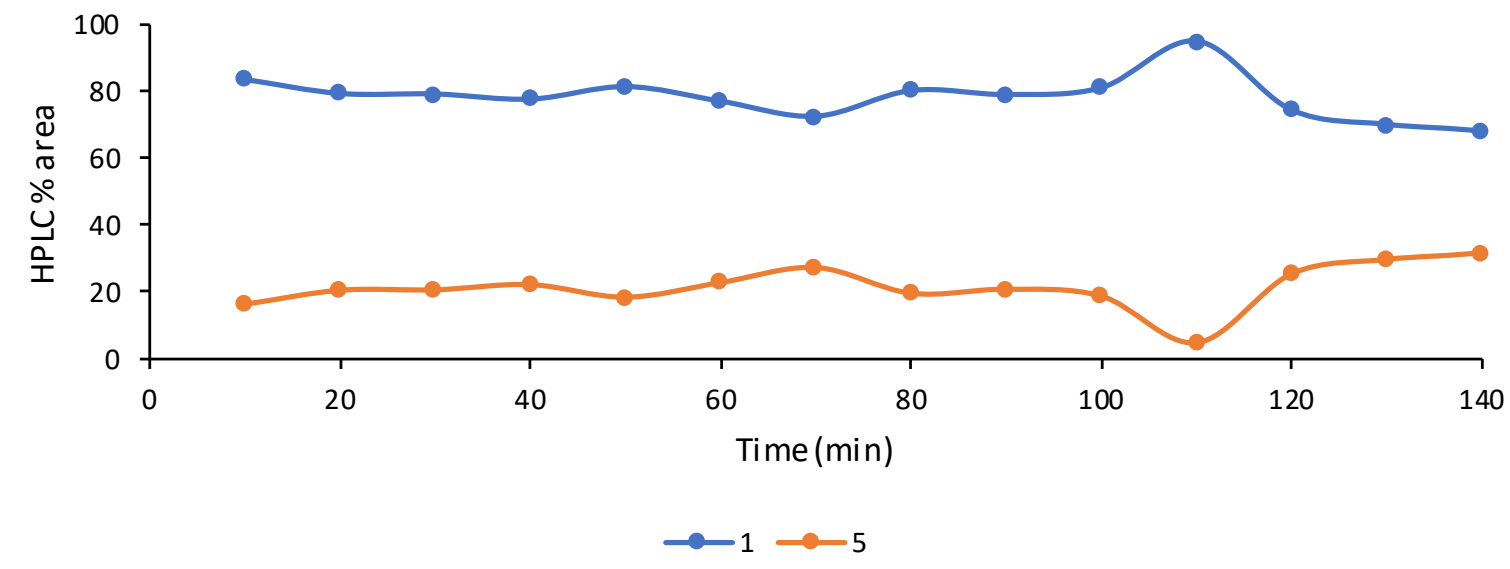

Figure S48 HPLC trend of $173 \mathrm{mg}$ 200-5PdC processing 0.163 M 1-methoxy-4-nitrobenzene over $140 \mathrm{~min}$, at $20 \mathrm{Bar}, 50{ }^{\circ} \mathrm{C}, 3.5$ eq $\mathrm{H}_{2}$ and $0.163 \mathrm{M}$ 1-methoxy-4-nitrobenzene $1 \mathrm{~mL} / \mathrm{min}$.

$178 \mathrm{mg}$ 200-5PdC, CatCart was washed with methanol $1 \mathrm{~mL} / \mathrm{min}$, at 21 Bar (hydrogen, 1 $\mathrm{mg} / \mathrm{mL}), 65^{\circ} \mathrm{C}$ for 10 minutes. 1-Methoxy-4-nitrobenzene $(5,15.46 \mathrm{~g})$ in methanol $(597 \mathrm{~mL})$ to give a solution $(0.169 \mathrm{M})$. The mixture was pumped through the CatCart at $1 \mathrm{~mL} / \mathrm{min}$, at 21 Bar (3.5 eq hydrogen, $1.18 \mathrm{mg} / \mathrm{mL}$ ), $65^{\circ} \mathrm{C}$, sampled every 5 minutes for HPLC (20 $\mu \mathrm{l}$ in $1 \mathrm{~mL}$ methanol). 


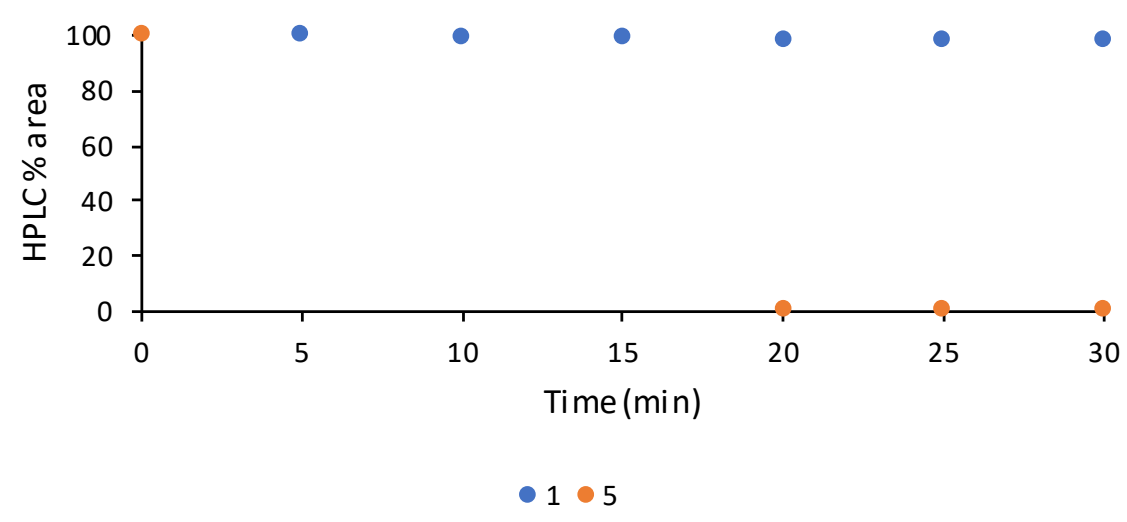

Figure S49 HPLC trend of $178 \mathrm{mg}$ 200-5PdC processing 0.169 M 1-methoxy-4-nitrobenzene over $30 \mathrm{~min}$, at $21 \mathrm{Bar}, 65^{\circ} \mathrm{C}$, 3.5 eq $\mathrm{H}_{2}$ and $0.169 \mathrm{M} 1$-methoxy-4-nitrobenzene $1 \mathrm{~mL} / \mathrm{min}$.

Continuous nitro reduction of 4-nitrobenzonitrile (10)



Scheme S9 Continuous nitro reduction of 4-nitrobenzonitrile (10).

$185 \mathrm{mg}$ 200-5PdC, CatCart was washed with THF $1 \mathrm{~mL} / \mathrm{min}$, at 10 Bar (3.5 eq hydrogen), 50 ${ }^{\circ} \mathrm{C}$ for 10 minutes. 4-nitrobenzonitrile $(1.5 \mathrm{~g})$ in THF $(60 \mathrm{~mL})$ prepared to give a yellow-orange solution $(0.169 \mathrm{M})$. The mixture was pumped through the CatCart at $1 \mathrm{~mL} / \mathrm{min}$, at $10 \mathrm{Bar}$ (3.5 eq hydrogen), $50^{\circ} \mathrm{C}$, sampled at $0,5,10,20$ minutes for HPLC (20 $\mu \mathrm{l}$ in $1 \mathrm{ml}$ methanol), after $20 \mathrm{~min}$ flow rate reduced to $0.5 \mathrm{~mL}$ min, sampled at $30 \mathrm{~min}$. 




Figure S50 HPLC trend of $185 \mathrm{mg}$ 200-5PdC processing 0.169 M 4-nitrobenzonitrile over 30 min, at $10 \mathrm{Bar}, 50^{\circ} \mathrm{C}, 3.5$ eq $\mathrm{H} 2$ and $0.169 \mathrm{M} 4$-nitrobenzonitrile 1 and $0.5 \mathrm{~mL} / \mathrm{min}$.

$185 \mathrm{mg}$ 200-5PdC, CatCart was washed with THF $0.5 \mathrm{~mL} / \mathrm{min}$, at 10.8 Bar (3.5 eq hydrogen), $50{ }^{\circ} \mathrm{C}$ for 10 minutes. 4-nitrobenzonitrile $(1.5 \mathrm{~g})$ in THF $(60 \mathrm{~mL})$ prepared to give a yelloworange solution $(0.169 \mathrm{M})$. The mixture was pumped through the CatCart at $0.5 \mathrm{~mL} / \mathrm{min}$, at 10.8 Bar (3.5 eq hydrogen), $50^{\circ} \mathrm{C}$, sampled at 0, 5, 10, 20, 30, 40, 50 and 60 minutes for HPLC (20 $\mu \mathrm{l}$ in $1 \mathrm{~mL}$ methanol).

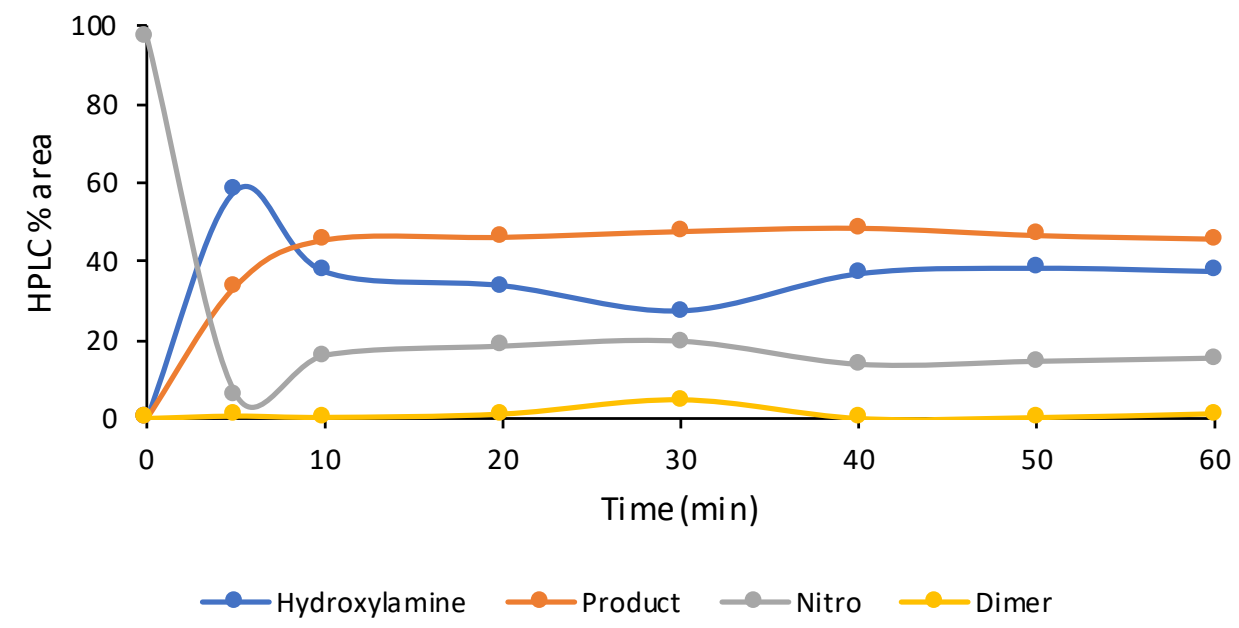

Figure S51 HPLC trend of $185 \mathrm{mg} 200-5 \mathrm{PdC}$ processing $0.169 \mathrm{M}$ 4-nitrobenzonitrile at 0.5 $\mathrm{mL} / \mathrm{min}$ over $60 \mathrm{~min}$, at $10.8 \mathrm{Bar}, 50^{\circ} \mathrm{C}$ and 3.5 eq $\mathrm{H}_{2}$. 
After 60min pressure increased to 25 Bar, sampled at 10, 20 and 30 minutes.

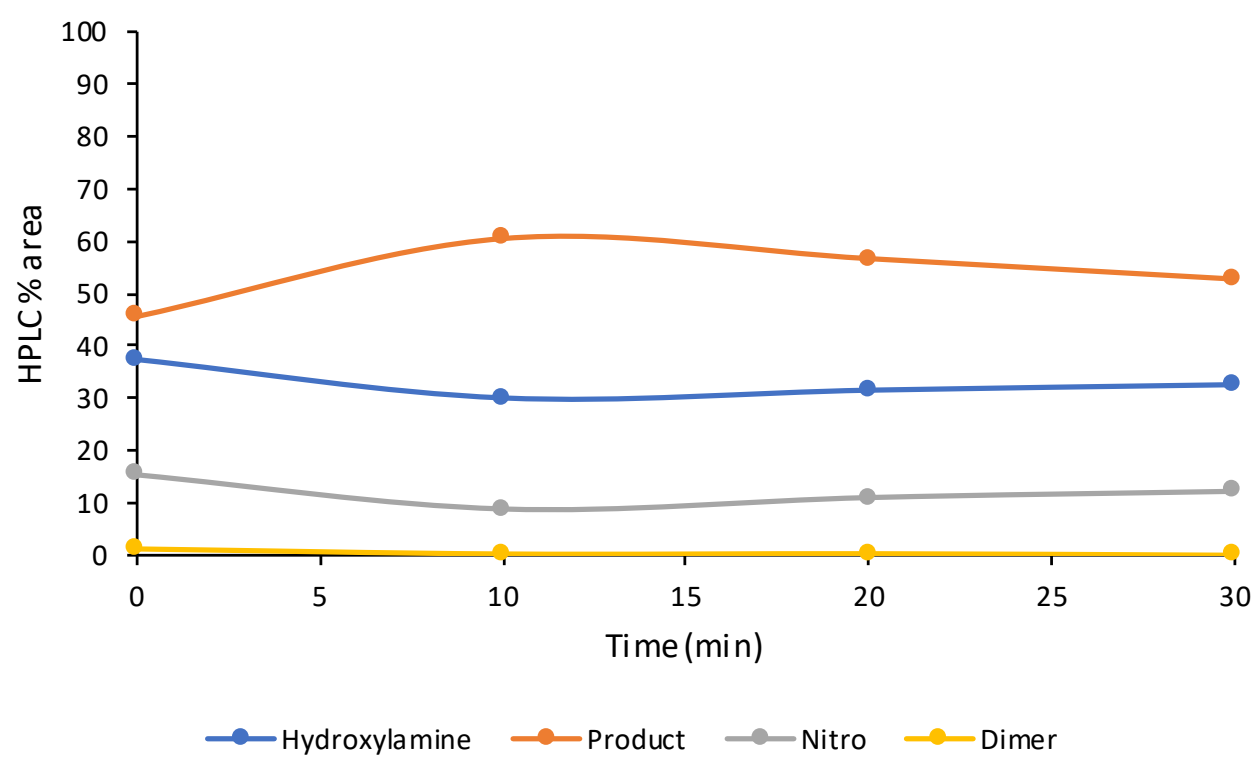

Figure S52 HPLC trend of $185 \mathrm{mg}$ 200-5PdC processing 0.169 M 4-nitrobenzonitrile 0.5 $\mathrm{mL} / \mathrm{min}$ over $30 \mathrm{~min}$, at $25 \mathrm{Bar}, 50^{\circ} \mathrm{C}$ and $3.5 \mathrm{eq} \mathrm{H}_{2}$.

$182 \mathrm{mg}$ 200-5PdC, CatCart was washed with THF $0.5 \mathrm{~mL} / \mathrm{min}$, at 25.4 Bar (3.5 eq hydrogen), $75{ }^{\circ} \mathrm{C}$ for 10 minutes. 4-nitrobenzonitrile $(1.5 \mathrm{~g})$ in THF $(60 \mathrm{ml})$ prepared to give a yelloworange solution $(0.169 \mathrm{M})$. The mixture was pumped through the CatCart at $0.5 \mathrm{~mL} / \mathrm{min}$, at 25.4 Bar (3.5 eq hydrogen), $75^{\circ} \mathrm{C}$, sampled at 0, 5 10, 20, 30, 40 and 50 minutes for HPLC (20 $\mu \mathrm{l}$ in $1 \mathrm{~mL}$ methanol). 


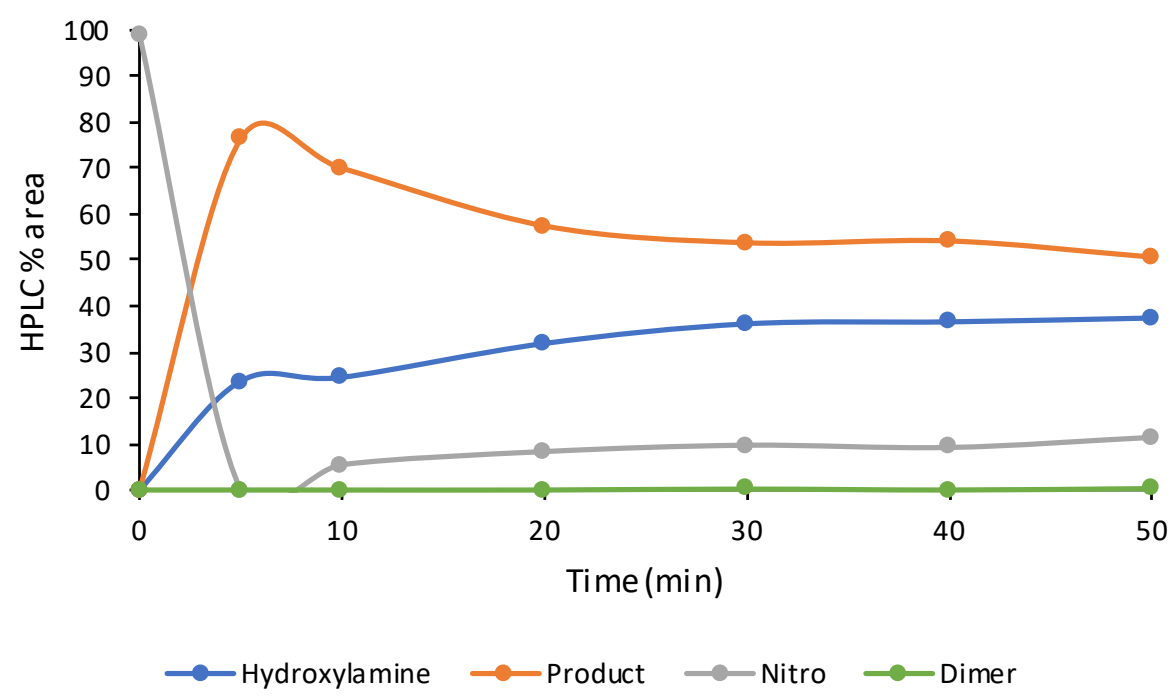

Figure S53 HPLC trend of $182 \mathrm{mg} 200$-5PdC processing 0.169 M 4-nitrobenzonitrile 0.5 $\mathrm{mL} / \mathrm{min}$ over $50 \mathrm{~min}$, at $25.4 \mathrm{Bar}, 75^{\circ} \mathrm{C}$, $3.5 \mathrm{eq} \mathrm{H}_{2}$.

After 50 minutes temperature increased to $100^{\circ} \mathrm{C}$, sampled at 10 and 20 minutes.

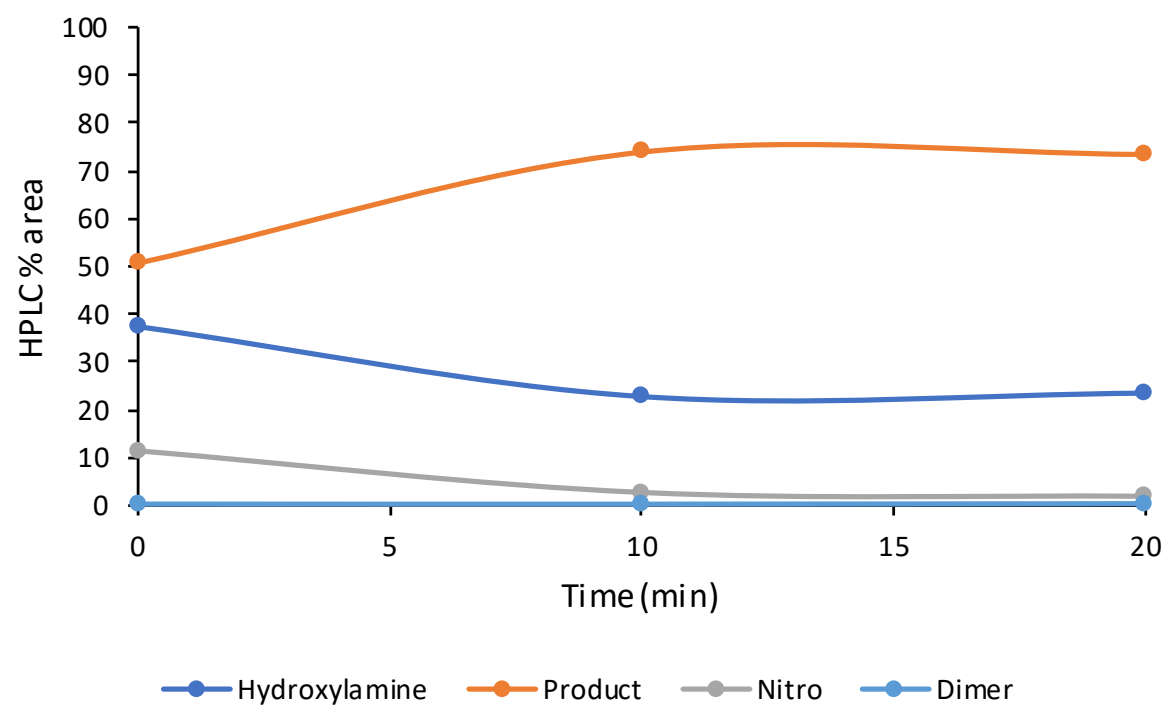

Figure S54 HPLC trend of $182 \mathrm{mg} 200$-5PdC processing 0.169 M 4-nitrobenzonitrile 0.5 $\mathrm{mL} / \mathrm{min}$ over $20 \mathrm{~min}$, at $25.4 \mathrm{Bar}, 100^{\circ} \mathrm{C}$, 3.5 eq $\mathrm{H}_{2}$.

After 20 minutes liquid flow rate reduced to $0.25 \mathrm{~mL} / \mathrm{min}$ sampled at 10 and 20 minutes. 


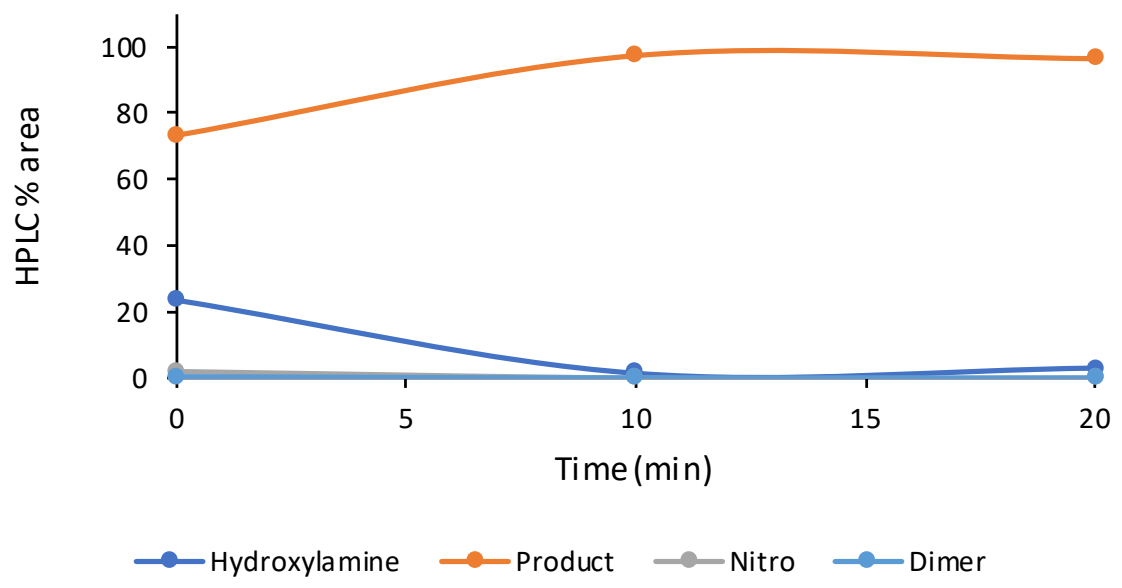

Figure S55 HPLC trend of $182 \mathrm{mg}$ 200-5PdC processing 0.169 M 4-nitrobenzonitrile 0.25 $\mathrm{mL} / \mathrm{min}$ over $20 \mathrm{~min}$, at $25.4 \mathrm{Bar}, 100^{\circ} \mathrm{C}$ and 3.5 eq $\mathrm{H}_{2} \cdot \mathrm{mL} / \mathrm{min}$. 
Continuous nitro reduction of methyl 4-nitrobenzoate (11)

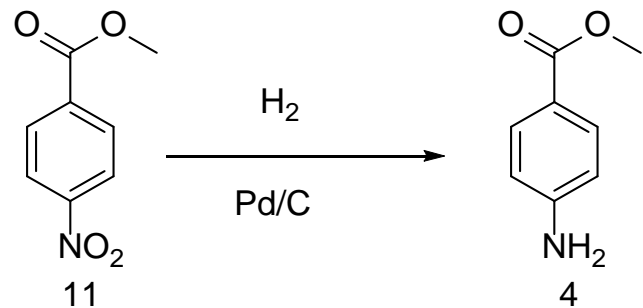

Scheme S10 Continuous nitro reduction of methyl 4-nitrobenzoate (11).

$170 \mathrm{mg}$ 200-5PdC, CatCart was washed with methanol $1 \mathrm{~mL} / \mathrm{min}$, at 20 Bar (3.5 eq hydrogen), $50{ }^{\circ} \mathrm{C}$ for 10 minutes. Methyl 4-(benzylamino)benzoate (1.99 g) was dissolved in ethanol (80 $\mathrm{ml})$ to give a solution $(0.138 \mathrm{M})$. The mixture was pumped through the CatCart at $1 \mathrm{~mL} / \mathrm{min}$, at $20 \mathrm{Bar}$ (3.5 eq hydrogen, $0.97 \mathrm{mg} / \mathrm{min}$ ), $50^{\circ} \mathrm{C}$, sampled at 10 , and 20 minutes for HPLC (20 $\mu \mathrm{l}$ in $1 \mathrm{ml}$ methanol). After 30 mintues the temperature was decreased to $30^{\circ} \mathrm{C}$, sampled at 10 . After 20 mintues the temperature was increased to $40{ }^{\circ} \mathrm{C}$, sampled at 10 and 20 minutes.

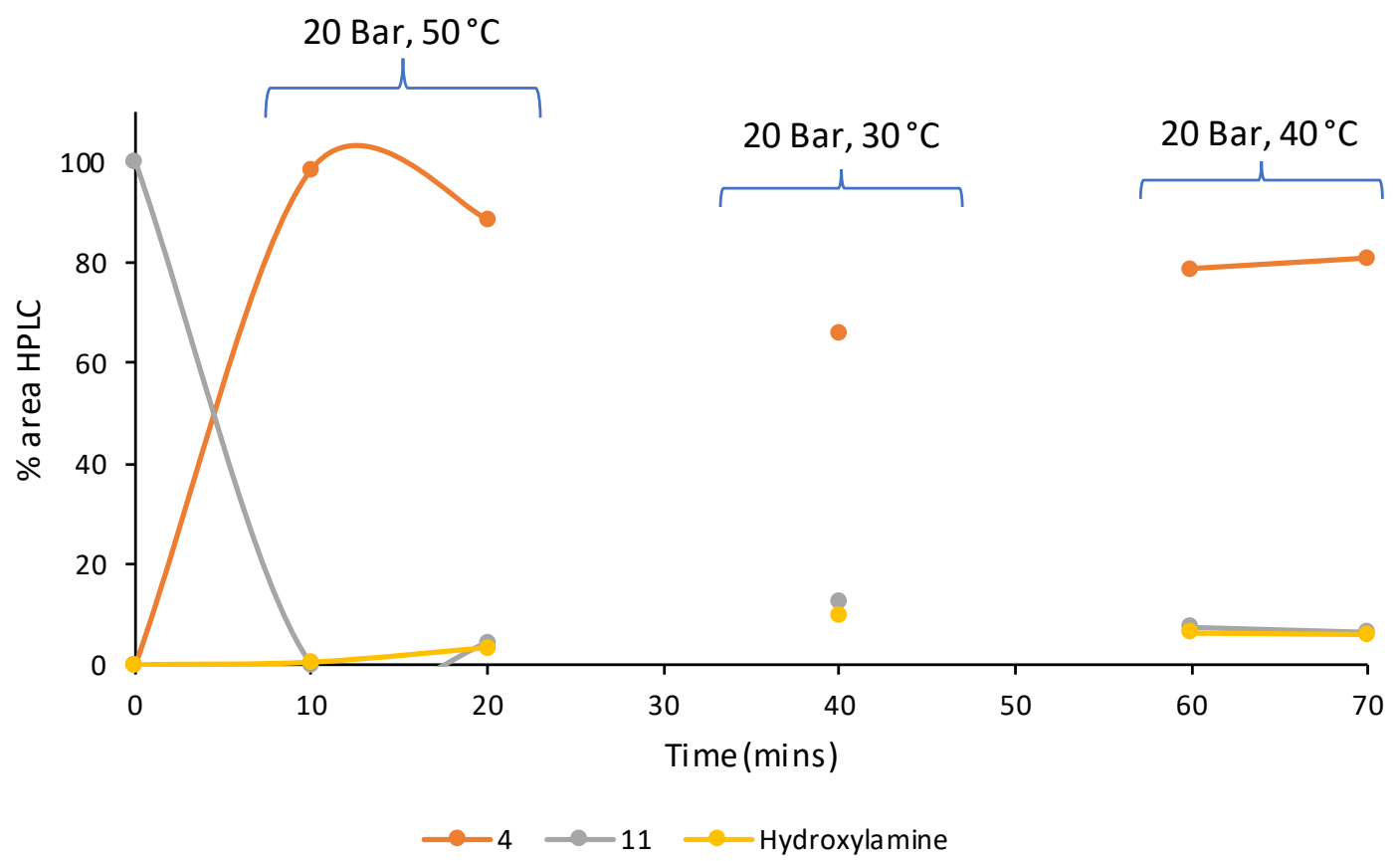

Figure S56 HPLC trend of $170 \mathrm{mg} 200-5 \mathrm{PdC}$ processing 0.138 M 4 Methyl 4(benzylamino)benzoate over $50 \mathrm{~min}$, at $20 \mathrm{Bar}, 50,30$ and $40^{\circ} \mathrm{C}, 3.5$ eq $\mathrm{H} 2$ and $0.169 \mathrm{M}$ Methyl 4-(benzylamino)benzoate $1 \mathrm{~mL} / \mathrm{min}$.

$172 \mathrm{mg}$ 200-5PdC, CatCart was washed with methanol $1 \mathrm{~mL} / \mathrm{min}$, at 20 Bar (hydrogen, 1 $\mathrm{mg} / \mathrm{min}$ ), $75^{\circ} \mathrm{C}$ for 10 minutes. Methyl 4-nitrobenzoate (19.98 g) was dissolved in methanol 
$(800 \mathrm{ml})$ to give a solution $(0.138 \mathrm{M})$. The mixture was pumped through the CatCart at 1 $\mathrm{mL} / \mathrm{min}$, at $20 \mathrm{Bar}$ (3.5 eq hydrogen, $0.97 \mathrm{mg} / \mathrm{min}$ ), $75^{\circ} \mathrm{C}$, sampled evey 10 minutes for a total of 460 minutes for HPLC (20 $\mu \mathrm{l}$ in $1 \mathrm{~mL}$ methanol).



Figure S57 HPLC trend of $172 \mathrm{mg} 200-5 \mathrm{PdC}$ processing $0.138 \mathrm{M}$ Methyl 4(benzylamino)benzoate over $460 \mathrm{~min}$, at $20 \mathrm{Bar}, 75^{\circ} \mathrm{C}$, $3.5 \mathrm{eq} \mathrm{H}_{2}$ and $0.138 \mathrm{M}$ Methyl 4(benzylamino)benzoate $1 \mathrm{~mL} / \mathrm{min}$. The inconstancy from 350-400 $\mathrm{min}$ is thought to be due to an issue with the furnace on the modified $\mathrm{H}$-Cube.

Continuous $N$-debenzylation of $N$-benzyl-4-methoxyaniline (7)

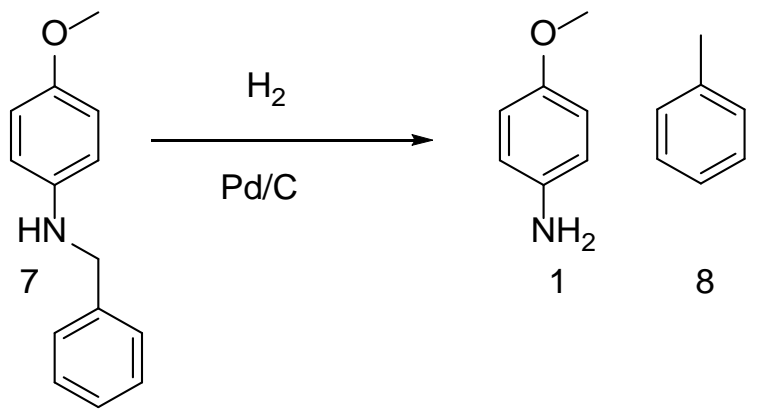

Scheme S11 Continuous $N$-Debenzylation of $N$-benzyl-4-methoxyaniline (7).

$184.4 \mathrm{mg}$ 200-5PdC, CatCart was washed with methanol $1 \mathrm{~mL} / \mathrm{min}$, at 40 Bar $(2.4$ eq hydrogen), $50{ }^{\circ} \mathrm{C}$ for 10 minutes. $N$-benzyl-4-methoxyaniline (7, 5 g) was dissolved in methanol $(145 \mathrm{~mL})$ to give a solution $(0.16 \mathrm{M})$. The mixture was pumped through the CatCart at $0.5 \mathrm{~mL} / \mathrm{min}$, at $40 \mathrm{Bar}\left(2.4 \mathrm{eq}\right.$ hydrogen,), $75^{\circ} \mathrm{C}$, sampled at 5,10 and 20 minutes for HPLC (20 $\mu \mathrm{l}$ in $1 \mathrm{~mL}$ methanol). 


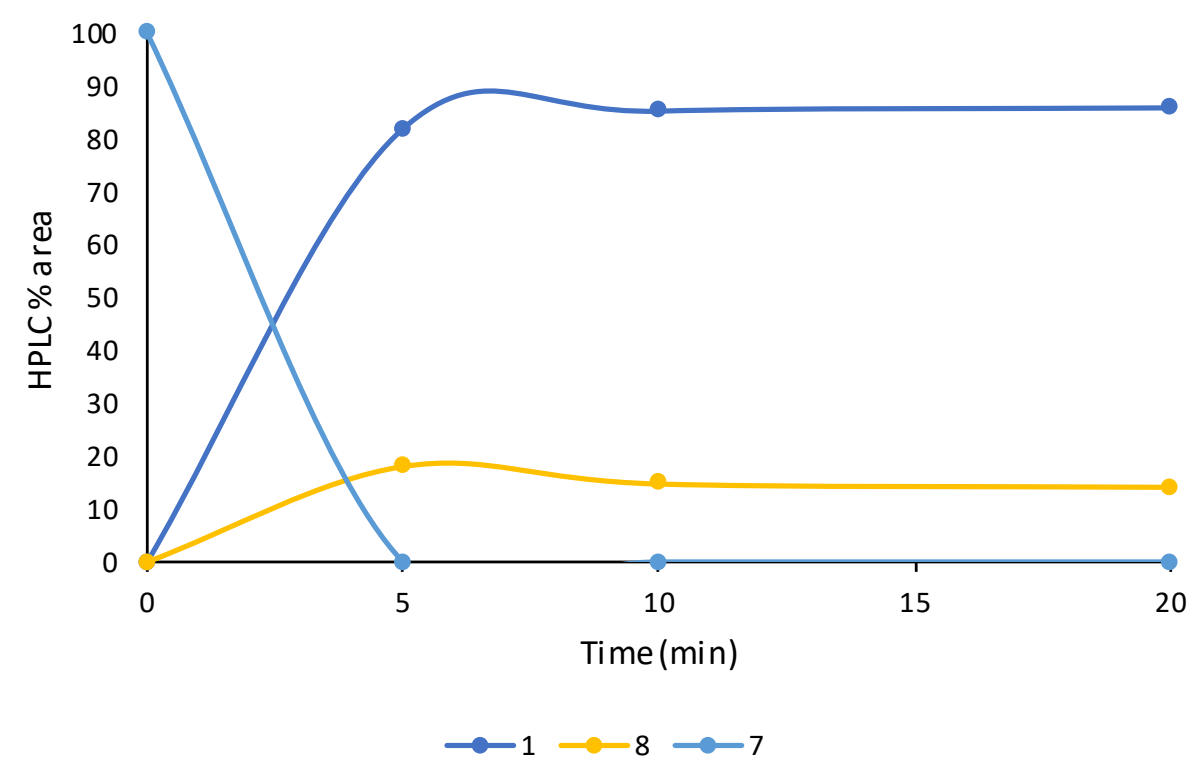

Figure S58 HPLC trend of 184.4 mg 200-5PdC processing 0.16 M N-benzyl-4methoxyaniline over $20 \mathrm{~min}$, at $40 \mathrm{Bar}, 50^{\circ} \mathrm{C}$, 2.4 eq $\mathrm{H}_{2}$ and $0.16 \mathrm{M} N$-benzyl-4methoxyaniline $1 \mathrm{~mL} / \mathrm{min}$.

$188.8 \mathrm{mg}$ 200-5PdC, CatCart was washed with methanol $1 \mathrm{~mL} / \mathrm{min}$, at 10 Bar $(1.2$ eq hydrogen), $20^{\circ} \mathrm{C}$ for 10 minutes. $N$-benzyl-4-methoxyaniline (5 g) was dissolved in methanol $(145 \mathrm{~mL})$ to give a solution $(0.16 \mathrm{M})$. The mixture was pumped through the CatCart at 1 $\mathrm{mL} / \mathrm{min}$, at $10 \mathrm{Bar}$ (1.2 eq hydrogen,), $20^{\circ} \mathrm{C}$, sampled at 6,10 and 20 minutes for HPLC (20 $\mu \mathrm{l}$ in $1 \mathrm{~mL}$ methanol). After $20 \mathrm{~min}$ temperature increased to $50^{\circ} \mathrm{C}$, sampled at 5,10 and 20 minutes for HPLC. After 20 min temperature increased to $75^{\circ} \mathrm{C}$, sampled at 6 and 10 minutes for HPLC, $(20 \mu \mathrm{l}$ in $1 \mathrm{~mL}$ methanol). 


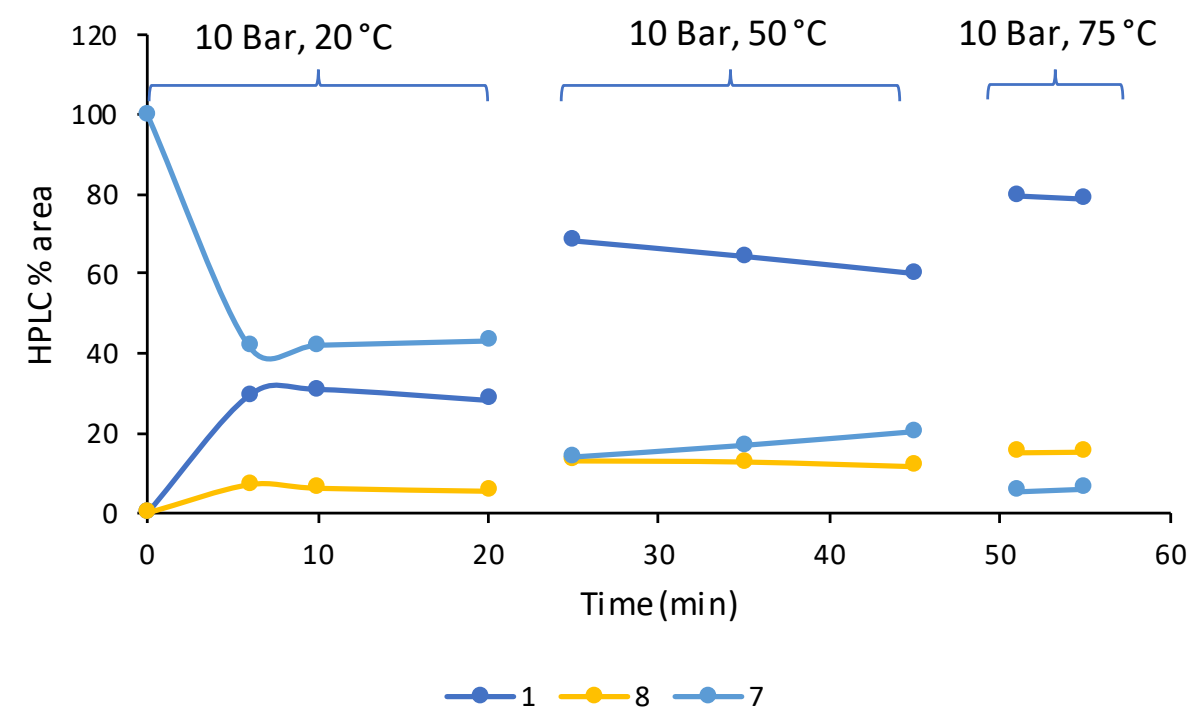

Figure S59 HPLC trend of $188.8 \mathrm{mg} 200-5 \mathrm{PdC}$ processing $0.16 \mathrm{M} \mathrm{N}$-benzyl-4methoxyaniline over $55 \mathrm{~min}$, at $10 \mathrm{Bar}, 20,50$ and $75^{\circ} \mathrm{C}$, 1.2 eq $\mathrm{H}_{2}$ and $0.16 \mathrm{M} \mathrm{N}$-benzyl-4methoxyaniline $1 \mathrm{~mL} / \mathrm{min}$.

CatCart was washed with methanol $1 \mathrm{~mL} / \mathrm{min}$, at 10 Bar (1.2 eq hydrogen), $75^{\circ} \mathrm{C}$ for 10 minutes. $N$-benzyl-4-methoxyaniline ( $5 \mathrm{~g}$ ) was dissolved in methanol (145 mL) to give a solution $(0.16 \mathrm{M})$. The mixture was pumped through the CatCart at $1 \mathrm{~mL} / \mathrm{min}$, at $10 \mathrm{Bar}(1.2$ eq hydrogen,), $75^{\circ} \mathrm{C}$, sampled at 6, 10, 20, and 35 minutes for HPLC (20 $\mu \mathrm{l}$ in $1 \mathrm{~mL}$ methanol).

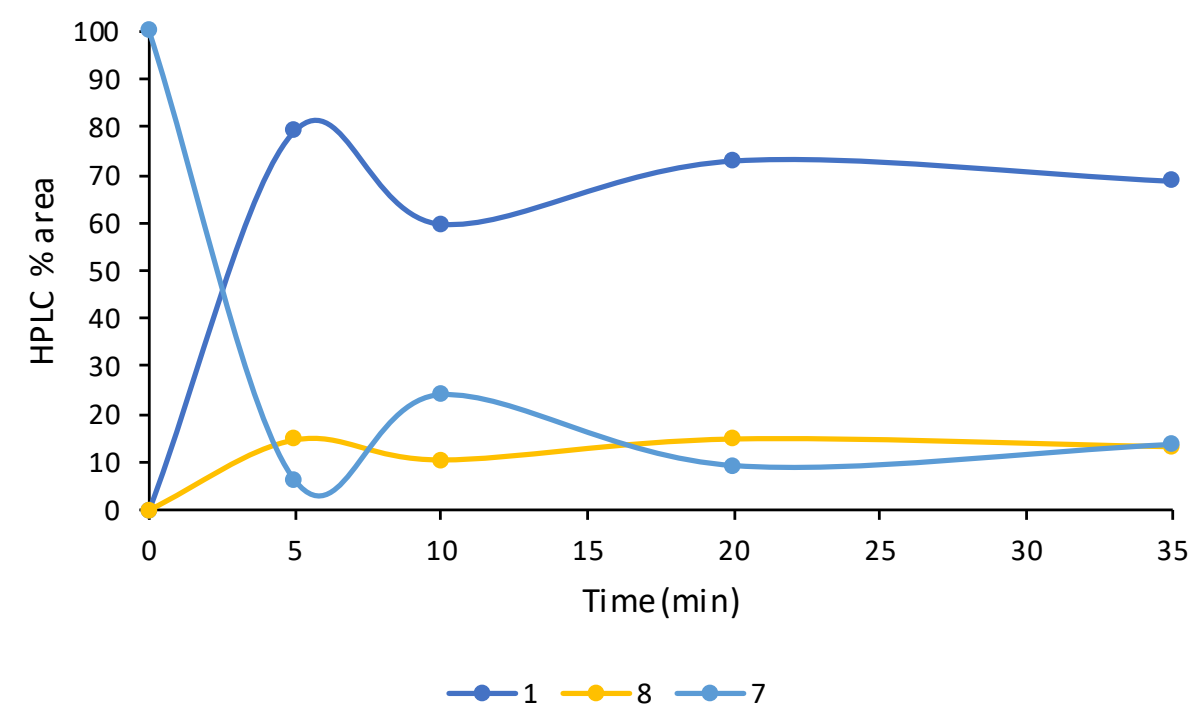

Figure S60 HPLC trend of $188.8 \mathrm{mg} 200-5 \mathrm{PdC}$ processing $0.16 \mathrm{M} N$-benzyl-4methoxyaniline over $35 \mathrm{~min}$, at $10 \mathrm{Bar}, 75^{\circ} \mathrm{C}$, 1.2 eq $\mathrm{H}_{2}$ and $0.16 \mathrm{M} \mathrm{N}$-benzyl-4methoxyaniline $1 \mathrm{~mL} / \mathrm{min}$. 
$186.5 \mathrm{mg}$ 200-5PdC, CatCart was washed with methanol $1 \mathrm{~mL} / \mathrm{min}$, at 10 Bar $(1.2$ eq hydrogen), $75{ }^{\circ} \mathrm{C}$ for 10 minutes. $N$-benzyl-4-methoxyaniline $(7.81 \mathrm{~g})$ was dissolved in methanol $(226.5 \mathrm{~mL})$ to give a solution $(0.162 \mathrm{M})$. The mixture was pumped through the CatCart at $1 \mathrm{~mL} / \mathrm{min}$, at 10 Bar (1.2 eq hydrogen,), $75^{\circ} \mathrm{C}$, sampled at 5 and 10 minutes then evey 10 minutes for a total of 210 minutes for HPLC (20 $\mu \mathrm{L}$ in $1 \mathrm{~mL}$ methanol).



Figure S61 HPLC trend of $186.5 \mathrm{mg}$ 200-5PdC processing 0.162 M N-benzyl-4methoxyaniline over $210 \mathrm{~min}$, at $10 \mathrm{Bar}, 75^{\circ} \mathrm{C}$, 1.2 eq $\mathrm{H}_{2}$ and $0.162 \mathrm{M} \mathrm{N}$-benzyl-4methoxyaniline $1 \mathrm{~mL} / \mathrm{min}$.

$170 \mathrm{mg}$ 200-5PdC, CatCart was washed with ethanol $1 \mathrm{~mL} / \mathrm{min}$, at 30 Bar (3.5 eq hydrogen), $75{ }^{\circ} \mathrm{C}$ for 10 minutes. $N$-benzyl-4-methoxyaniline $(4 \mathrm{~g})$ was dissolved in ethanol $(160 \mathrm{ml})$ to give a solution $(0.117 \mathrm{M})$. The mixture was pumped through the CatCart at $1 \mathrm{~mL} / \mathrm{min}$, at 30 Bar (3.5 eq hydrogen, $0.82 \mathrm{mg} / \mathrm{min}), 75^{\circ} \mathrm{C}$, sampled at 5, 10 and 20 minutes for HPLC (20 $\mu \mathrm{l}$ in $1 \mathrm{ml}$ methanol). After 20 minutes temperature decreased to $50{ }^{\circ} \mathrm{C}$ sampled at 5,10 and 20 minutes. Then pressure decreased to 20 Bar sampled at 20 minutes. Conditions changed to 30 Bar (3.5 eq hydrogen, $0.82 \mathrm{mg} / \mathrm{min}$ ), $60{ }^{\circ} \mathrm{C}, 1 \mathrm{~mL} / \mathrm{min}$, sampled at 5, 15, 35 and 50 minutes. 


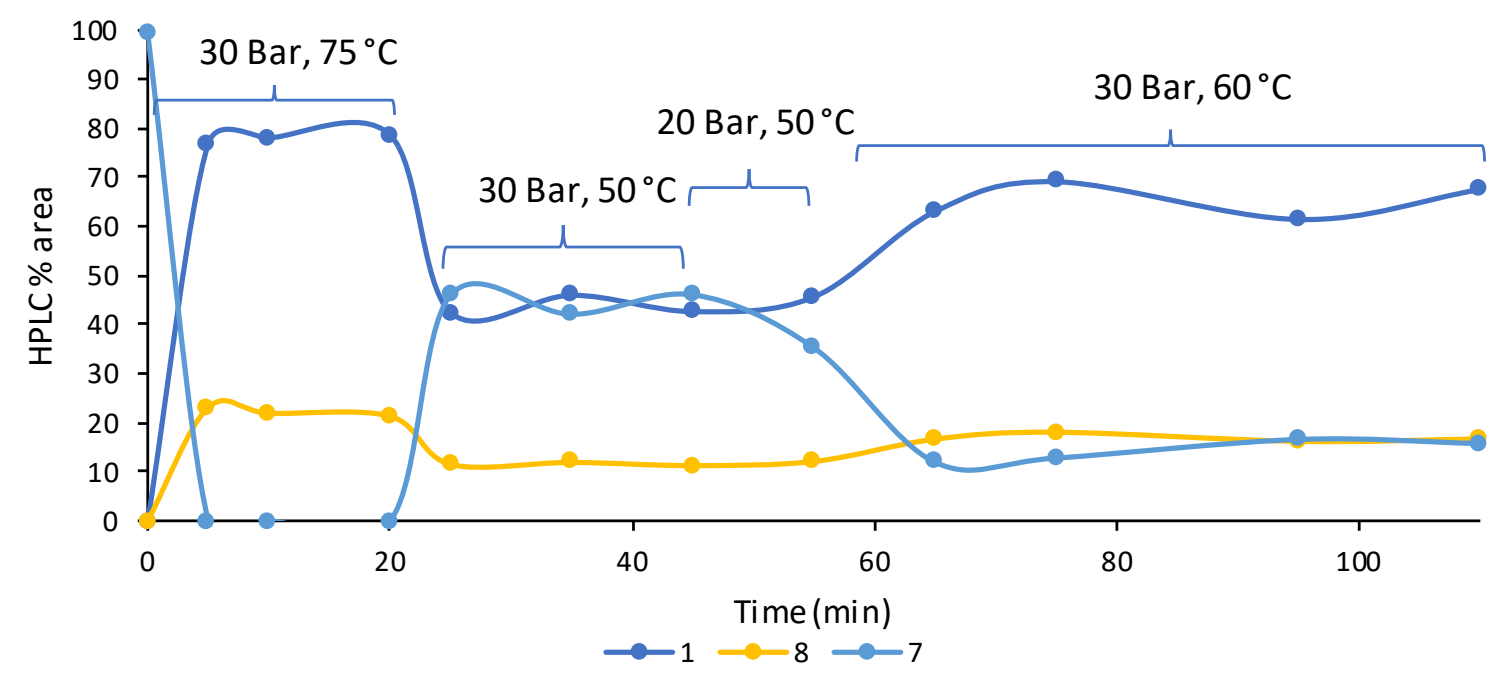

Figure S62 HPLC trend of $170 \mathrm{mg} 200-5 \mathrm{PdC}$ processing $0.117 \mathrm{M} \mathrm{N}$-benzyl-4methoxyaniline over $110 \mathrm{~min}$, at 30 and $20 \mathrm{Bar}, 75,50$ and $60^{\circ} \mathrm{C}$, 3.5 eq $\mathrm{H}_{2}$ and $0.117 \mathrm{M} \mathrm{N}$ benzyl-4-methoxyaniline $1 \mathrm{~mL} / \mathrm{min}$.

$170 \mathrm{mg}$ 200-5PdC, CatCart was washed with ethanol $1 \mathrm{~mL} / \mathrm{min}$, at $30 \mathrm{Bar}$ (3.5 eq hydrogen), $60{ }^{\circ} \mathrm{C}$ for 10 minutes. $N$-benzyl-4-methoxyaniline $(1.99 \mathrm{~g})$ was dissolved in ethanol $(80 \mathrm{ml})$ to give a solution $(0.117 \mathrm{M})$. The mixture was pumped through the CatCart at $1 \mathrm{~mL} / \mathrm{min}$, at $30 \mathrm{Bar}$ (3.5 eq hydrogen, $0.82 \mathrm{mg} / \mathrm{min}$ ), $60^{\circ} \mathrm{C}$, sampled at 5, 10, 20, 30 and 40 minutes for HPLC ( $20 \mu \mathrm{l}$ in $1 \mathrm{ml}$ methanol). After 40 mintues the temperature was decreased to $55^{\circ} \mathrm{C}$, sampled at 10 and 20 minutes. After 20 mintues the temperature was decreased to $50^{\circ} \mathrm{C}$, sampled at 15 minutes. 


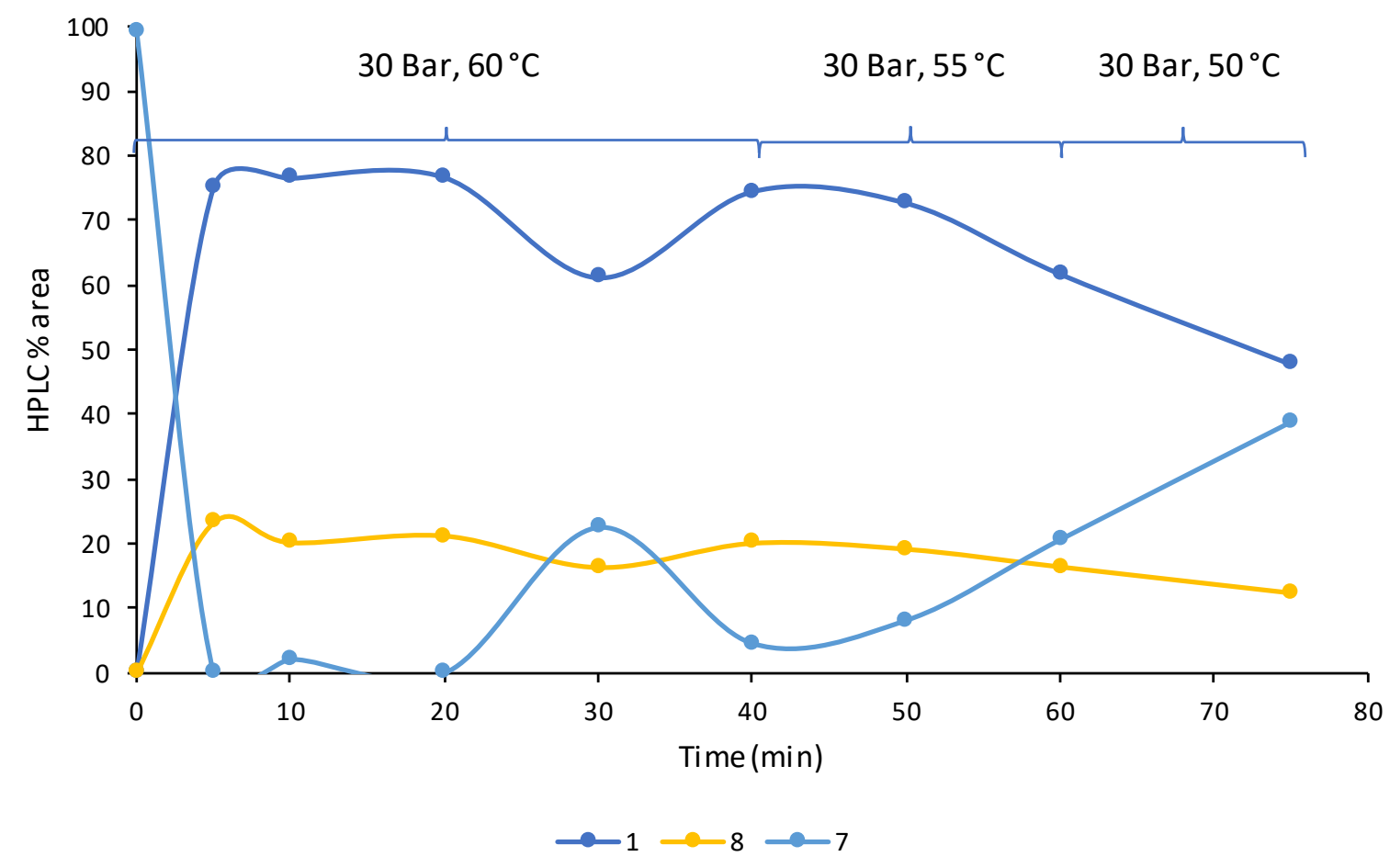

Figure S63 HPLC trend of $170 \mathrm{mg}$ 200-5PdC processing 0.117 M N-benzyl-4methoxyaniline over $110 \mathrm{~min}$, at $30 \mathrm{Bar}, 60,55$ and $50^{\circ} \mathrm{C}, 1.2$ eq $\mathrm{H}_{2}$ and $0.117 \mathrm{M} N$-benzyl4-methoxyaniline $1 \mathrm{~mL} / \mathrm{min}$. 


\title{
Operating Procedure for packing a CatCart.
}

\author{
Check list:
}

1. New empty CatCart.

2. Ensure that the required catalyst mass is available and weighted. Ensure that there are water and tissues available in the fume hood.

3. Ensure that vacuum controller is connected to the vacuum supply in the fume hood.

4. Ensure that the empty CatCart has adequate frit size for the catalyst.

The following steps must be followed to pack the CatCart reactor with a hydrogenation catalyst. The reactor must not be left unattended during the packing process.

1. Connect the CatCart to the vacuum controller and secure it in a vertical position.

2. Turn on the vacuum controller and the vacuum on the fume hood.

3. Select 100 mbar as the vacuum pressure and press run.

4. Add the required amount of catalyst to the column. Activated catalyst must be added in a water slurry following the steps below:

a. Ensure that the catalyst slurry is well mixed and add it to the reactor using a plastic pipette.

b. Ensure that the reactor is filled with slurry or water until the top to ensure that the catalyst is always wet.

c. Once the required amount of catalyst has been added, additional water must be added for approximately 2 minutes in order to let the catalyst settle.

5. Add an inert packing, such as glass beads, to cover the empty space of the reactor when necessary, not letting the catalyst dry out.

6. Stop the vacuum controller.

7. Remove the packed reactor from the vacuum controller.

8. Place CatCart in CatCart selear.

9. Insert frits, and sealing ring.

10. Seal the CatCart using the CatCart sealer.

11. Place the reactor in the Catcart into the modified H-Cube ensuring that the connections are tightened. 